Universidad de Lima

Facultad de Psicología

Carrera de Psicología

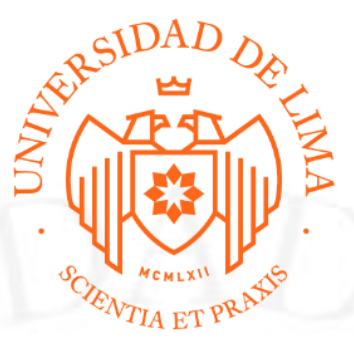

\title{
ADAPTACIÓN DEL INVENTARIO DE AFRONTAMIENTO COPE EN ADULTOS PERTENECIENTES A LA POBLACIÓN ECONÓMICAMENTE ACTIVA DE LIMA METROPOLITANA
}

Tesis para optar el Título Profesional de Licenciado en Psicología

\section{Jocelyn Kristel Polanco Cano}

Código 20090891

\author{
Asesor \\ Manuel Cueva Rojas \\ Lima - Perú \\ Julio de 2019
}




\section{AGRADECIMIENTOS}

Al egresar de la Universidad de Lima tome la decisión de desarrollar una tesis, principalmente porque tenía la intención de dejar un aporte en la investigación psicológica del Perú y qué mejor seleccionando un tema el cual viene cobrando mayor atención no solo en el área clínica de la psicología, sino también en la organizacional y en otras profesiones. Estoy segura que el resultado de esta tesis servirá para ayudar a las empresas a poder crear programas que tengan como finalidad ayudar a su personal a tener mejores estrategias de afrontamiento ante situaciones estresantes, evitando de este modo, el estrés, el cual conlleva a tener efectos negativos en las personas.

Desde un inicio supe que hacer una tesis no iba a ser fácil, se iba a necesitar una motivación constante e invertir mucho tiempo en el levantamiento y desarrollo de información; sin embargo hoy me siento feliz y satisfecha de haberla realizado. Considero que esta experiencia sin duda me ayudó a poder desarrollar varias cualidades en mí, como la capacidad a la frustración, la persistencia, la búsqueda de soluciones, la constancia, entre otros. Cualidades que estoy segura me ayudarán a futuro a poder hacer frente a diversas situaciones cotidianas.

Gracias a mi familia, quien estuvo siempre motivándome a seguir cuando veía los días oscuros, en especial a mis padres, quienes fueron las personas que me motivaron a desarrollar mi tesis desde que egrese de la Universidad. Gracias a mi tía, quien desde el cielo, cuida cada paso que doy. Gracias a mis amigos quienes estuvieron aguantando mis frustraciones y mis desmotivaciones. Gracias a todas las personas que se tomaron un tiempo para desarrollar la prueba. Gracias a las empresas que confiaron en mi investigación. En general, agradezco a todos los que contribuyeron a poder desarrollar esta investigación. 


\section{ADAPTACIÓN DEL INVENTARIO DE AFRONTAMIENTO COPE EN ADULTOS PERTENECIENTES A LA POBLACIÓN ECONÓMICAMENTE ACTIVA DE LIMA METROPOLITANA}




\section{TABLA DE CONTENIDO}

CAPÍTULO I: PLANTEAMIENTO DEL PROBLEMA ....................

$1.1 \quad$ Presentación del problema .......................................................... 1

1.2 Justificación y relevancia ............................................................... 3

CAPÍTULO II: MARCO TEÒRICO.....................................................6

2.1 El concepto de estrés .................................................................6

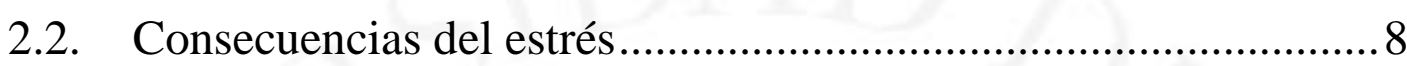

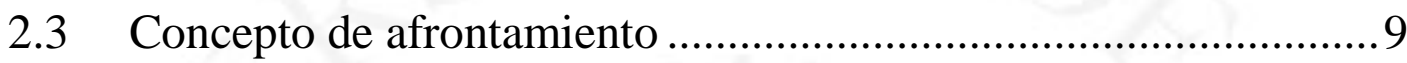

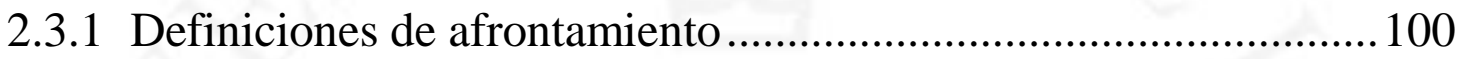

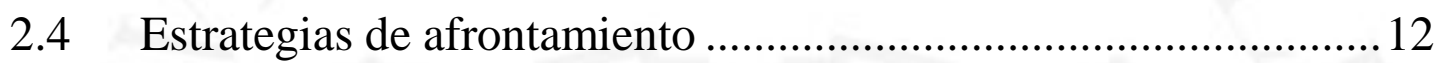

2.5 Recursos de afrontamiento ........................................................ 13

2.6 Modelo de estrés y afrontamiento de Lazarus y Folkman.............15

CAPÍTULO III: OBJETIVOS, HIPÓTESIS Y DEFINICIÓN DE

VARIABLES............................................................................................18

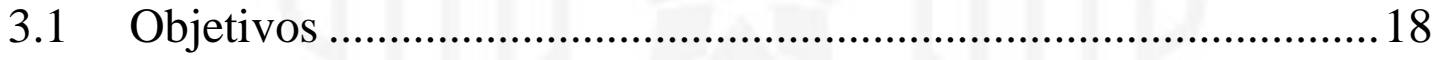

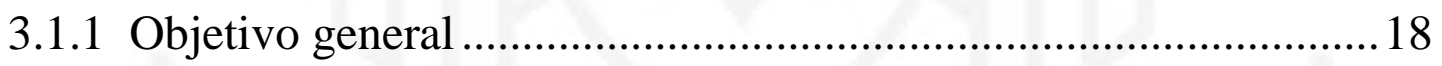

3.1.2 Objetivos específicos ............................................................... 18

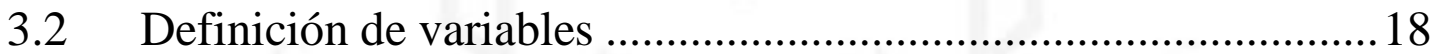

CAPÍTULO IV: METODOLOGÌA ....................................................20

4.1 Tipo y diseño de investigación .....................................................20

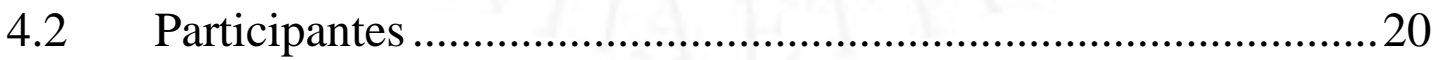

4.3 Técnicas de recolección de información....................................222

4.4 Procedimiento de recolección de datos .......................................24

CAPÍTULO V: RESULTADOS ........................................................26

CAPÍTULO VI: DISCUSION.................................................................4

CONCLUSIONES.............................................. 50

RECOMENDACIONES..........................................51 
REFERENCIAS........................................................ 52

ANEXOS...................................................... 61 


\section{ÍNDICE DE FIGURAS}

Figura 1. Gráficos de Normalidad e Histogramas del Factor 1 y Factor 2 ........ 39 


\section{ÍNDICE DE TABLAS}

Tabla 1. Coeficiente V de Aiken para la representatividad de los items del Inventario de Afrontamiento COPE

Tabla 2. Coeficiente V de Aiken para la claridad de los items del Inventario de Afrontamiento COPE .29

Tabla 3. Resultados del método de Hull en el primer análisis factorial .32

Tabla 4. Cargas factoriales de los items en el primer análisis factorial .33

Tabla 5. Resultados del método de Hull en el tercer análisis factorial .34

Tabla 6. Cargas factoriales de los ítems en el tercer análisis factorial .35

Tabla 7. Correlación Item- Test del Inventario COPE

Tabla 8. Estadistcos descriptivos y anàlisis de normalidad con la Prueba Shapiro-Wilk del Inventario COPE

Tabla 9. Estadísticos de Prueba de U de Mann-Whitney según variable sexo .39

Tabla 10. Baremos clasificados en percentiles de acuerdo al sexo de los participantes para las puntuaciones obtenidas del Inventario COPE 


\section{ÍNDICE DE ANEXOS}

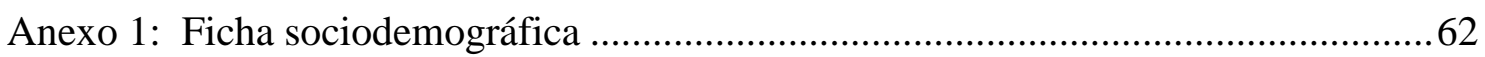

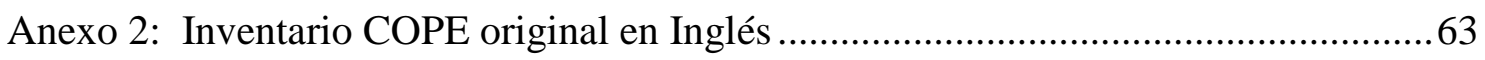

Anexo 3: Inventario COPE versión oficial en Español ............................................67

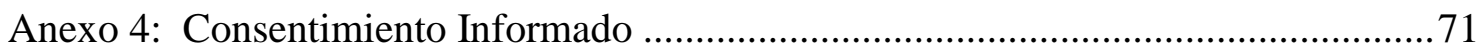

Anexo 5: Presupuesto de investigación ..................................................................... 72

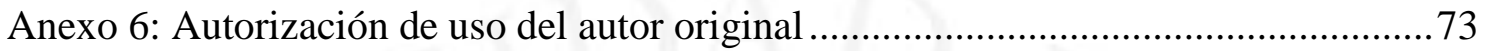

Anexo 7: Autorización de uso de la autora de la versión oficial en Español..................74

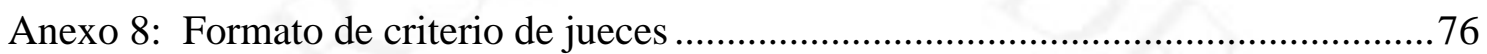

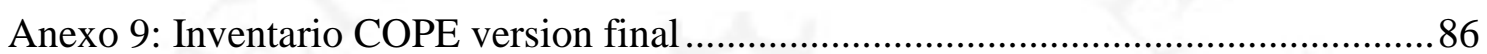

Anexo 10:Distribución de la muestra según variables sociodemográfica .......................8 


\section{RESUMEN}

El Inventario de afrontamiento COPE (Carver, Scheier y Weintraub; 1989) fue creado para evaluar las diversas maneras en la que las personas responden ante situaciones de estrés. El presente trabajo de investigación tiene como objetivo adaptar y analizar las propiedades psicométricas del COPE versión de 60 ítems en una muestra de 612 personas pertenecientes a la población económicamente activa de Lima Metropolitana. Los resultados de las puntuaciones del instrumento usado confirman evidencias de confiabilidad y validez. A través del criterio de 8 jueces se obtuvieron evidencias de validez vinculadas al contenido, con un rango de $\mathrm{V}$ de Aiken que fluctuaba entre .88 a 1.00. Así, se reportaron evidencias de validez relacionadas a la estructura interna mediante el análisis factorial exploratorio, obteniendo una estructura bidimensional compuesto por 22 ítems cada factor (factor $1 \omega=.92$ con y factor $2 \omega=.93$ ). Además, se comparó las estrategias de afrontamiento según el sexo y se encontraron diferencias estadísticamente significativas para el factor 1, presentándose una clasificación de baremos en percentiles. A raíz de lo encontrado, se propuso una nueva estructura del Inventario de afrontamiento COPE compuesto por 44 ítems. Finalmente, establecida la validez y confiabilidad de la prueba se comprobó que el instrumento mide la variable que pretende medir y de manera precisa.

Palabras clave: afrontamiento, población económicamente activa, evidencias de validez, adaptación, confiabilidad. 


\begin{abstract}
The Cope Inventory (Carver, Scheier and Weintraub, 1989) was created to evaluate the different ways in which people respond to stressful situations. The objective of this research was to adapt and analyze the psychometric properties of the COPE Inventory of 60 item version in a sample of 612 people belonging to the economically active population of Metropolitan Lima. The outcome scores from the instrument used, confirmed reliability and validity evidence. Validity evidence based on the test content was obtained through 8 experts, with a range of Aiken's V that fluctuated between .88 to 1.00. Thus, validity evidence based on internal structure was reported through an exploratory factor analysis, obtaining a bidimensional structure composed each factor by 22 items (factor $1 \omega=.92$ and factor $2 \omega=.93$ ). In addition, coping strategies were compared according to sex and statistically significant differences were found for factor 1 , so it was presented in a ranking of scales in percentiles. As a result, a new structure of the COPE Inventory composed of 44 items was proposed. Finally, established the validity and reliability of the test, it was found that the instrument measures the variable that it intends to measure and in an accurate way.
\end{abstract}

Key words: Coping, economically active population, evidence of validity, adaptation, reliability. 


\section{INTRODUCCION}

La presente investigación responde a la necesidad que se encuentra actualmente de investigar y desarrollar con mayor profundidad el constructo de afrontamiento con la finalidad de evitar el síndrome del estrés en la población económicamente activa. En el primer capítulo de la investigación se desarrolla el planteamiento del problema, donde se introduce el tema a investigar mediante el planteamiento de problema y además se explica la justificación y relevancia del estudio, haciendo mención a la carencia de un estudio de la versión de 60 ítems del Inventario COPE en una muestra peruana de PEA. En el segundo capítulo, se expone el marco teórico el cual inicia con información correspondiente al concepto del estrés y sus consecuencias para posteriormente ahondar en el constructo del afrontamiento, revisando el concepto, las definiciones, las estrategias de afrontamiento, los recursos de afrontamiento y finalmente el modelo de estrés y afrontamiento de Lazarus y Folkman.

En el tercer capítulo se encuentran los objetivos del estudio y las definiciones tanto conceptuales como operacionales del constructo de afrontamiento y estrategias de afrontamiento. En el cuarto capítulo, se detalla el método a utilizar, explicando el tipo y diseño de investigación, las técnicas de recolección de datos y procedimiento de recolección de datos. Asimismo se proporciona información respecto a la muestra utilizada, características y distribución. En el quinto capítulo, se reportan los resultados encontrados en la investigación respecto a la adaptación lingüística, las evidencias de validez vinculadas al contenido, las evidencias de validez vinculadas a la estructura interna, estimación de confiabilidad, análisis de discriminación de los ítems y elaboración de baremos.

En el capítulo sexto, se presenta la discusión del estudio del proceso de adaptación de la prueba y de los resultados del análisis psicométrico. Asimismo se realizan comparaciones con respecto a los resultados pertenecientes a otras investigaciones. Adicionalmente, se puntualiza el cumplimiento de las 22 directrices para la adaptación de pruebas proporcionada por La Comisión Internacional de Test (Muñiz, Elousa y Hambleton, 2013) y los Estándares para la evaluación educativa y psicológica establecidos por AERA, APA, NCME (2014). Finalmente, se presentan las conclusiones y recomendaciones identificadas en base a los procesos ejecutados en la investigación. Adicionalmente, se ofrece la sección de anexos en el cual se encuentra la ficha 
sociodemográfica, Inventario COPE en inglés y español, consentimiento informado, cronograma, presupuesto de la investigación, autorización de uso del autor original y de la autora de la versión ofician en español, formato de criterio de jueces y el Inventario COPE versión final. 


\section{CAPÍTULO I: PLANTEAMIENTO DEL PROBLEMA}

\subsection{Presentación del problema}

El afrontamiento es un término amplio que hace alusión a los esfuerzos que se hacen para poder direccionar los problemas relacionados al estrés (Lazarus y Folkman, 1984). Actualmente el constructo afrontamiento viene ganando mayor popularidad, ya que es un término que es usado en la vida diaria; sin embargo, aún no ha adquirido el mismo nivel de difusión como el término estrés (Bailey y Clarke, 2013). Ambos son usados frecuentemente, debido a que se encuentran relacionados al ser el afrontamiento un mediador entre el estresor y la experiencia que resulta de este, es decir el estrés (Lazarus y Folkman, 1984). Además, el desarrollo de un modelo de estrés y afrontamiento, exige que se describa una interrelación entre estos dos constructos (Seiffge-Krenke, 2015).

Carver y Connor-Smith (2010) mencionan que el afrontamiento es definido a menudo como los esfuerzos para prevenir o disminuir una amenaza, daño, pérdida o angustia, y que el estrés es producido cuando la persona experimenta la sensación de que los recursos con los que cuenta para hacer frente a situaciones demandantes, son amenazados o perdidos.

En relación a lo anterior, la Organización Panamericana de la Salud (OPS, 2016), sostiene lo siguiente:

"Hoy el mundo del trabajo- con sus avances industriales, la globalización, el desarrollo tecnológico y las comunicaciones virtuales- nos impone retos y condiciones que con frecuencia exceden los límites de nuestras habilidades y capacidades. Su resultado es el estrés, que puede conducirnos a disfunciones físicas, mentales y sociales; incluso dañar nuestra salud, mermar nuestra productividad y afectar nuestros círculos familiares y sociales" (parr.2).

Lo mencionado no es ajeno a la realidad peruana, Astrete et al., (2018) afirma que el $80 \%$ de peruanos han sufrido o actualmente padecen de estrés, lo cual repercute en insomnio y cambios frecuentes de ánimo. Además que el género femenino evidencia tener una mayor recurrencia de situaciones de estrés a comparación del genero opuesto, siendo el factor influyente de la diferencia, la carga de actividades como ser madre, trabajadora, labores domésticas, entre otras. Asimismo, se ha identificado que los 
principales factores que causan estrés en los peruanos son los problemas económicos y los de salud. Otros factores influyentes son la inseguridad ciudadana, inestabilidad laboral, responsabilidades en el centro de estudio, hogar o trabajo, problemas de pareja y problemas con hijos (Instituto de Análisis y Comunicación Integración, 2015)

Actualmente, el estrés crónico se ha convertido en una problemática muy recurrente en el ámbito laboral, debido a que se ha venido incrementando los casos donde se evidencia la presencia del estrés, independientemente del tipo de profesión que ejerza el trabajador (Garcia-Moran y Gil-La Cruz, 2016). Adicionalmente, estudios demuestran que las personas económicamente activas (PEA) emplean una tercera parte de su tiempo en el trabajo, por lo que se ha comenzado a prestar mayor atención en las condiciones y efectos laborales, de modo que se pueda trabajar en mejorar las condiciones de protección para hacer frente a los riesgos ya sean físicos como psicosociales (Organización Mundial de la Salud [OMS], 2014). Por este motivo, para contrarrestar los efectos que producen las demandas laborales, actualmente se vienen desarrollando diversos programas o intervenciones enfocados a manejar y prevenir el estrés donde el afrontamiento también es incluido como aspecto importante. En ese sentido, la OPS (2013) sostiene que para realizar una evaluación e intervención del estrés en el trabajo, es necesario primero solicitar ayuda psicológica. Segundo, iniciar un tratamiento de estresores psicosociales actuales. Tercero aprender a manejar el estrés y como cuarto paso, trabajar en el fortalecimiento de estrategias de afrontamiento positivas y el apoyo social.

Asimismo, el afrontamiento implica varios fenómenos que logran que a comparación de otros aspectos del comportamiento humano, sea relevante para la adaptación ante experiencias estresantes o demandantes (Eckenrode, 2013). De acuerdo a lo mencionado, Castaño y León (2010) confirman que las estrategias de afrontamiento que hace uso la persona pueden servir como facilitador o como un obstáculo para relacionarse de manera efectiva con las personas que lo rodean. Es decir que estos influyen directamente en nuestras habilidades interpersonales, lo cual generaría que en caso de no saber afrontar una situación de estrés, la relación con los demás se vea afectada, llegando a generar en contextos laborales un clima laboral negativo o dificultar el trabajo en equipo para la consecución de metas en común.

De igual manera, está comprobado que las estrategias de afrontamiento usadas por las personas influyen directamente en su bienestar emocional, el cual es importante para prevenir algunas enfermedades consideradas como crónicas. Respecto a esto, 
Fernández-Abascal (1997) menciona que las estrategias que hacen uso las personas para hacer frente a las demandas del ambiente, tienen un alto índice de relación con ciertas enfermedades, particularmente las crónicas. Es importante que las personas tomen conocimiento de cuáles son las estrategias de afrontamiento que suelen usar y cuáles son realmente las más efectivas, puesto que algunas podrían lograr ocasionar consecuencias negativas a largo plazo, no solo a nivel emocional, sino también a nivel físico. En base a esta valoración, lograrían reevaluar la forma cómo afrontan las situaciones de estrés para poder cambiarlas por otras más efectivas en un futuro.

Como resultado del incremento de interés por realizar mayores investigaciones del constructo de afrontamiento, actualmente encontramos que muchos profesionales, entre ellos psicólogos, que realizan un proceso de evaluación como parte de un programa o intervención, mediante el uso de pruebas cuyas propiedades psicométricas han sido desarrolladas y validadas en muestras con diferentes características a la que desean estudiar, por lo que las inferencias de los resultados obtenidos se encontrarían estarían sesgados, no solo por la características de la muestra, sino también por la falta de adaptación de cultura o lenguaje (McKay, 2008). Por consiguiente, los diagnósticos o evaluaciones realizados llegan a carecer de fiabilidad, logrando influir no solo en el diagnóstico, sino también en la intervención a diseñar. Entonces no solo se llega a perder la esencia de la evaluación, sino que también se pierde la posibilidad de realizar una medición válida (Fernández, Pérez, Alderete, Richaud y Fernández-Liporace, 2011).

Considerando lo anterior y con la intención de incrementar la cantidad de pruebas adaptadas, validadas y estandarizadas en el contexto peruano, la presente investigación pretende responder a la siguiente pregunta: ¿Las puntuaciones derivadas del Inventario COPE presentan adecuadas evidencias de validez y confiabilidad en una población de adultos pertenecientes a la población económicamente activa de Lima Metropolitana?

\subsection{Justificación y relevancia}

En el Perú, se han realizado varios estudios con el Inventario COPE, basándose en los resultados de la adaptación realizada por Cassuso (1996), quien aplicó la versión del Inventario COPE de 52 ítems en una población de jóvenes universitarios; sin embargo, solo se ha realizado un único estudio con la versión de 60 ítems a cargo de Cassaretto y Chau (2016), en el cual se adaptó el instrumento en una población con similares 
características. En este sentido, los resultados alcanzados en los estudios antes mencionados, no pueden ser referentes para estudiar adultos que pertenezcan a la PEA, quienes de acuerdo a la OPS (2017), representan el 50\% (460 millones) de la población en las Américas y Caribe, debido a que estos cuentan con características diferenciales.

Por lo que, a nivel práctico se aportará de dos maneras. Primero, al realizar esta adaptación en este grupo poblacional, se estaría contribuyendo a que diversos profesionales puedan contar con una herramienta para evaluar el afrontamiento en adultos que pertenezcan a la PEA, que de acuerdo al Instituto Nacional de Estadísticas e Informática (INEI, 2017) representa el 50,72 \% de la población total de peruanos. Segundo, contribuirá al ámbito de la Psicología de la salud ocupacional, puesto que el COPE aportará no solo al diagnóstico sino ayudaría a guiar los contenidos del programa de intervención ante el estrés. La Organización Internacional del Trabajo (OIT, 2013) afirma que una política de prevención del estrés en los centros de trabajo debe ser integrado a el programa de seguridad laboral y salud de la empresa

Al respecto, Ceballos, Valenzuela y Paravic (2014) sostienen que el ser el estrés algo aparentemente inevitable en los lugares de trabajo, resulta necesario contar con instrumentos que nos permitan identificar qué estrategias estamos empleado para hacerle frente a esta situación desde una primera instancia, para posteriormente realizar intervenciones en las cuales se pueda enseñar a las personas a cómo afrontar el estrés. Además, Sandín (2008) recalca que un afrontamiento inapropiado puede ser nocivo para la salud, por lo tanto, es importante prestar mayor atención a las estrategias de afrontamiento para poder tener conocimientos de los recursos con los que se cuenta, de modo que se pueda prevenir un cuadro de estrés. Es importante recalcar a su vez que el Inventario COPE, a comparación de otras pruebas que también miden el afrontamiento como los son el Ways of Coping Inventory (Folkman y Lazarus, 1980), Multidimensional Assessment of Coping (Endler y Parker, 1990), Coping Strategies Inventory (Tobin, Holroyd, Reynolds y Kigal, 1989), Coping Responses Inventory (Moos, 1997) y The Coping Strategy Indicator (Amirkhan, 1994) ; logra identificar una mayor cantidad de estrategias con un menor número de ítems, lo que ayuda a realizar un diagnóstico más profundo.

A nivel teórico, el adaptar el Inventario COPE en una muestra de adultos pertenecientes a la PEA sirve para que se puedan hacer estudios comparando diversas muestras, ya sea con estudiantes, o adultos que también pertenezcan a la PEA de otros 
países. En relación a esto, Cardoso, Gómez-Conesa e Hidalgo (2010) indican que un beneficio de adaptar pruebas, no solo es más rápido, práctico y económico que construir un test nuevo, sino que también permite realizar estudios comparativos entre países. En relación a lo mencionado, Fernández et al., (2011), Muñiz et al., (2013) y los Estándares para la evaluación educativa y psicológica establecidos por AERA, APA, NCME (2014) hacen mención de la creencia errónea que muchas personas tienen al considerar que los test se encuentran automáticamente aptos para usarlos y no toman en consideración de que estos deben estar adaptados en base a las diferencias interculturales, entre la muestra originaria y la muestra que se pretende evaluar.

Finalmente, a nivel metodológico, la investigación contribuye con evidencias de confiabilidad y validez de la versión de 60 ítems del Inventario COPE con respecto a la muestra seleccionada, lo cual favorece a futuros estudios para que los investigadores hagan uso de una prueba válida y confiable, de la cual no ha habido muchas investigaciones con la versión actualizada en Perú. Adicionalmente a ello, tener una prueba adaptada al medio permitirá realizar mayores investigaciones con la finalidad de comparar diversos tipos de muestra También servirá como instrumento para diversos programas de salud y seguridad en el trabajo que tengan como objetivo investigar o medir el afrontamiento. 


\section{CAPÍTULO II: MARCO TEÓRICO}

Se ha considerado conveniente iniciar el marco teórico explicando brevemente el concepto y las consecuencias del estrés para posteriormente brindar mayor detalle acerca del afrontamiento, ya que ambos se encuentran relacionados al ser el afrontamiento un proceso mediante el cual la persona modera los efectos adversos del estrés (Aldwin, 2012).

\subsection{El concepto de estrés}

Al existir mayor interés por ahondar en el concepto de estrés, se encontró un gran dilema a la hora de definirlo, debido a que muchos autores hasta la actualidad difieren sin llegar a un acuerdo de qué es exactamente el estrés. Para aclarar dicha variación de definiciones, Buendía (1993) señala que la definición del estrés hace alusión básicamente a tres aspectos: como estímulo, como respuesta y como interacción entre individuo y ambiente. Al definir al estrés como estímulo, unos de las personajes que más representativos de esta postura, es Cannon (1932), quien sostiene que el estrés es una alteración de la homeostasis que se presenta ante situaciones tales como el frio, descenso de la glucemia, falta de oxígeno, entre otros. Partiendo de este concepto, De Rivera (2010) lo define como un estímulo o situación que perturba el estado fisiológico normal de un organismo, al igual que los cambios que requieran un mayor esfuerzo o tensión física, mental o emocional.

En cambio, si se considera el estrés como respuesta, se define frecuentemente como la reacción problemática ante los estímulos que ocasionan estrés (Lazarus 2000). Generalmente, se usa este tipo definiciones para el ámbito de medicina y biología. Por ejemplo Selye, quien considera que este término se refiere a un grupo de reacciones fisiológicas y procesos que se originan como respuesta ante la demanda ambiental, es decir de un estímulo estresor (Lazarus y Folkman, 1984). De este modo, el estrés según Selye, se produciría cuando se origina una alteración por un estímulo nocivo dentro del funcionamiento normal de la persona. Entonces, para hacer frente de manera adecuada al estrés, es necesario tener en consideración que su composición se basa de dos elementos: los acontecimientos y las exigencias externas implicadas en nuestras vidas, lo cual incluye la reacción interna de la persona ante ellos (Lee, 2010). 
En cambio, al definir el estrés como una interacción entre individuo y ambiente se puede encontrar a Lazarus como principal partidario que defiende este tipo de definición. A diferencia de los otros tipos de definiciones de estrés, las teorías interaccionistas brindan al individuo un papel más activo y le brindan mayor importancia a los factores psicológicos implicados entre el estímulo estresante y la respuesta. Así, Lazarus y Folkman (1984), definen al estrés como un conjunto de relaciones que se da entre la persona y la situación, siendo esta última evaluada ya sea como algo que demanda mayores recursos de los que cuenta el individuo y que por lo tanto amenazaría su bienestar emocional.

Por otro lado, el término "estrés" recién se hizo popular a partir de la Segunda Guerra Mundial, donde dejo de ser exclusivo de uso militar y empezó a ser competencia de todas las personas, debido a que nadie podía librarse del estrés, lo que obligaba en cierto sentido a aprender a manejarlo (Lazarus, 2000). En relación a lo mencionado, este autor refiere que diversos profesionales, entre los cuales se encuentran filósofos, antropólogos, fisiólogos psicólogos y trabajadores sociales habían usado términos como conflicto, frustración, trauma, anomalía, ansiedad, depresión y angustia emocional, para hacer alusión a un mismo significado, por lo que se procedió en unificar todos estos conceptos bajo el término de estrés. Es así, como recién en 1960 el estrés se volvió un constructo popular en el área psicológica, psicosomática e investigación en enfermería (Rice, 2012). Así, comenzó a incrementarse el interés por estudiar el concepto de estrés y del afrontamiento, ha sido influenciado por cinco hechos: el interés por las diferencias individuales, el incremento en la preocupación acerca de la importancia del entorno en lo que respecta a los problemas del hombre, el aumento del enfoque experimental acerca del curso de la vida, la reaparición del interés en el componente psicosomático y finalmente en el progreso de la terapia enfocada no solo en la prevención, sino también en el tratamiento de la enfermedad (Lazarus y Folkman; 1984).

En resumen, el término estrés cuenta con varios significados, cada uno se orienta a una de las tres corrientes previamente señaladas; sin embargo aún no hay un consenso para llegar una definición general. En ese sentido, Lazarus y Folkman (1984) sugieren considerar al estrés como un concepto organizador, el cual hace alusión a un grupo de fenómenos que son relevantes no solo para el proceso de adaptación de los humanos, sino también para el de los animales. Entonces, la causa principal por la que una persona percibe el estrès es porque el cerebro 
interpreta una situación como amenazante, enviando una señal al sistema endocrino, el cual prepara al cuerpo para tener una respuesta de pelea, mostrando de esta manera un efecto físico en el individuo, producto de la situación percibida como estresante (Miller \& Shelly, 2010).

\subsection{Consecuencias del estrés}

Se ha encontrado que el estrés cumple un rol importante en la determinación de los trastornos mentales y también de enfermedades físicas, logrando ser considerado no solo como un gran influyente, sino también como causante de dichas dolencias (Buendía, 1993; Lee, 2010; Campillo, 2012). No obstante, es importante recalcar que para que se produzca una enfermedad, no depende exclusivamente de que la persona tenga estrés. En ese sentido, Lazarus y Folkman (1984) confirman que para que se genere una enfermedad relacionada al estrés, no basta exclusivamente con tener un episodio de estrés, sino que es necesario que se den otras condiciones como tejidos vulnerables o procesos de afrontamiento inadecuados. Asimismo, Selye (1952) afirma que independientemente al tipo de estrés a la cual la persona sea expuesta, igualmente, logra aumentar la susceptibilidad a todas las enfermedades.

De igual manera, Rice (2012) confirma que muchas disciplinas tales como psicología, enfermería y medicina, han determinado que tanto el estrés, como el afrontamiento son importantes variables que afectan la salud, llegando a afectar a nivel fisiológico al producir las siguientes sensaciones: picazón, falta de aliento, mareo, nauseas, tensión muscular, fatiga y problemas de sueño. Además, asegura que el estrés y el afrontamiento están vinculados con los inicios de ciertas enfermedades, tales como condiciones cardiovasculares, cáncer, resfríos, desórdenes alimenticios, enfermedades respiratorias, artritis, síndrome de intestino irritable, colitis ulcerosa, entre otras. Adicionalmente, es relevante mencionar que existe otra forma cómo el estrés afecta al desarrollo de enfermedades, y es al alterar los patrones de comportamiento que tienen las personas con respecto a su salud. Es decir, que al encontrarse el individuo bajo situaciones de estrés habrá una tendencia en modificar ciertos hábitos de salud a los que no estaba acostumbrado, los cuales podrán incitar la aparición de una enfermedad (Taylor, Hano, Sánchez y Reynoso, 2007). 
En ese sentido, Llaneza (2017) confirma que las consecuencias del estrés son diversas y numerosas. Además, considera que los efectos pueden ser agrupados por:

- Efectos psicológicos: Ansiedad, agresión, apatía, aburrimiento, depresión, fatiga, frustración, culpabilidad, vergüenza, irritabilidad y mal humor, melancolía, poca estima, nerviosismo, soledad, amenaza y tensión,

- Efectos conductuales: Propensión a sufrir accidentes, drogadicción, arranques emocionales, anorexia, bulimia, consumo excesivo de bebidas o cigarros, excitabilidad, conducta impulsiva, habla afectada, risa nerviosa, inquietud y temblores.

- Efectos cognitivos: Incapacidad para tomar decisiones y concentrarse olvidos frecuentes, hipersensibilidad a la crítica y bloqueo mental.

- Efectos fisiológicos: Aumento de catecolaminas y corticoides en sangre y orina, elevación de los niveles sanguíneos de glucosa, incremento del ritmo cardiaco y de la presión sanguínea, sequedad de boca, reducción de la salvación, hiperventilación, dificultad para respirar, liberación de glucosa, aumento del colesterol y triglicéridos, etc.

- Efectos organizacionales: Absentismo, relaciones laborales pobres, baja productividad, mal clima laboral, antagonismo, insatisfacción en el trabajo, abandono del trabajo, resistencia al cambio, falta de creatividad, falta de iniciativa, alto índice de accidentes y de rotación de personal.

\subsection{Concepto de afrontamiento}

El afrontamiento es un concepto que se comenzó a estudiar gracias a la corriente freudiana e inicialmente fue conceptualizado como un mecanismo de defensa, siendo aproximadamente en los años 60 donde se comienza a utilizar el afrontamiento dentro de la psicología (Endler y Parker, 1990). Para Folkman y Lazarus (1980) dichos mecanismos de defensa cumplen con dos funciones principales. La primera es básicamente modificar la situación estresante que se está aconteciendo, por lo que se harían uso de las estrategias de resolución de problemas ya sea para modificar las circunstancias problemáticas o para contribuir con nuevos recursos que contrarresten el efecto negativo (afrontamiento centrado en el problema). La segunda función consiste en regular los estados emocionales producidos por la situación estresante (afrontamiento centrado en la emoción). Asimismo, es importante señalar que el afrontamiento puede ser tanto anticipatorio como también 
consecuente. Esto, debido a que puede iniciarse previo a la situación estresante, así como puede darse después de haber experimentado el acontecimiento de estrés. (Buendía, 1993).

Moos y Schaefer (1993) consideran que son cuatro las perspectivas que pueden considerarse como precursoras del concepto de afrontamiento: la teoría de la evolución, las teorías del ciclo vital, la perspectiva psicoanalítica y los estudios de casos sobre el manejo de crisis de vida y transiciones. La primera, plantea que el ajuste comunal es el producto de la adaptación individual y de las estrategias de afrontamiento específicas que favorecen a la sobrevivencia de las personas. La segunda, indica que se pasan por 8 etapas en la vida y que la adecuada solución de estas deja recursos de afrontamiento que pueden ayudar en las futuras crisis. En cuanto a la tercera, Freud quién fue el responsable de introducir el concepto de defensa, afirmó que las personas ponen en marcha mecanismos psicológicos para deformar, disfrazar y rechazar sentimientos negativos, logrando de este modo introducir los conceptos de defensa y represión.

Con respecto a la importancia del afrontamiento, Lazarus y Folkman (1984) consideran que este concepto juega un papel sumamente significativo dentro de las psicoterapias y programas educativos que tienen como fin el poder trabajar y mejorar los recursos adaptativos. Por ende, dichos recursos son el objetivo de desarrollo para que el individuo pueda hacerle frente a situaciones o estímulos estresantes. Por último, Cohen \& Lazarus (1979) sostienen que el afrontamiento está centrado en cinco objetivos primordiales hacia los cuales se orientan. Estos objetivos son: reducir condiciones ambientales que puedan ser dañinas y aumentar las posibilidades de recuperarse del daño, tolerar los eventos negativos, mantener una imagen de sí mismo positiva, conservar el equilibrio emocional y seguir manteniendo las relaciones interpersonales que seas satisfactorias.

\subsubsection{Definiciones de afrontamiento}

Las definiciones que Lazarus y Folkman (1984) brindan se basan en dos tipos de literaturas donde se pueden encontrar al afrontamiento. La primera, es la experimental, la cual se deriva de la teoría psicoanalítica del ego y mediante la cual lo definen como "los actos que controlan las condiciones aversivas del entorno, disminuyendo por lo tanto, el grado de perturbaciones psicofisiológicas producidas por estas” (p.141). En cambio, bajo 
la literatura teórica, que proviene de la experimentación con los animales, el afrontamiento es considerado como un conjunto de pensamientos y actos que al ser flexibles y realistas brindan la posibilidad de solucionar problemas y por ende, logran reducir el estrés. Entonces, como resultado del estrés se produce disturbios en el mecanismo homoestático ya sea del individuo o del animal (Cannon, 1932).

Asimismo, Stone y Neal (citados en Buendía, 1993) brindan una definición similar a la encontrada en la literatura teórica. Consideran que el afrontamiento está constituido únicamente por aquellas conductas o pensamientos que son utilizados conscientemente por el individuo para controlar los efectos producidos por anticipación o experiencia de la situación estresante. Buendía (1993) afirma que el afrontamiento implica tanto los esfuerzos cognitivos y también los conductuales que hace uso la persona para poder controlar situaciones estresantes, de modo que logre reducir o eliminar la experiencia del estrés. Además, define a las estrategias de afrontamiento como aquellas formas que el individuo usa para hacer frente al estrés.

Por su parte, Everly y Lalingen (2013) definen el término afrontamiento como un esfuerzo para aminorar las consecuencias negativas del estrés, las cuales pueden ser tanto psicológicos como conductuales, y van a depender de las estrategias de afrontamiento que utilice la persona. En contraste, es importante señalar que Lazarus y Folkman (1984) brindan otra definición adicional a las que ya habían dado anteriormente, considerando el afrontamiento como el proceso mediante el cual el organismo hace frente a las exigencias producidas por la relación individuo - ambiente, las cuales son valoradas como estresantes. A diferencia de los autores mencionados, Sánchez-Cánovas (1991) entiende afrontamiento como los esfuerzos que el individuo realiza, ya sean cognitivos o conductuales, que le permiten hacer frente al estrés, controlando tanto las demandas que provoca, así como los estados emocionales que conlleva, mientras que Martín, Jimenez y Fernández - Abascal (2000) entienden como afrontamiento a un proceso dinámico, cambiante que utiliza el individuo para hacer frente a las demandas del entorno o de la propia persona para resolver los conflictos causados por estos mismos.

Lazarus y Launier (1978) mencionan que la definición de afrontamiento cuenta con varios aspectos importantes. Primero, la relación entre afrontamiento y los eventos estresantes es considerada como un proceso dinámico debido a que al afrontar una situación estresante, se realiza diversos intercambios entre el ambiente que cuenta con recursos, demandas y contrastes, con la persona que a su vez tiene sus propios recursos, 
valores y compromisos. Adicionalmente, como segundo aspecto, consideran que el afrontamiento no solo sucede en un momento en específico, sino que es un conjunto de respuestas que se dan durante un periodo de tiempo dentro del cual la persona y el ambiente se influencian mutuamente. Finalmente, el tercer aspecto importante, es la amplitud de la definición de afrontamiento, puesto a que dicho proceso engloba varias acciones y reacciones ante los estresores.

\subsection{Estrategias de afrontamiento}

En reiteradas oportunidades se ha confundido la definición de estrategia de afrontamiento con la de estilo de afrontamiento, llegando en ocasiones a ser consideradas como sinónimos; sin embargo, es importante aclarar que ambos difieren y cuentan con definiciones distintas. Respecto a los estilos de afrontamiento, Guevara, Hernández y Flores (2001) afirman que estos hacen alusión a predisposiciones propias de cada persona para hacer frente a las situaciones. Además, consideran que estas son las responsables de las preferencias de cada individuo a la hora de hacer uso de un tipo de estrategia de afrontamiento. De manera similar, Taylor et al., (2007) sostiene que los estilos de afrontamiento son una predisposición general para manejar eventos estresantes en una forma particular, y son concebidos como rasgos de personalidad que determinan la forman cómo las personas se comportan de manera general. Incluso, desempeñan un papel importante cuando los eventos se perciben como estresantes.

Por otro lado, en relación a las estrategias de afrontamiento, Fernández - Abascal (1997) confirma que estas pueden ser consideradas como los procesos de afrontamiento concretos que se usan en diferentes contextos y que tienen el poder de variar en función no solo de las condiciones del contexto, sino también de las características de la persona y del momento en que se da los estímulos que actúan en cada momento. A su vez, Buendía (1993) señala que se ha demostrado que si bien es cierto una estrategia puede resultar eficaz y adaptativa en un momento en particular para afrontar una situación estresante, puede que dicha estrategia posteriormente no sea eficaz para afrontar la misma clase de situación. Además que ninguna estrategia puede ser considerada como buena o mala, por lo que es necesario evaluar el contexto cuando se va a seleccionar el tipo de afrontamiento, puesto a que aún es necesario desarrollar principios que briden la posibilidad de determinar si el proceso de afrontamiento es adecuado tanto para los 
aspectos situacionales propios de la interacción que se da con el ambiente - individuo como para los aspectos personales (Lazarus y Folkman, 1984).

Entonces, las estrategias de afrontamiento vienen a formar parte de un proceso de adaptación mediante el cual el individuo demuestra contar con la capacidad de intervenir para lograr adaptarse a aquellos estímulos nocivos para él. Referente a esto, Valdés y De Flores (1990) afirman que con el tiempo, el término adaptación ha sido sustituido por lo que hoy se llaman estrategias de adaptación, puesto a que el individuo se logra adaptar en base a cuatro ejes: psicofisiológico, conductual, psiconeuroendocrino y psicoinmunológico. Por otro lado, cabe señalar que si las estrategias de afrontamiento son utilizadas de manera exagerada o extrema, su uso se vuelve inapropiado, llegando a perder su categoría de recurso para afrontar a las situaciones estresantes, por lo que terminan convirtiéndose en síntomas que brindan indicios de descontrol y desequilibrio por parte del individuo. De esta manera, mientras la persona presente mayor grado de desorganización interna, los recursos de afrontamiento que usará se volverán más primitivos. (Lazarus y Folkman, 1984).

\subsection{Recursos de afrontamiento}

Baum y Singer (1989, citados en Tello, 2009) definen a los recursos de afrontamiento como capacidades de afrontamiento que brindan inmunidad ante el daño que puede producir el estrés. Entonces, consideran a los recursos como predisposiciones procedentes de tres aspectos: componentes genéticos, influencia del medio ambiente y de relaciones relevantes. Lo mencionado, demuestra la importancia que tienen los recursos de afrontamiento ante el bienestar emocional y fisiológico de la persona. Al contar con estos recursos ayudará a prevenir los efectos provenientes del estrés.

Para Lazarus y Folkman (1984), los recursos de afrontamiento son aquellas fuentes a las cuales el individuo recurre para poder afrontar eficazmente una situación de estrés. Estos recursos pueden ser tantos personales, que son características individuales de la persona y también sociales, como fuentes de apoyo externos a la persona. De acuerdo a estos autores, entre los diversos tipos de recursos que se usan destacan principalmente dos clasificaciones. La primera que hace alusión a las propiedades de la persona, entre las cuales se encuentran recursos físicos (salud y energía), recursos psicológicos (creencias positivas) y los recursos psicosociales (técnicas para la resolución 
de problemas y habilidades sociales). La segunda clase son los relativos a los aspectos ambientales, dentro de los cuales se hallan los recursos materiales (dinero y bienes) y los recursos sociales (apoyo social).

En relación a este último, se ha podido determinar que el apoyo social es un recurso con gran poder de influencia dentro del proceso de afrontamiento a una situación de estrés, ya sea desde un punto inicial como prevención, así como para el periodo donde la persona ya se encuentra en un marco de estrés, sirviendo como respaldo para el proceso de superación y recuperación de los efectos del afrontamiento ineficiente. Al respecto, Sandín (2008) asegura que el apoyo social implica no solo compañía humana, sino también lazos sociales, contacto social significativo, pertenencia a una red social, apoyo persona, entre otros. Es importante hacer referencia que también existen factores en el ambiente que pueden ejercer influencia en la forma cómo se van a emplear los recursos de afrontamiento, llegando a restringir el uso adecuado de los recursos de la persona. Lazarus y Folkman (1986) llaman a estas limitaciones "coactores" y consideran que muchos de estos provienen de factores personales. Entonces, coactor incluye a los condicionantes personales (valores y creencias), los condicionantes ambientales y el grado de amenaza de la situación. De esta forma, ellos aseguran que la manera cómo la persona va a afrontar la situación, depende fundamentalmente tanto en los recursos con los que cuente en ese momento el individuo, como también de las limitaciones que puedan generar alguna dificultad en la utilización de estos recursos. Concluyen que es importante no solo contar con los recursos, sino sobre todo saber usarlos ante las exigencias del ambiente.

Por otro lado, Zeidner y Hammer (1992), sostienen que los recursos de afrontamiento con los que cuentan las personas, forman parte de la misma capacidad adaptativa que ayuda a generar inmunidad ante los posibles daños que implica vernos expuestos ante un evento estresante. Así, confirman que los recursos de afrontamiento también tienen otras funciones en el proceso de adaptación de la persona. Por ejemplo, pueden ayudar en el incremento de las capacidades con las que cuenta la persona, así como también pueden influir en el nivel de la intensidad de las respuestas, en la forma como la persona interpreta el evento y en la cantidad de esfuerzo que le pone a las acciones para afrontar las situaciones. Entonces, para predecir la forma cómo la persona va a afrontar los eventos estresantes, no basta con conocer los recursos de afrontamiento con los que cuenta, ya que estos no son constantes en el tiempo. En relación a esto, 
Lazarus y Folkman (1984) sostienen que dichos recursos cuentan con la capacidad para ampliarse, reducirse y algunos pueden ser impredecibles e ir en función de la experiencia y de las exigencias requeridas para afrontar ciertas etapas de la vida.

\subsection{Modelo de estrés y afrontamiento de Lazarus y Folkman}

Queda claro que el estrés se encuentra directamente relacionado al afrontamiento, por lo que es importante antes de describir el modelo de afrontamiento propuesto por Lazarus, explicar con detalle el modelo cognitivo transaccional que explica el desarrollo del estrés del individuo, como punto inicial a la activación del afrontamiento como estrategia para hacerle frente. Este modelo resalta la importancia de los factores psicológicos que se encuentran entre los estímulos y respuestas del estrés, poniendo en prioridad la evaluación cognitiva. Igualmente, la definición que le da al estrés, se basa en la interacción entre el individuo y su entorno.

En lo que respecta a la relación individuo-entorno, esta se basa en dos procesos importantes: la evaluación cognitiva y el afrontamiento. Se define el primero como un proceso en el cual se evalúa y se determina el motivo, además de examinar hasta dónde llegan a ser estresantes las relaciones entre individuo y su entono. (Lazarus y Folkman, 1984). La evaluación cognitiva se define como "un proceso mediador que pone en movimiento el tren de acontecimientos psicológicos al completo, incluidas la actividad de afrontamiento, la reacción emocional y los cambios somáticos que forman parte de cualquier estado de estrés" (Lazarus y Folkman,1984, p.303).

Por lo tanto, para los autores, los estímulos internos de la persona van a interactuar con el entorno produciendo las evaluaciones cognitivas. Este proceso va a ser esencial para que el individuo pueda poner en acción su proceso de afrontamiento al encontrarse con una situación estresante. Así, la evaluación cognitiva que se da va a consistir en tres fases denominadas: evaluación primaria, evaluación secundaria y reevaluación. Las dos primeras fases son interdependientes e influyen en la otra, puesto a que la información que se obtenga en la primera, va a ser crucial para que pueda proceder a realizarse la evaluación secundaria.

Básicamente, la evaluación primaria consiste en el proceso mediante el cual se hace una valoración donde se llega a determinar las consecuencias que se podrían dar de la interacción con dicho medio, por lo que los efectos serían un reflejo de lo que significan 
sus compromisos. Asimismo, en esta evaluación va a poder identificar cuáles serían los costos y beneficios de esta interacción. En relación a esto, Lazarus y Folkman (1984) señalan que existen tres tipos de evaluación primaria. La primera es la irrelevante, que se da cuando la interacción con el entorno no tiene ningún tipo de amenaza, no gana ni pierde algo. El segundo es la benigna-positiva, mediante el cual al interactuar con un entorno, se llega a obtener como consecuencia algo positivo, es decir si contribuye al bienestar de la persona. Finalmente, el tercer tipo es la evaluación estresante, que son aquellas que llegan a significar un daño o pérdida para la persona, lo que se va a traducir en términos de amenaza o desafío.

Cuando se evalúa la situación como estresante puede ser clasificada a su vez en tres tipos. La situación al tener efectos perjudiciales va a ser valorada como daño. Por otro lado, aquellas que sean evaluadas como un posible daño a futuro, serán valoradas como amenaza, mientras que las que se evalúen como algo que se puede superar y que podría beneficiar al individuo se valorarán como reto (Taylor et al., 2007). Adicionalmente, para que una situación sea considerada como algo que produce en la persona incomodidad, existen ciertos factores que influenciarán, como por ejemplo las habilidades o capacidades de la persona, restricciones de las tradiciones, recursos disponibles de la persona en el contexto y normas (Rice, 2012).

Con respecto a la segunda evaluación, esta se da cuando el individuo ha valorado el contexto como algo amenazante o desafiante, por lo que utilizará la información obtenida de la primera instancia, para poder determinar qué es lo que puede hacerse. En esta parte del proceso, se logrará evaluar las estrategias de afrontamiento que podrán ser usadas. La última fase es la reevaluación que trata de un nuevo análisis que se da de la situación estresante en base a la nueva información obtenida que produce un cambio en la persona en comparación de la parte inicial, donde no era claro si es que iba a poder lograr tomar acciones para poder modificarla o hacerle frente de manera apropiada.

Este modelo destaca la existencia del estrés psicológico, el cual es definido por Lazarus y Folkman (1984) como el resultado de una relación entre el sujeto y el entorno que ha sido percibido por este como algo amenazante o que excede los recursos con los que cuenta, por lo que podría poner en peligro su bienestar. Dicha interacción entre individuo y entorno, cuenta con dos características esenciales. La primera es que las propiedades del estrés y las del afrontamiento son contextuales, por lo que tienen la posibilidad de variar de acuerdo al contexto en el cual se encuentra el sujeto. La segunda 
es que tanto el estrés psicológico como el afrontamiento, pueden variar en el trascurso de la interacción (Lazarus y Folkman, 1984).

Mediante este modelo, Lazarus y Folkman (1986) afirman que la aparición del estrés está condicionado a valoraciones cognitivas que la persona realiza ante una determinada situación: primero, si el evento le trae consecuencias (primera valoración) y si posterior a la evaluación, la situación es categorizada como amenazante o desafiante ante los recursos que posee la persona (segunda valoración). Así, estos autores consideran que las respuestas que da el individuo luego de las evaluaciones de la situación no son tendencias de respuestas automáticas, sino más bien son intencionales, complejas y de crucial importancia para la adaptación del ser humano (Anson y Ponsford, 2006). Por lo tanto, en base a este modelo, Carver et al., (1989) construyen el instrumento psicométrico denominado "COPE" para evaluar los diferentes tipos de estrategias de afrontamiento al estrés. 


\section{CAPÍTULO III: OBJETIVOS, HIPÓTESIS Y DEFINICIÓN DE VARIABLES}

\subsection{Objetivos}

\subsubsection{Objetivo general}

- Adaptar y analizar las propiedades psicométricas del Inventario de afrontamiento COPE en un grupo de adultos pertenecientes a la PEA de Lima Metropolitana.

\subsubsection{Objetivos específicos}

- Realizar la adaptación lingüística del Inventario COPE.

- Obtener evidencias de validez vinculadas al contenido del Inventario COPE mediante el método de criterio de jueces, usando la V de Aiken.

- Obtener evidencias de validez vinculadas a la estructura interna del Inventario de afrontamiento COPE a través del análisis factorial exploratorio.

- Analizar la discriminación de los ítems del Inventario de afrontamiento COPE.

- Estimar la confiabilidad por consistencia interna de las puntuaciones obtenidas del Inventario COPE mediante el coeficiente de Omega.

- Elaborar los baremos para adultos pertenecientes a la PEA mediante percentiles.

\subsection{Definición de variables}

\section{Afrontamiento:}

Es entendido como los esfuerzos cognitivos y conductuales que se encuentran en cambios continuos y que se producen con la finalidad de controlar las demandas ya sean internas o externas, las cuales son consideradas como excedentes ante los recursos con los que cuenta la persona (Lazarus y Folkman, 1984).

Operacionalmente, se puede definir este concepto a partir del puntaje que se obtiene mediante el Inventario COPE (Carver et al., 1989) en su versión de 60 ítems. 


\section{Estrategias de afrontamiento:}

Las estrategias de afrontamiento son entendidas como los recursos psicológicos que las personas emplean para hacer frente a eventos estresantes ya que ayudan a evitar y reducir los conflictos (Amaris et al., 2013).

Son definidas operacionalmente a través del puntaje que se alcanzan por la suma de los ítems que pertenecen a cada una de las 15 estrategias de afrontamiento propuestas por Carver et al., (1989) en la versión de 60 ítems, las cuales son Afrontamiento activo, Planificación, Supresión de actividades competentes, Postergación del afrontamiento, Búsqueda de apoyo social por razones instrumentales, Búsqueda de apoyo social por razones emocionales, Reinterpretación positiva y crecimiento, aceptación, Negación, Acudir a la religión, Enfocar y liberar emociones, Desentendimiento conductual, Desentendimiento mental, Humor y finalmente Consumo de alcohol o Drogas. 


\section{CAPÍTULO IV: METODOLOGÌA}

\subsection{Tipo y diseño de investigación}

La presente investigación corresponde a un estudio del tipo psicométrico debido a que en base a los puntajes procedentes del Inventario COPE, se podrán obtener evidencias de validez y confiabilidad. Asimismo, con los puntajes se elaborará baremos según las características demográficas de la muestra (Alarcón, 2008). Por otro lado, es una investigación correlacional de corte transeccional, ya que se recolectará información con el propósito de describir la variable, analizar su comportamiento en un mismo tiempo y además no se intentará manipular la variable a estudiar (Hernandez, Fernández y Baptista, 2014).

\subsection{Participantes}

El estudio tuvo como población objetiva personas de ambos sexos que pertenecen a la PEA (población económicamente activa) de Lima Metropolitana. Los participantes cuentan con una edad mínima de los 18 años, dado a que evaluar menores de edad requiere de un consentimiento informado de sus padres o tutor (Lozano, 2015; Cañete, Guilhem y Brio, 2012). Asimismo, las personas seleccionadas se dedican únicamente a la actividad laboral. Lo mencionado, implica la exclusión de aquellos que se encuentren realizando estudios de pregrado, debido a que la adaptación de la versión del COPE de 52 ítems y la adaptación de la versión de 60 ítems del Inventario COPE en el Perú, fueron realizadas en estudiantes universitarios de pregrado. Hacer esta exclusión permitirá realizar futuras investigaciones comparando los resultados en muestras distintas. Por lo tanto, la muestra se compuso de $54.74 \%$ hombres y $45.26 \%$ mujeres.

Por otro lado, se consideró a las personas que tengan trabajos formales e informales. Esto, debido a que se tiene registrado que del total de la PEA en el Perù, el $73,2 \%$ cuenta con empleo informal y solo el $26,8 \%$ con un empleo formal (INEI, 2016). Además, participaron personas pertenecientes a las 6 categorías de la PEA, que de acuerdo al Ministerio de Trabajo y Promoción del Empleo (MINTRA, 2012) son las siguientes: 
- Empleador o patrono: Titular de la empresa que tiene a su cargo trabajadores remunerados.

- Empleado: Trabajador que presta sus servicios a un empleador y que percibe un sueldo a cambio.

- Obrero: Trabajador que desempeña actividades manuales y cuyo empleador retribuye un salario a cambio.

- Trabajador independiente: Persona que trabaja de manera individual o asociada explotando una empresa y que no tiene trabajadores a cargo que remunera.

- Trabajador del hogar: Persona que brinda servicios a una vivienda particular y recibe un sueldo a cambio.

- Trabajador familiar no remunerado: Persona que presta sus servicios a una empresa cuyo dueño es familiar y recibe a cambio propinas u otras formas de pago diferentes a un sueldo.

Con respecto al tamaño de la muestra Kass \& Tinsley (1979) recomiendan contar con 5 a 10 participantes por cada ítem del instrumento a usar, teniendo como mínimo 300 participantes, con lo cual los paramentos de la prueba tendrían una tendencia a ser estables. Teniendo en cuenta lo mencionado, Comrey y Lee (1992) consideran que una muestra de 100 personas es pobre, de 300 es buena, 500 muy buena y de 1000 es excelente. , esto debido a que las muestras mayores de 1000 son más adecuadas para la mayoría de objetivos de análisis factoriales. Asimismo, estos autores consideran que el tamaño de muestra es importante para que el coeficiente de la correlación del error estándar sea suficientemente pequeña para que los análisis factoriales resultantes de estas correlaciones produzcan soluciones estables.

Por lo tanto, para determinar el tamaño de la muestra a estudiar se utilizó como criterio la fórmula de Nunnally (1987), mediante la cual se propone que para validar una prueba es necesario hacer uso de una muestra equivalente a la multiplicación de los ítems del instrumento por 10. Esto, con la finalidad de minimizar el error de muestreo. En este sentido, puesto a que el Inventario COPE cuenta con 60 ítems, se requirió una muestra mínima de 600 participantes, por lo que se aplicó a 660 trabajadores de Lima Metropolitana; sin embargo, se excluyeron 48 pruebas debido a que se encontraban incompletos y por estar cursando estudios de pregrado, quedando un total de 612 encuestas (Anexo 10). Además, el método de muestreo a utilizar fue no probabilístico de 
tipo intencional, puesto a que la selección de los participantes se realizó en base a los requisitos que se consideraron pertinentes para la investigación (Cruz, Olivares y Gonzales, 2014).

\subsection{Técnicas de recolección de información}

Primero, se hizo uso de una ficha sociodemográfica la cual permitió el acceso de los datos principales de las personas que participaron en el estudio, tales como edad, tipo de estudios, clasificación de la PEA, ocupación y sexo. El segundo instrumento que se ha utilizado en la investigación fue la última actualización de 60 ítems de la versión disposicional del Inventario de Estimación de Afrontamiento (COPE) elaborado por Carver et al., (1989), el cual tiene como finalidad identificar las estrategias que hacen uso las personas cuando se encuentran bajo situaciones de estrés. Los autores en su investigación hicieron uso de la versión disposicional y tuvieron como muestra a estudiantes universitarios del Estado de Miami, Estados Unidos, obteniendo un coeficiente de alfa de Cronbach que variaba entre .45 y .92. Adicionalmente, realizaron el procedimiento test- retest después de 8 semanas de aplicada la prueba, obteniendo valores que oscilaban entre .46 a .86. (Carver et al., 1989).

Inicialmente el inventario COPE contaba con 52 ítems que hacían alusión a 13 subescalas, comúnmente llamadas "estrategias", con las cuales las personas pueden hacerle frente al estrés. Estas son: Afrontamiento activo $(\alpha=.62)$, Planificación $(\alpha=.80)$ supresión de actividades competentes $(\alpha=.68)$, Postergación del afrontamiento $(\alpha=.72)$ búsqueda de apoyo social por razones instrumentales $(\alpha=.75)$, Búsqueda de apoyo social por razones emocionales $(\alpha=.85)$, Reinterpretación positiva y crecimiento $(\alpha=.68)$, Aceptación $(\alpha=.65)$, Negación $(\alpha=.71)$, acudir a la religión $(\alpha=.92)$, Enfocar y liberar emociones $(\alpha=.77)$, Desentendimiento conductual $(\alpha=.63)$ y Desentendimiento mental $(\alpha=.45)$. Adicionalmente a estas sub escalas, se adicionaron dos más con carácter experimental: Humor $(\alpha=.91)$ y Consumo de drogas o alcohol $(\alpha=.89)$; sin embargo, al obtener evidencias psicométricas satisfactorias, se decidió mantenerlas obteniendo un inventario final de 60 ítems y 15 sub escalas. Esta nueva versión tiene una traducción oficial al castellano, la cual fue realizada por Calvete, profesora de la Universidad de Deusto en España. 
En relación a lo previamente mencionado, se han encontrado evidencias de validez y confiabilidad de la última versión de 60 ítems en nuestro medio, utilizando una muestra de estudiantes universitarios cuyas edades fluctuaron entre los 16 a 25 años (M= 18.27 y D.E= 1.39 años). Cassaretto y Chau (2016) demostraron niveles de confiabilidad obtenidos mediante el alfa de Cronbach, los cuales oscilaron entre .53 a .91 para cada una de sus subescalas. Con respecto a las evidencias de validez provenientes de la estructura interna se realizó un análisis factorial exploratorio con rotación oblicua y extracción de componentes principales, comprobando la pertinencia del uso del mismo y alcanzando valores de $\mathrm{KMO}=.80, p=.01$. Asimismo, se encontró la existencia de 13 factores que logran explicar el 65.15, y se encontraron fusionadas por un lado las escalas de afrontamiento activo con planificación y por el otro lado, la búsqueda de apoyo social por razones instrumentales con la búsqueda de apoyo social por razones emocionales aparecen fusionadas.

El Inventario COPE cuenta con dos versiones, la disposicional y la situacional, básicamente difieren en que la primera tiene como finalidad estudiar las respuestas típicas de forma cómo afrontaría generalmente la persona bajo situaciones de estrés, mientras que la versión situacional se enfoca netamente en una situación específica de estrés, la cual describe y contesta las preguntas basándose en dicho escenario (Carver et al., 1989). Además, las opciones de respuesta se basan en la frecuencia en la que se realiza lo mencionado en el ítem y se encuentran presentadas en un formato Likert que va del 1 al 4, siendo 1 (no suelo hacer esto en lo absoluto, 2 (suelo hacer esto un poco), 3 (suelo hacer esto moderadamente) y 4 (suelo hacer esto mucho). En relación a ello, Crespo y Cruzado (1997) indican que la correcta corrección de la prueba para identificar las estrategias de afrontamiento consiste básicamente en sumar los ítems de cada subescala. Después se deberá dividir el resultado de la sumatoria entre el número de ítems de cada subescala.

Los ítems del Inventario propuesto por Carver et al., (1989) se encuentran agrupados de la siguiente manera:

- Afrontamiento activo: 5, 25, 47 y 58 .

- Planificación: 19, 32, 39 y 56.

- Supresión de actividades competentes: 15, 33, 42 y 55 .

- Postergación del afrontamiento: 10, 22, 41 y 49. 
- Búsqueda de apoyo social por razones instrumentales: 4, 14, 30 y 45.

- Búsqueda de apoyo social por razones emocionales: 11, 23, 34, y 52.

- Reinterpretación positiva y crecimiento: 1, 29, 38 y 59 .

- Aceptación: 13, 21, 44 y 54.

- Negación: 6, 27, 40 y 57.

- Acudir a la religión: 7, 18, 48 y 60.

- Enfocar y liberar emociones: 3, 17, 28 y 46.

- Desentendimiento conductual: 9, 24, 37 y 51 .

- Desentendimiento mental: 2, 16, 31 y 43.

- Humor: 8, 20, 36 y 50.

- Consumo de alcohol o drogas: 12, 26, 35 y 53.

\subsection{Procedimiento de recolección de datos}

Para el desarrollo de esta investigación, inicialmente se realizó una revisión gramatical y cultural de cada uno de los ítems de la prueba traducida por Calvete para poder adaptarlo a nuestro contexto. Asimismo, se hizo una revisión técnica mediante la cual se identificó los ítems que contenían negaciones, conjunciones y disyunciones. Al identificarlos, se procedió a redactarlos nuevamente con el fin de incrementar la claridad del Inventario.

Seguidamente, los ítems fueron sometidos al proceso de criterio de jueces. De acuerdo a Escurra (1988) el proceso de criterio de jueces consiste en solicitar la revisión de los ítems de una prueba por jueces para que ellos emitan la aprobación o desaprobación. Por lo tanto, 8 especialistas con experiencia en el tema de afrontamiento y en investigación verificaron los ítems redactados para confirmar que efectivamente dicha redacción representa lo que se desea evaluar y contaba con una redacción clara.

Teniendo los resultados de los jueces, se procedió a modificar la prueba, y con esta nueva versión se procedió a aplicar una prueba piloto a una muestra de 20 personas por causalidad en la población que se desea evaluar, con el propósito de verificar si los ítems y las instrucciones eran comprensibles. Después, se contactó a 6 empresas para la aplicación del instrumento, se expuso a los representantes de las compañías los objetivos de la investigación, las condiciones de la aplicación, los términos de la confidencialidad y se les solicitó una autorización. Se estableció un cronograma de aplicación de acuerdo a la disponibilidad brindada. Ya en el momento de aplicación del instrumento, se 
mencionó a los participantes los objetivos de la investigación y se les solicito su participación voluntaria. A las personas que accedieron, se les explicó las instrucciones e inmediatamente se les entregó el consentimiento informado, la ficha sociodemográfica y el Inventario COPE.

Asimismo, fue creada una encuesta virtual que explicaba los objetivos de la investigación, las instrucciones y solicitaba la aprobación del consentimiento informado en el cual se encontraban datos como el objetivo de la investigación, persona a cargo, características de la prueba, los límites de la confidencialidad, quiénes tendrían acceso de los resultados y la posibilidad de desistir de participar en la investigación. De esta manera, el link donde se encontraban dichos documentos fue enviado a personas que cumplieran con los requisitos. Finalmente, con las encuestas correctamente desarrolladas, fue creada una base de datos para ser analizada con los programas SPPS versión 24 y Factor en su versión 10.8.04 (Lorenzo-Seva y Ferrando, 2015). 


\section{CAPÍTULO V: RESULTADOS}

\subsection{Adaptación Lingüística}

La adaptación lingüística del Inventario COPE consistió de cuatro etapas. La primera se basó en realizar una revisión gramatical de la versión oficial traducida en español, en la cual se identificó las negaciones, conjunciones y disyunciones. Una vez modificado los ítems se procedió a la segunda etapa, la cual consistió en una evaluación del instrumento realizada por 8 psicólogos con el grado de magister, de los cuales 7 se encontraban familiarizados en la investigación del afrontamiento y 1 en psicometría. Cada uno de ellos recibió un documento donde se indicaban las instrucciones del Inventario, base teórica de la prueba, los ítems y la dimensión a la cual correspondía cada uno de ellos. Se les solicitó hacer realizar una evaluación de cada uno de los ítems con respecto a los siguientes conceptos:

a) Sintaxis: Si los ítems cuentan con un orden correcto de las palabras, de modo que la oración exprese de manera clara lo que el mensaje desea transmitir o si es que el ítem genera confusión o ambigüedad a la hora de leerlo.

b) Pertenencia: Si los ítems corresponden a la dimensión en la que han sido agrupados o si es que el ítem no es representativo del área.

Posteriormente, una vez recogidos los formatos completos, se trascribió los resultados a una base de datos. A partir de las respuestas brindadas se realizaron ciertas modificaciones en los ítems. Cabe mencionar que hubieron reiterados comentarios de los jueces acerca de la similitud de tres de los cuatros ítems pertenecientes de la estrategia de afrontamiento Humor (Hago bromas sobre la situación, Bromeo sobre ello y Hago bromas de la situación), por lo que se procedió con la tercera fase del proceso de adaptación lingüística, la cual consiste en aplicar el método de traducción inversa, el cual es considerado como uno de los procedimientos más idóneos para poder identificar posibles complicaciones relacionadas a las traducciones deficientes (Hambleton, 1996, 2005). 
Para ello, se recurrió a tres personas norte americanas bilingües con amplio conocimiento de los idiomas español e inglés y asimismo, familiarizados tanto con la cultura peruana como con la americana. Se les hizo entrega de un documento donde se encontraban los ítems observados en ambos idiomas. Con el resultado de sus traducciones se realizó una comparación con la finalidad de generar una propuesta que considere el común de las sugerencias. Al determinar la traducción a utilizar de cada uno de los ítems observados, se efectuaron las modificaciones pertinentes para obtener la versión final del Inventario la cual sería usada para la presente investigación.

Para finalizar, la cuarta etapa consistió en ejecutar el estudio piloto, el cual fue realizado en una muestra de 20 personas, 15 de sexo femenino y 5 masculino. A los participantes se les preguntó si habían tenido alguna dificultad a la hora de leer las instrucciones o al desarrollar la prueba; no obstante, ninguna de las personas evaluadas demostró presentar dificultad alguna para desarrollar la prueba. Con ello, se confirmó que el instrumento es comprensible para la población objetiva de la investigación y que además requería un tiempo aproximado de 15 minutos para su resolución. Adicionalmente, se identificó que en caso la aplicación sea presencial, era recomendable desarrollarlo en un ambiente cómodo, por la longitud de la prueba y era necesario proveer de lapiceros ya que en ocasiones las personas no siempre portaban este u otro medio de escritura similar. En caso la aplicación sea virtual, se detectó la necesidad de contar con una conexión de internet estable con la finalidad de que se registren las respuestas sin inconvenientes

\subsection{Evidencias de validez vinculadas al contenido}

Con la finalidad de poder obtener las evidencias de validez vinculadas al contenido, se apeló a la modalidad de criterio de jueces, los cuales tienen como propósito poder determinar si los ítems representan lo suficiente el objetivo a medir, garantizar su precisión técnica y determinar que tan bien se ajustan los ítems con respecto a los principios de calidad de la escritura (Sireci y Faulkner-Bond, 2014). Por lo tanto, se solicitó la participación de ocho jueces que cumplían con los siguientes requisitos: psicólogos de profesión, docentes universitarios, grado de magister y ser especialistas en investigación de la variable afrontamiento. En base a las respuestas brindadas estos especialistas, las cuales fueron dicotómicas de 0 a 1 , se estimó el Coeficiente de V de 
Aiken, el cual es una de las técnicas usadas con la finalidad de cuantificar la relevancia de los ítems en relación a un dominio de contenido proveniente de los jueces cuyo rango va del .00 al 1.00, siendo este último sinónimo de un acuerdo total entre los especialistas (Merino y Livia, 2009). A partir de este análisis, se pudo identificar cuáles son los ítems que no cumplían con el valor mínimo necesario el cual según Guilford (1954) es de 88 para que puedan ser considerados como válidos. Ante ello, se procedió a decidir cuáles iban a ser los ítems que requerían ser modificados.

Teniendo en cuenta que fueron 8 jueces que participaron en la evaluación de las evidencias de validez vinculadas al contenido del Inventario de Afrontamiento COPE, es necesario que como mínimo 7 de ellos se encuentren de acuerdo. Esto, con la finalidad de que el ítem cuente con validez de contenido, considerando un nivel de significación de $\mathrm{p}<.05$ (Escurra, 1988). A continuación los resultados del Coeficiente V de Aiken respecto a la representatividad y claridad de los ítems pertenecientes al Inventario de Afrontamiento COPE:

Tabla 1

Coeficiente $V$ de Aiken para la representatividad de los items del Inventario de Afrontamiento COPE

\begin{tabular}{cccc}
\hline Ítem & V de Aiken & Ítem & V de Aiken \\
\hline 1 & $1.00^{*}$ & 31 & $.88^{*}$ \\
2 & $1.00^{*}$ & 32 & $.88^{*}$ \\
3 & $1.00^{*}$ & 33 & $1.00^{*}$ \\
4 & $1.00^{*}$ & 34 & $1.00^{*}$ \\
5 & $1.00^{*}$ & 35 & $1.00^{*}$ \\
6 & $1.00^{*}$ & 36 & $1.00^{*}$ \\
7 & $1.00^{*}$ & 37 & $1.00^{*}$ \\
8 & $1.00^{*}$ & 38 & $1.00^{*}$ \\
9 & $1.00^{*}$ & 39 & $.88^{*}$ \\
10 & $.88^{*}$ & 40 & $1.00^{*}$ \\
11 & $1.00^{*}$ & 41 & $1.00^{*}$ \\
12 & $1.00^{*}$ & 42 & $1.00^{*}$ \\
13 & $1.00^{*}$ & 43 & $1.00^{*}$ \\
14 & $.88^{*}$ & 44 & $1.00^{*}$ \\
15 & $1.00^{*}$ & 45 & $1.00^{*}$ \\
16 & $.88^{*}$ & 46 & $.88^{*}$ \\
17 & $1.00^{*}$ & 47 & $1.00^{*}$
\end{tabular}




\begin{tabular}{rrrr}
18 & $1.00^{*}$ & 48 & $1.00^{*}$ \\
19 & $1.00^{*}$ & 49 & $1.00^{*}$ \\
20 & $1.00^{*}$ & 50 & $.88^{*}$ \\
21 & $.88^{*}$ & 51 & $1.00^{*}$ \\
22 & $.88^{*}$ & 52 & $1.00^{*}$ \\
23 & $1.00^{*}$ & 53 & $1.00^{*}$ \\
24 & $1.00^{*}$ & 54 & $.88^{*}$ \\
25 & $1.00^{*}$ & 55 & $1.00^{*}$ \\
26 & $1.00^{*}$ & 56 & $1.00^{*}$ \\
27 & $1.00^{*}$ & 57 & $1.00^{*}$ \\
28 & $1.00^{*}$ & 58 & $1.00^{*}$ \\
29 & $.88^{*}$ & 59 & $1.00^{*}$ \\
30 & $.88^{*}$ & 60 & $1.00^{*}$ \\
\hline & & &
\end{tabular}

Tabla 2

Coeficiente $V$ de Aiken para la claridad de los ítems del Inventario de Afrontamiento COPE

\begin{tabular}{cccc}
\hline Ítem & $\begin{array}{c}\text { V de } \\
\text { Aiken }\end{array}$ & Ítem & $\begin{array}{c}\text { V de } \\
\text { Aiken }\end{array}$ \\
\hline 1 & .63 & 31 & $.88^{*}$ \\
2 & $.88^{*}$ & 32 & .75 \\
3 & $.88^{*}$ & 33 & $.88^{*}$ \\
4 & $.88^{*}$ & 34 & $.88^{*}$ \\
5 & .63 & 35 & .75 \\
6 & $1.00^{*}$ & 36 & $.88^{*}$ \\
7 & $.88^{*}$ & 37 & $1.00^{*}$ \\
8 & $1.00^{*}$ & 38 & $.88^{*}$ \\
9 & $1.00^{*}$ & 39 & $.88^{*}$ \\
10 & $.88^{*}$ & 40 & $1.00^{*}$ \\
11 & $.88^{*}$ & 41 & $.88^{*}$ \\
12 & $.88^{*}$ & 42 & $1.00^{*}$ \\
13 & $.75^{*}$ & 43 & .63 \\
14 & $.88^{*}$ & 44 & $.88^{*}$ \\
15 & $.88^{*}$ & 45 & $.75^{*}$ \\
16 & $1.00^{*}$ & 46 & $.75^{*}$ \\
17 & $.75^{*}$ & 47 & $.88^{*}$ \\
18 & $1.00^{*}$ & 48 & $1.00^{*}$ \\
19 & $.88^{*}$ & 49 & $.75^{*}$ \\
20 & .63 & 50 & .50
\end{tabular}




\begin{tabular}{cccc}
21 & $.75^{*}$ & 51 & $1.00^{*}$ \\
22 & .63 & 52 & $.88^{*}$ \\
23 & $.88^{*}$ & 53 & $.75^{*}$ \\
24 & $.88^{*}$ & 54 & $1.00^{*}$ \\
25 & $.88^{*}$ & 55 & $1.00^{*}$ \\
26 & $.75^{*}$ & 56 & $.88^{*}$ \\
27 & $1.00^{*}$ & 57 & $1.00^{*}$ \\
28 & $.88^{*}$ & 58 & $1.00^{*}$ \\
29 & .63 & 59 & $.88^{*}$ \\
30 & $.88^{*}$ & 60 & $1.00^{*}$ \\
\hline
\end{tabular}

$* \mathrm{p}<.05$.

De acuerdo a los resultados presentados en la Tabla 3, se puede evidenciar que los 60 ítems cuentan con un valor mínimo de $\mathrm{V}$ de Aiken de .88 para a un nivel de significancia de $p<.05$, demostrando así, que el contenido de los ítems representa adecuadamente lo que el Inventario intenta medir. Además, a partir de los resultados obtenidos del coeficiente de V de Aiken para la claridad mostrados en la tabla 3, se optó por realizar cambios en los ítems 1, 5, 13, 17, 22, 29, 32, 45, 46, 49 y 50 por sugerencia de los jueces, con la finalidad de aumentar su compresión. También, 2 jueces consideraron pertinente modificar el ítem 21 "Acepto que ha sucedido y que no puede cambiarse"; sin embargo, este no fue cambiado dado a que las recomendaciones planteaban cambio de artículos y conjunciones que no aportaban sustancialmente a la claridad del ítem original. Dentro de las propuestas se obtuvieron las siguientes: "Acepto lo sucedido y que no puede cambiarse" y "Acepto tanto lo que ha sucedido, como el hecho de que no puede cambiarse".

De igual manera, los jueces indicaron haber ambigüedad en los ítems 36 y 20, ambos pertenecientes a la estrategia Humor, motivo por el cual los 4 ítems alusivos a dicha estrategia $(8,20,36,50)$ fueron revisados y pasaron por un proceso de traducción, tal como se mencionó previamente. Con respeto a los ítems 26, 35, 43 y 53, los cuales pertenecen a la estrategia de Consumo de Alcohol y Drogas fueron modificados agregándose la conjunción (y) a la disyunción (o), con la finalidad de brindar mayor amplitud a los participantes. Por ejemplo en el ítem 53 "Utilizo alcohol o drogas para ayudarme a superarlo" fue cambiado por "Utilizo alcohol y/o drogas para ayudarme a superarlo". 


\subsection{Evidencias de validez vinculadas a la estructura interna}

Para poder analizar las evidencias de validez vinculadas a la estructura interna del Inventario COPE, se ejecutó un análisis factorial exploratorio (AFE) sobre los 60 ítems que conforman la prueba. Se seleccionó AFE debido a que es una de las técnicas más usadas en investigaciones relacionadas con el desarrollo y validación de pruebas, puesto a que con ella se puede analizar diversos factores comunes que sustentan las respuestas de los ítems que conforman la prueba (Lloret, Ferreres, Hernández y Tomás; 2014). Este procedimiento se realizó con una matriz de correlaciones policóricas, ya que las opciones de respuesta son politómicas y las variables son de tipo ordinal (Burga; 2006).

Para establecer la estructura factorial del Inventario, se utilizó el método de Hull mediante la extracción de mínimos cuadrados no ponderados (ULS) siguiendo la sugerencia de Ferrando y Anguiano - Carrasco (2010) por ser eficiente y por no requerir una estimación inicial de comunalidades. Al ser indispensable el indicar el número de factores a ser extraídos (Pett, Lackey y Sullivan; 2003), se consideró comenzar el análisis con 15 factores de acuerdo a lo que sustentado por la teoría. Cabe mencionar que el análisis se llevó a cabo haciendo uso del método de rotación oblicua promin con la finalidad de mejorar la interpretabilidad de los factores, además que este tipo de método logra obtener mejores resultados a comparación de procedimientos más populares. (Lorenzo -Seva; 1999). Además se optó por este método ya que existe una interacción entre los factores de la prueba.

En virtud de lo mencionado, se llevaron a cabo 3 análisis factoriales exploratorios para poder obtener la versión final del Inventario COPE. En el primer análisis factorial exploratorio realizado los resultados demuestran que la matriz de correlación usada presenta la existencia de un KMO de .90. Asimismo, el test de esfericidad de Barlett arroja como resultados $\left.X^{2}[1770, N=612]=14267.6, p<.001\right)$ lo cual demuestra correlaciones estadísticamente significativas entre las variables. Los resultados señalan valores apropiados para la factorización (Hair, Black, Babin y Anderson, 2014). Además, la varianza explicada común compartida fue de $68,23 \%$. En este primer análisis se consideraron 15 factores de acuerdo a la teoría; sin embargo, al aplicar el método de Hull, el programa sugirió la existencia de 2 factores, por lo que se procedió en iniciar un segundo análisis. 
En el segundo análisis se repitió el procedimiento previamente mencionado, por lo que para el proceso de determinación de factores, se consideraron solo a 2 y como resultado se corroboró la propuesta de 2 factores que explicaban el 33,67\% de la varianza compartida. Seguidamente, se analizaron las cargas factoriales, detectando que los ítems 2, 8, 11, 20, 50, 54 contaban con una carga menor a lo recomendado por Field (2009) el cual sugiere un mínimo de .40, también se evidenciaron que los ítems 7, 15, 18, 21, 28, 43, 48, 55 y 60 no poseían carga alguna. De igual manera, se observó que el ítem 49 cargó en ambos factores.

Finalmente, se procedió a ejecutar un último análisis con la finalidad de obtener la nueva estructura factorial, por lo que se consideró pertinente la eliminación de los ítems previamente identificados, los cuales no cumplían con los criterios usados. En esta ocasión se obtuvo un KMO de .91 y el test de esfericidad de Barlett dio un valor de $X^{2}$ [946, $N=612]=10239.7, p<.001)$. De este modo, se logró obtener una estructura factorial final compuesta por 44 ítems y 2 factores que explicaron el $40.20 \%$ de la varianza compartida, teniendo el primer factor una varianza de $20,99 \%$ y el segundo factor de $19,21 \%$.

Tabla 3

Resultados del método de Hull en el primer análisis factorial

\begin{tabular}{cccc}
\hline $\begin{array}{c}\text { Número de } \\
\text { factores }\end{array}$ & $\begin{array}{c}\text { Bondad de } \\
\text { ajuste }\end{array}$ & g.l. & Scree test \\
\hline 0 & 0.000 & 1770 & 0.000 \\
1 & 0.535 & 1710 & 1.412 \\
2 & 0.908 & 1651 & $8.453^{\mathrm{a}}$ \\
3 & 0.951 & 1593 & 1.457 \\
4 & 0.980 & 1536 & 2.608 \\
5 & 0.991 & 1480 & 1.711 \\
6 & 0.998 & 1425 & 1.349 \\
7 & 1.002 & 1371 & 2.099 \\
8 & 1.004 & 1318 & 0.000 \\
\hline
\end{tabular}

${ }^{\text {a }}$ Número óptimo de factores : 2 
Tabla 4

Cargas factoriales de los ítems en el primer análisis factorial

\begin{tabular}{|c|c|c|c|}
\hline Ítem & Factor 1 & Factor 2 & Comunalidad \\
\hline Ítem 1 & & .46 & .81 \\
\hline Ítem 2 & & .32 & .67 \\
\hline Ítem 3 & .45 & & .74 \\
\hline Ítem 4 & & .44 & .74 \\
\hline Ítem 5 & & .57 & .74 \\
\hline Ítem 6 & .49 & & .93 \\
\hline Ítem 7 & & & .90 \\
\hline Ítem 8 & .39 & & .89 \\
\hline Ítem 9 & .60 & & .79 \\
\hline Ítem 10 & .44 & & .75 \\
\hline Ítem 11 & & .38 & .68 \\
\hline Ítem 12 & .75 & & 1.00 \\
\hline Ítem 13 & .48 & & .68 \\
\hline Ítem 14 & & .56 & .79 \\
\hline Ítem 15 & & & .56 \\
\hline Ítem 16 & .50 & & .61 \\
\hline Ítem 17 & .56 & & .92 \\
\hline Ítem 18 & & & 1.00 \\
\hline Ítem 19 & & .63 & .84 \\
\hline Ítem 20 & .36 & & .93 \\
\hline Ítem 21 & & & .78 \\
\hline Ítem 22 & .50 & & .92 \\
\hline Ítem 23 & & .47 & .97 \\
\hline Ítem 24 & .65 & & .97 \\
\hline Ítem 25 & & .43 & .59 \\
\hline Ítem 26 & .81 & & 1.00 \\
\hline Ítem 27 & .66 & & .84 \\
\hline Ítem 28 & & & .73 \\
\hline Ítem 29 & & .62 & .93 \\
\hline Ítem 30 & & .59 & .91 \\
\hline Ítem 31 & .44 & & .69 \\
\hline Ítem 32 & & .70 & .77 \\
\hline Ítem 33 & & .57 & .73 \\
\hline Ítem 34 & .51 & & .78 \\
\hline Ítem 35 & .78 & & 1.00 \\
\hline Ítem 36 & .44 & & .80 \\
\hline Ítem 37 & .72 & & .87 \\
\hline Ítem 38 & & .73 & .86 \\
\hline Ítem 39 & & .78 & .86 \\
\hline Ítem 40 & .55 & & .86 \\
\hline
\end{tabular}




\begin{tabular}{lccc} 
Ítem 41 & & .52 & .69 \\
Ítem 42 & & .51 & .96 \\
Ítem 43 & & & .76 \\
Ítem 44 & & .57 & .89 \\
Ítem 45 & & .63 & .92 \\
Ítem 46 & .47 & & .79 \\
Ítem 47 & & .72 & 1.00 \\
Ítem 48 & & & .96 \\
Ítem 49 & .32 & .42 & .77 \\
Ítem 50 & .35 & & .93 \\
Ítem 51 & .45 & & .70 \\
Ítem 52 & & .52 & .91 \\
Ítem 53 & .82 & & 1.00 \\
Ítem 54 & & .38 & .79 \\
Ítem 55 & & & .65 \\
Ítem 56 & & .63 & .83 \\
Ítem 57 & .57 & & .87 \\
Ítem 58 & & .71 & .85 \\
Ítem 59 & & .75 & .86 \\
Ítem 60 & & & .86 \\
\hline
\end{tabular}

Tabla 5

Resultados del método de Hull en el tercer análisis factorial

\begin{tabular}{cccc}
\hline $\begin{array}{c}\text { Número de } \\
\text { factores }\end{array}$ & $\begin{array}{c}\text { Bondad de } \\
\text { ajuste }\end{array}$ & g.l. & Scree test \\
\hline 0 & 0.000 & 946 & 0.000 \\
1 & 0.518 & 902 & 1.165 \\
2 & 0.953 & 859 & $16.007^{\mathrm{a}}$ \\
3 & 0.980 & 817 & 1.823 \\
4 & 0.994 & 776 & 1.880 \\
5 & 1.001 & 736 & 3.818 \\
6 & 1.003 & 697 & 0.000 \\
\hline
\end{tabular}

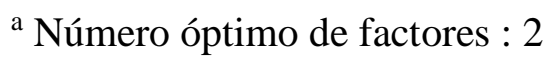


Tabla 6

Cargas factoriales de los ítems en el tercer análisis factorial

\begin{tabular}{|c|c|c|c|}
\hline Ítem & Factor 1 & Factor 2 & Comunalidad \\
\hline Ítem 1 & & .43 & .22 \\
\hline Ítem 3 & .47 & & .22 \\
\hline Ítem 4 & & .46 & .24 \\
\hline Ítem 5 & & .56 & .32 \\
\hline Ítem 6 & .47 & & .22 \\
\hline Ítem 9 & .59 & & .36 \\
\hline Ítem 10 & .43 & & .21 \\
\hline Ítem 12 & .76 & & .61 \\
\hline Ítem 13 & .49 & & .29 \\
\hline Ítem 14 & & .57 & .34 \\
\hline Ítem 16 & .49 & & .25 \\
\hline Ítem 17 & .57 & & .32 \\
\hline Ítem 19 & & .62 & .41 \\
\hline Ítem 22 & .48 & & .26 \\
\hline Ítem 23 & & .49 & .31 \\
\hline Ítem 24 & .64 & & .45 \\
\hline Ítem 25 & & .46 & .26 \\
\hline Ítem 26 & .82 & & .70 \\
\hline Ítem 27 & .64 & & .41 \\
\hline Ítem 29 & & .62 & .39 \\
\hline Ítem 30 & & .62 & .41 \\
\hline Ítem 31 & .42 & & .18 \\
\hline Ítem 32 & & .72 & .52 \\
\hline Ítem 33 & & .59 & .35 \\
\hline Ítem 34 & .53 & & .31 \\
\hline Ítem 35 & .80 & & .66 \\
\hline Ítem 36 & .40 & & .24 \\
\hline Ítem 37 & .72 & & .55 \\
\hline Ítem 38 & & .70 & .53 \\
\hline Ítem 39 & & .75 & .62 \\
\hline Ítem 40 & .53 & & .28 \\
\hline Ítem 41 & & .52 & .28 \\
\hline Ítem 42 & & .53 & .30 \\
\hline Ítem 44 & & .56 & .32 \\
\hline Ítem 45 & & .65 & .43 \\
\hline Ítem 46 & .48 & & .28 \\
\hline Ítem 47 & & .72 & .53 \\
\hline Ítem 51 & .44 & & .19 \\
\hline
\end{tabular}


Ítem 52

Ítem 53

Ítem 56

Ítem 57

Ítem 58

Ítem 59
.54

.83

.55
.32

.71

.40

.30

.50

$.72 \quad .58$

\subsection{Estimación de confiabilidad}

Se estimó el nivel de confiabilidad proveniente de las puntuaciones de la aplicación del Inventario COPE, mediante la consistencia interna a través del Coeficiente Omega, al ser este menos riesgoso para la sobrestimación y subestimación de la confiabilidad (Dunn, Baguley y Brunden, 2013). El nivel alcanzado fue de .96, cumpliendo con los valores mínimos aceptables propuestos por Campo-Arias y Oviedo (2008) de .70 para ser considerado como adecuado para estimar la confiabilidad. Además, en el análisis de cada factor, el resultado para el primero fue de .92 para el segundo .93.

\subsection{Análisis de la discriminación de los ítems}

Con respecto al análisis de la discriminación de los ítems, se optó por usar el método de correlación de ítem- test cuyos resultados se muestran en la Tabla 8. Se verificó que las correlaciones cuenten con un valor superior a .20 (Kline, 1995), llegando a la conclusión que todos cumplían con dicho criterio. Posteriormente, se consideró pertinente con la finalidad de aumentar la precisión, tomar en cuenta el valor de .30 (Gil, 2011; Field, 2009). De igual manera, toda las correlaciones cumplieron con este nuevo criterio, presentando una buena capacidad discriminativa. 
Tabla 7

Correlación Ítem-test del Inventario COPE

\begin{tabular}{|c|c|c|}
\hline & Ítem & $\begin{array}{c}\text { Correlación Ítem - Test } \\
\text { Corregida }\end{array}$ \\
\hline \multirow[t]{22}{*}{ Factor 1} & Ítem 3 & .39 \\
\hline & Ítem 6 & .40 \\
\hline & Ítem 9 & .49 \\
\hline & Ítem 10 & .39 \\
\hline & Ítem 12 & .55 \\
\hline & Ítem 13 & .40 \\
\hline & Ítem 16 & .43 \\
\hline & Ítem 17 & .49 \\
\hline & Ítem 22 & .44 \\
\hline & Ítem 24 & .52 \\
\hline & Ítem 26 & .58 \\
\hline & Ítem 27 & .55 \\
\hline & Ítem 31 & .36 \\
\hline & Ítem 34 & .41 \\
\hline & Ítem 35 & .54 \\
\hline & Ítem 36 & .35 \\
\hline & Ítem 37 & .55 \\
\hline & Ítem 40 & .48 \\
\hline & Ítem 46 & .41 \\
\hline & Ítem 51 & .40 \\
\hline & Ítem 53 & .57 \\
\hline & Ítem 57 & .49 \\
\hline \multirow[t]{15}{*}{ Factor 2} & Ítem 1 & .37 \\
\hline & Ítem 4 & .42 \\
\hline & Ítem 5 & .48 \\
\hline & Ítem 14 & .52 \\
\hline & Ítem 19 & .54 \\
\hline & Ítem 23 & .45 \\
\hline & Ítem 25 & .39 \\
\hline & Ítem 29 & .54 \\
\hline & Ítem 30 & .56 \\
\hline & Ítem 32 & .63 \\
\hline & Ítem 33 & .52 \\
\hline & Ítem 38 & .61 \\
\hline & Ítem 39 & .64 \\
\hline & Ítem 41 & .45 \\
\hline & Ítem 42 & .45 \\
\hline
\end{tabular}




$\begin{array}{ll}\text { Ítem } 44 & .47 \\ \text { Ítem } 45 & .58 \\ \text { Ítem } 47 & .62 \\ \text { Ítem 52 } & .48 \\ \text { Ítem 56 } & .55 \\ \text { Ítem 58 } & .59 \\ \text { Ítem 59 } & .59\end{array}$

\subsection{Elaboración de baremos}

Con el objetivo de elaborar los baremos del Inventario COPE, se comenzó analizando la normalidad. Para ello, se recurrió a la prueba de Shapiro-Wilk de bondad de ajuste a la curva normal, ya que al ser comparada con otras, resulta ser una de las más consolidadas y con mayor potencia estadística (Pedrosa, Juanrros-Basterretxea, Robles- Fernandez, Basteiro \& García- Cueto, 2014). Los resultados de la prueba demuestran que para la los factores 1 y 2 se rechaza la hipótesis nula, lo que implica que ambos provienen de una población que no se encuentra distribuida normalmente a nivel de significancia de $p<.05$. En ese sentido, se procedió a utilizar la prueba no paramétrica de U de Mann-Whitney en la variable sexo y como consecuencia, se evidenció diferencias estadísticamente significativas exclusivamente en el Factor 1, más no en el Factor 2, de modo que se presentó la necesidad de elaborar baremos diferenciados para el primer factor.

Tabla 8

Estadísticos descriptivos y análisis de normalidad con la Prueba Shapiro-Wilk del Inventario COPE

\begin{tabular}{lcccccc}
\hline & $n$ & $M$ & $D E$ & $M e$ & $W$ & $p$ \\
\hline Factor 1 & 612 & 1.83 & 0.45 & 1.77 & 0.96 & $<.001$ \\
& & & & & & \\
Factor 2 & 612 & 2.92 & 0.49 & 2.95 & 0.97 & $<.001$ \\
\hline
\end{tabular}



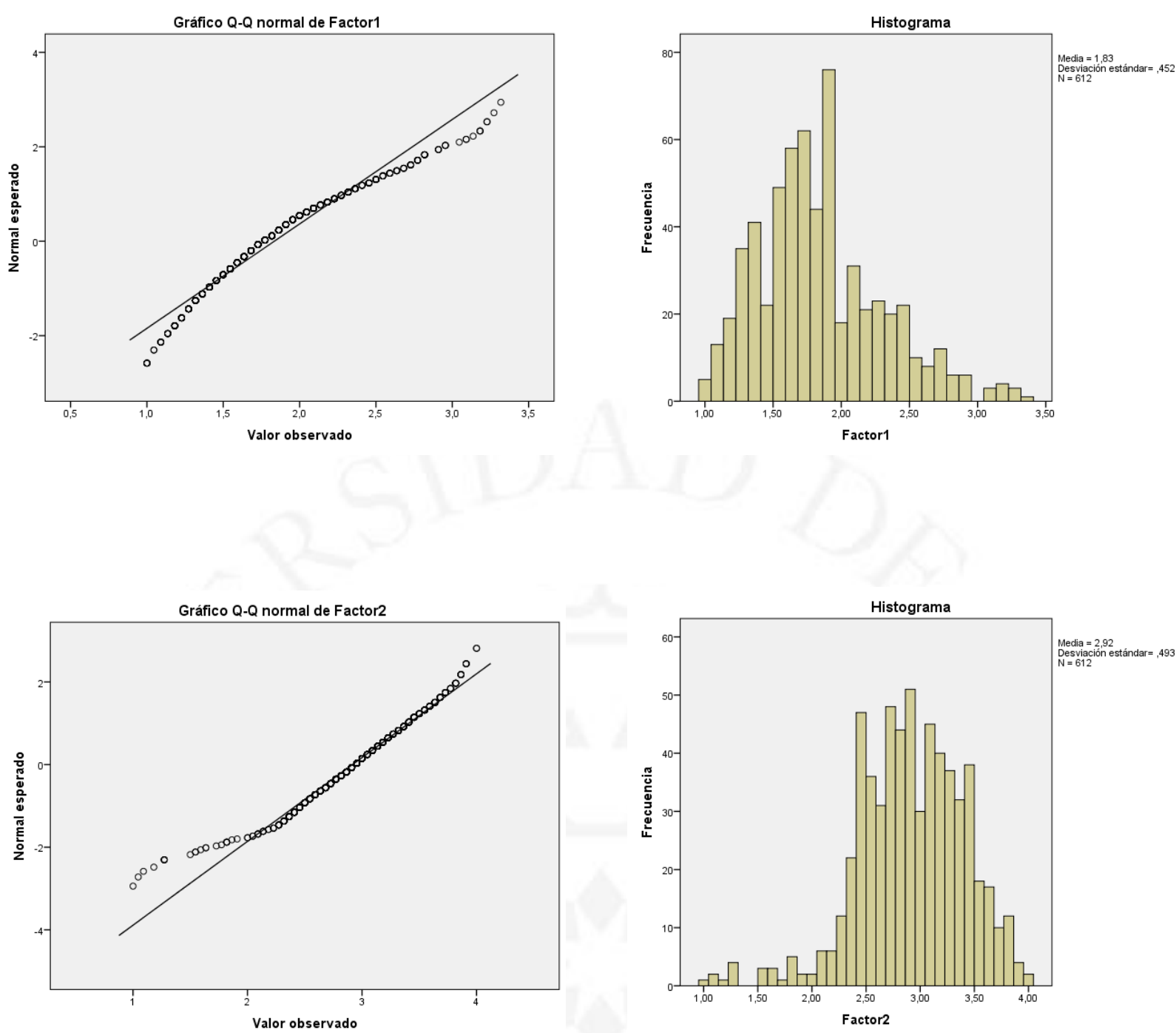

Figura 1. Gráficos de Normalidad e Histogramas del Factor 1 y Factor 2

Tabla 9

Estadísticos de Prueba de U de Mann-Whitney según variable Sexo

\begin{tabular}{cccc}
\hline & $U$ & $Z$ & sig \\
\hline Factor 1 & 38723.50 & -3.527 & $<.001$ \\
& & & \\
Factor 2 & 41374.00 & -0.2308 & .21 \\
\hline
\end{tabular}


Tabla 10

Baremos clasificados en percentiles de acuerdo al sexo de los participantes para las puntuaciones obtenidas del Inventario COPE

\begin{tabular}{cccc}
\hline & \multicolumn{2}{c}{ Factor1 } & Factor2 \\
\cline { 2 - 4 } Percentil & Femenino & Masculino & Total \\
\cline { 2 - 4 } & $(\mathrm{n}=277)$ & $(\mathrm{n}=335)$ & $(\mathrm{n}=612)$ \\
\hline 99 & 2.78 & 3.23 & 3.90 \\
95 & 2.41 & 2.84 & 3.68 \\
90 & 2.27 & 2.65 & 3.55 \\
85 & 2.14 & 2.50 & 3.41 \\
80 & 2.05 & 2.32 & 3.32 \\
75 & 1.95 & 2.23 & 3.23 \\
70 & 1.91 & 2.09 & 3.18 \\
65 & 1.86 & 2.00 & 3.09 \\
60 & 1.82 & 1.95 & 3.05 \\
55 & 1.73 & 1.86 & 3.00 \\
50 & 1.73 & 1.82 & 2.95 \\
45 & 1.68 & 1.77 & 2.86 \\
40 & 1.64 & 1.68 & 2.82 \\
35 & 1.59 & 1.64 & 2.77 \\
30 & 1.55 & 1.59 & 2.68 \\
25 & 1.50 & 1.55 & 2.60 \\
20 & 1.41 & 1.45 & 2.55 \\
15 & 1.36 & 1.41 & 2.45 \\
10 & 1.31 & 1.32 & 2.36 \\
5 & 1.18 & 1.23 & 2.12 \\
\hline
\end{tabular}

Nota: $\mathrm{N}=612$. 


\section{CAPÍTULO VI: DISCUSIÓN}

A continuación, se revisarán los resultados obtenidos del proceso de adaptación de la prueba y se comentarán los resultados obtenidos producto del análisis psicométrico efectuado. Para ello, es importante señalar que dos documentos que orientan respecto al proceso de adaptación son las 22 directrices para la adaptación de pruebas proporcionada por La Comisión Internacional de Test (Muñiz et al., 2013) y los Estándares para la evaluación educativa y psicológica establecidos por AERA, APA, NCME (2014), los cuales serán utilizados para reflexionar acerca del proceso y los hallazgos de esta investigación. La presente investigación tuvo como objetivo principal el adaptar y analizar las propiedades psicométricas del Inventario de afrontamiento COPE (Carver et al., 1989) en un grupo de adultos pertenecientes a la PEA de Lima Metropolitana

En la actualidad viene siendo frecuente la adaptación de instrumentos de auto reporte a diferentes contextos culturales de donde fueron elaborados (Blanch y Aluja, 2016). . El interés de investigar en la muestra seleccionada se debe a que en la actualidad el estrés es uno de los síndromes con mayor prevalencia en personas pertenecientes al mundo laboral y el afrontamiento es uno de los aspectos más investigados en la literatura del estrés (Zorrilla, 2017), siendo este último un recurso que ayuda a la persona a contrarrestar el daño producido. Por lo tanto, las puntuaciones derivadas de la aplicación del Inventario COPE pretenden brindar información acerca de las estrategias de afrontamiento usadas ante situaciones de estrés. De este modo, la investigación se alinea a la directriz DP4 que refiere el análisis de la importancia del constructo que será medido mediante el test en la población de interés (p. 153), así como con el estándar 1.1 el cual recalca que el evaluador ha debido establecer claramente cómo se pretende interpretar y utilizar consecuentemente las puntuaciones de las pruebas. Indica adicionalmente, que las poblaciones a las que está dirigido el test deben ser delimitadas y el constructo o constructos que la prueba pretende evaluar deben describirse con claridad.

La importancia de la aplicación del Inventario COPE radica en los resultados que se obtienen sobre las estrategias de afrontamiento usadas en caso de situaciones de estrés, lo cual genera la posibilidad de ser utilizado en el futuro para el diagnóstico de riesgos psicosociales, así como también la posibilidad de desarrollar programas de intervención ante el estrés; para ello, el test podría ser complemento con otros constructos relacionados como por ejemplo el estrés, personalidad, bienestar, entre otros. De esta forma, se podría 
aportar en la implementación de intervenciones dirigidas a la seguridad y salud de los trabajadores en centros de trabajo. Es así, como según lo mencionado, se hace alusión al estándar 1.6, en el cual se sugiere que para el uso de una prueba con la finalidad de producir beneficios indirectos, aparte de la información sobre la utilidad de las interpretaciones de los puntajes, es necesario hacer explícita la justificación para anticipar este beneficio, proporcionando argumentos lógicos o teóricos y evidencia empírica del beneficio indirecto (p. 24).

$\mathrm{Si}$ bien es cierto, esta investigación tiene como muestra objetiva a adultos pertenecientes a la PEA, los autores (Carver et al., 1989) indican que la prueba puede ser usada para cualquier tipo de muestra con diferentes características, el único tipo de población que excluye es a los adolescentes y niños. En ese sentido, se presenta en la investigación, la información requerida por los estándares 4.1 y 4.2, donde se solicita que en las especificaciones de la prueba deben describirse en los propósitos de la prueba, la población a la que se encuentra dirigida, la duración, los formatos de ítem, los procedimientos en la administración de la prueba, variaciones permitidas, maneras de calificación, las propiedades psicométricas esperadas de los ítems de la prueba, el orden de estos y las secciones (p.85). A parte, antes de iniciar con el proceso de adaptación fue necesario solicitar el permiso al autor de la prueba. En este caso, Carver, autor del Inventario COPE mantiene en su página web la cual se encuentra auspiciada por la Universidad de Miami, un listado de pruebas diseñadas por él y otros colaboradores a las cuales se puede acceder gratuitamente, inclusive a las versiones oficiales en otros idiomas (Carver, 2007). Cabe señalar que en la misma página el autor menciona que todos los instrumentos se encuentran disponibles para ser aplicados exclusivamente en ámbitos de investigación y enseñanza, recalcando que no será aplicado cargo alguno y solicitando que no envíen correos solicitándole autorizaciones ya que considera que con lo mencionado basta para hacer uso de los test.

Además, al encontrarse disponible la versión oficial del instrumento en español, se procedió a contactar a la autora de la traducción, Calvete, para poder solicitar su autorización para el uso del instrumento. De esta manera, al contar con la autorización para el uso del instrumento en su versión original (Anexo 2), y la prueba en la versión en español (Anexo3), se garantizó la directriz DP1, según la cual es indispensable que previo al inicio de la adaptación se deba obtener los permisos de quién cuente con los derechos de propiedad intelectual del instrumento (p.153). Así, al contar con la versión oficial en 
el español, se comenzó revisando cada uno de los ítems con la finalidad de verificar la presencia de coloquialismos propios de la cultura española; sin embargo, no se evidenció en ningún ítem. Asimismo, se propuso cambiar la redacción de 18 ítems, previo a la entrega de formato a los jueces (Anexo 8) con la finalidad de que puedan ser comprendidos con mayor facilidad por la muestra seleccionada.

En efecto, fueron 8 los jueces que participaron, los cuales tenían nacionalidad peruana, eran psicólogos de profesión, docentes universitarios, tenían el grado de magister y 7 especialistas en investigación de la variable afrontamiento y 1 en psicometría, a quienes se les explicó el objetivo de la investigación, se les brindó una base teórica de la prueba y además, se les explicó su rol como jueces y la forma cómo debían completar el formato. Cabe señalar que en ningún caso se dio comunicación o coordinación entre ellos con respecto a sus juicios sobre el instrumento. Según lo mencionado, se cumplen con la directrices DD1 y los estándares 4.8 y 1.9, mediante los cuales se hace hincapié en que el proceso de revisión de pruebas debe incluir el uso de jueces expertos para revisar los ítems, de modo que se asegure que el proceso de adaptación tenga en consideración las diferencias culturales, psicológicas y lingüísticas, para lo cual es necesario registrar todo el proceso, incluyendo las instrucciones brindadas, sus calificaciones, experiencias relevantes, características demográficas, instrucciones y la capacitación brindada, la interacción entre ellos y el reporte del nivel de acuerdo.

A raíz del análisis de $\mathrm{V}$ de Aiken para la claridad y representatividad, se estableció .88 como valor mínimo. Respecto a representatividad se obtuvo respuestas positivas en todos los ítems, lo que refleja que los ítems pertenecen a la dimensión en la que han sido agrupados. Por su parte, en los resultados de claridad se obtuvieron valores menores a .88 en 10 ítems y en consecuencia a ello, se procedió a realizar cambios de redacción. Precisamente, un ejemplo de los cambios consistió en agregar la conjunción (y) a la disyunción (o) en ciertos ítems con la finalidad de brindar mayor amplitud a los participantes respecto al enunciado. De este modo, con el proceso descrito previamente, se presta atención a la directriz DP5, la cual señala la importancia de evaluar la influencia de diferencias tanto culturales y lingüísticas en la muestra que sea significativa para el instrumento que será adaptado (p.154).

Asimismo, producto de las observaciones de los jueces, se logró identificar que 3 de los 4 ítems pertenecientes a la estrategia Humor eran muy similares (ítem 20: "Hago bromas sobre la situación", ítem 36: "Bromeo sobre ello" e ítem 50: "Hago bromas de 
la situación"). Por lo tanto, se consideró pertinente solicitar la participación de 3 traductores que dominan a la perfección tanto el idioma inglés como el español y se optó por hacer uso del método de traducción inversa. Como resultado del proceso mencionado, se obtuvieron los siguientes ítems: "Hago bromas sobre la situación” (ítem 20), "evito tomar la situación con tanta seriedad incluso hago chistes" (ítem 36) y "llevo la situación por el lado divertido" (ítem 50). De este modo, se desarrolló un diseño que consistió en 4 fases: Revisión gramatical, evaluación de sintaxis y representación por criterio de jueces, traducción inversa y estudio piloto, cumpliendo tanto con la directriz DP3 la cual consiste en escoger el diseño de adaptación de pruebas que sea más adecuado (p.153), como con la directriz DD2, que señala el uso de procedimientos deben ser los apropiados para asegurar la adecuada adaptación del instrumento de acuerdo a la población objetiva (p.154).

Una vez lista la versión final del instrumento a utilizar, se consideró pertinente realizar una prueba piloto con la finalidad de corroborar si las instrucciones al igual que cada uno de los ítems eran lo suficientemente claros y por ende comprensibles para el tipo de muestra seleccionada. Cabe señalar que no hubo ninguna modificación en las instrucciones de la versión oficial en español. Se seleccionó 20 personas por causalidad, $75 \%$ eran de sexo femenino y $15 \%$ masculino. De este modo se confirmó que las personas no presentaron observación alguna y pudieron desarrollar la prueba de manera efectiva. Por consiguiente, no fue necesario realizar modificaciones. Lo mencionado se encuentra relacionado con la directriz DD4, donde se explica la necesidad de brindar la información correspondiente que demuestre que el formato de los ítems, estilo de corrección, escala de respuesta, el método y reglas corrección sean los adecuados de acuerdo a la población de interés. Igualmente, se da por cumplido el estándar 4.15 al presentar instrucciones con suficiente claridad con la finalidad de que otros puedan replicar las condiciones de la administración de la prueba para obtener datos de confiabilidad y validez (p.90), así como el estándar 4.16, al señalar que las instrucciones presentadas a los evaluados deben contener suficientes detalles para que puedan responder a la tarea de la manera que se espera, de manera que estos detalles formen parte de la estandarización de las instrucciones cuando se aplique la prueba (p.90).

Asimismo, producto de la aplicación piloto, se logró determinar no solo el tiempo promedio que se requiere para desarrollar la prueba, sino de la presencia de otras condiciones que podrían influir en la resolución de la prueba. Este proceso proporcionó 
información necesaria para responder ante la directriz DD3 la cual resalta la necesidad de brindar información y evidencias que aseguren que las instrucciones y el contenido del instrumento cuenten con un significado similar en las poblaciones a las que será dirigido y adicionalmente para responder a la directriz DA2 en la que se señala la importancia de detallar las condiciones necesarias que deben ser consideradas para la aplicación del instrumento en las poblaciones de interés (p.154). Por lo tanto, la información proporcionada por la aplicación piloto demostró que no había necesidad de realizar cambios en la prueba.

Como parte del proceso de aplicación en este estudio, se solicitó el consentimiento informado de cada uno de los participantes donde se encontraba información explicita de la investigación. Esto, con la finalidad de seguir las recomendaciones citadas en el estándar 8.4, el cual afirma que se requiere de un consentimiento informado de los participantes o del representante legal antes de la aplicación (p.134). También se tuvo en consideración el estándar 4.17, el cual se señala que se debe brindar afirmaciones sobre el objetivo en todos los materiales que se les entregue a los participantes (p.91) y el estándar 10.7, que recomienda que antes a la aplicación, el evaluador debe brindar a los participantes información con la finalidad de tener un mejor entendimiento de la prueba (p.165).

Así, se continuó con la aplicación de la prueba usando 2 formas, virtual y física. En ambos casos se presentó el consentimiento informado de manera previa y se usó las mismas instrucciones emitidas por los autores de la prueba original, garantizando el cumplimiento del estándar 6.1, que menciona que se debe seguir de manera cuidadosa los procedimientos que se encuentran estandarizados para la administración previamente especificados por el autor (p.114). Como resultado, en la aplicación física se evidenció diversos casos en los que se omitieron las respuestas de algunos ítems, lo cual generó el descarte del $7.27 \%$ de los tests aplicados. Vale la pena mencionar que en la aplicación virtual, no permitía que el participante avance al siguiente ítem sin haber primero respondido el anterior, evitando de este modo la omisión de respuestas. De lo mencionado, resulta evidente que dicha condición fue ventajosa para poder tener mayor cantidad de pruebas válidas.

Respecto a lo mencionado en el párrafo anterior, cabe señalar que si bien es cierto los autores indican que la manera correcta de corregir el Inventario COPE es al realizar una suma de los valores obtenidos según los ítems que conforman cada una de las 
estrategias, es importante recalcar que los objetivos de la presente investigación se basan en el análisis de propiedades estadísticas de la prueba y no en analizar las tendencias del uso de estrategias de afrontamiento en la muestra seleccionada. Habiéndose dicho esto, queda claro que se encuentra la metodología de corrección es explicada, más no usada. Así, se presta atención al estándar 4.22 que menciona que se debe especificar los procedimientos utilizados para interpretar los puntajes de la prueba según el autor (p. 93).

Con la finalidad de poder obtener evidencias de validez vinculada a la estructura interna, mediante el programa Factor se obtuvo una estructura factorial final de 2 factores después de los 3 análisis factoriales exploratorios realizados. Dicho resultado, no solo fue inconsistente con la literatura, sino también con investigaciones previas, incluyendo la adaptación realizada en el Perú la cual resultó con una estructura de 13 factores. Si bien es cierto la estructura bifactorial obtenida dista en gran medida con la adaptación peruana (Cassaretto y Chau, 2016), se asemeja más a otras adaptaciones como por ejemplo la realizada en Croacia (Hudek-Knežević, Kardum, y Vukmirović, 1999) cuya estructura fue de 3 factores y tanto en Rumania (Crasovan y Sava, 2013), Italia (Sica, Novara, Dorz y Sanvio, 1997) como en Estonia (Kallasmaa y Pulver, 2000) con una estructura de 4 factores.

Ahora, si bien es cierto la propuesta de los autores iniciales nos indica que son 15 estrategias las que mide la prueba, la estructura bifactorial producto de los AFEs realizados podría encontrarse en relación a la teoría proporcionada por Lazarus y Folkman, para la creación de su instrumento Ways of Coping Inventory ((Folkman y Lazarus, 1980) en la cual se mantiene una estructura de 2 escalas llamadas estilo centrado en la emoción y estilo centrado en la tarea. Para entender mejor este punto, es importante señalar que la página web de Carver (2007) expresa firmemente que el instrumento COPE mide exclusivamente estrategias de afrontamiento y no estilos, como muchos autores han asumido; sin embargo, en la investigación original de Carver et al., (1989) indica claramente que la prueba fue diseñaba en base a un marco teórico compuesto por el modelo de estrés y el modelo de auto regulación conductual de Lazarus. Lo mencionado, ha podido ser motivo de confusión, conllevando a autores de otras investigaciones (Cassaretto y Chau, 2016; Pillaca, 2013; Solano, 2012; Rodriguez, 2012; Soto, 2010; Asencio, 2015; Becerra, 2013; Torrejòn, 2011; Quiros, 2013 ; Pineda, 2012; Rojas y Ramos, 2013; Agüero, Rodriguez, Ibarra, De la fuente y Mangué, 2014; Valadez, Flores, Garcés, Solís y Reynaga, 2016) a considerar que la prueba adicionalmente a medir 
estrategias, también mide estilos de afrontamiento, como lo son el estilo centrado en la emoción y el estilo centrado en la tarea; sin embargo, también es relevante recordar que existe una diferencia conceptual entre los conceptos de estilo y estrategia, por lo cual no podemos asumir que tienen el mismo significado.

Es relevante mencionar que en investigaciones previas (Kallasmaa y Pulver, 2000; Cassaretto y Chau, 2016) se excluyeron de los análisis a las escalas de acudir a la religión, Humor y Uso de drogas y alcohol. La decisión de excluirlos se debido a que estas estrategias tenían antecedentes de localizarse consistentemente dentro de un factor; sin embargo, se optó por considerar en el AFE las 15 escalas propuestas con la finalidad de analizar en conjunto las estrategias tal como se realizó en la versión italiana (Sica et al., 1997), croata (Hudek-Knežević et al., 1999) y rumana (Crasovan y Sava, 2013).

Respecto a la confiabilidad, a diferencia de todas las investigaciones relacionadas al COPE en las cuales usaron al alfa de cronbach y alfa ordinal, se consideró pertinente en esta oportunidad hacer uso del coeficiente de Omega. Si bien el Coeficiente de alfa es la medida más popular para analizar la confiabilidad en investigaciones psicológicas, esto se debe principalmente a que los investigadores aún no conocen otras alternativas (Cervantes, 2005). No obstante, este método presenta gran cantidad de inconvenientes como los siguientes: se basa en supuestos que no siempre se cumplen tales como la $\square \square$ equivalencia de su partes y ausencia de los errores de correlación, el incumplimiento de estas suposiciones provoca que se atenué las estimaciones de coherencia interna de una medición, además que en la muestra no se refleje el impacto que tiene la eliminación de ítems en la confiabilidad de la población y finalmente que su cálculo no refleje la variabilidad que se presenta en el proceso de estimación, por lo que proporciona confiabilidad imprecisa en la consistencia de la administración de una prueba (Dunn et al., 2013; Cervantes, 2005). A diferencia del alfa, el Coeficiente Omega no depende del número de ítems y trabaja con cargas factoriales, generando que los cálculos sean más estables; sin embargo, a pesar de ser una medida con mayor precisión, aún es poco frecuente su uso, probablemente porque no se encuentra en paquetes estadísticos comerciales (Ventura y Caycho, 2017).

En virtud de lo mencionado, el valor obtenido del Coeficiente de omega para el puntaje total del inventario COPE fue de .96. Asimismo, al obtenerse una estructura factorial compuesta de dos factores producto de los análisis factoriales exploratorios realizados, se procedió en estimar la confiabilidad de cada uno de los factores. Los 
hallazgos proporcionan un coeficiente de .92 para el primer factor y de .93 para el segundo. Lo mencionado previamente confirma que el Inventario COPE cuenta con evidencias de confiabilidad relacionadas a la consistencia interna (Campo-Arias y Oviedo, 2008). De este modo, se garantiza el cumplimiento del estándar 2.5, el cual señala que los procedimientos de estimación de confiabilidad deben ser consistentes con la estructura de la prueba (p.43). Cabe resaltar además que los resultados de las evidencias de confiabilidad van en concordancia con los estándares 2.0 que indica que se debe proporcionar evidencias apropiadas de confiabilidad / precisión para la interpretación de las puntuaciones para cada uso. (p. 42) y con el 2.3, el cual sugiere que para cada puntaje total, puntuación parcial o combinación de puntajes que deben ser interpretados, se deben informar las estimaciones de índices relevantes de confiabilidad (p. 43). A parte, es importante señalar que un indicador que refleja el buen índice de evidencia de confiabilidad, es el resultado del nivel de discriminación de las puntuaciones de los ítems del test, y en el caso de esta investigación, los resultados superan el de .30 (Gil, 2011; Field, 2009).

Una vez que se obtuvieron las evidencias de validez y confiabilidad de la prueba se procedió en la elaboración de los baremos de la variable sexo. Las puntuaciones derivadas de los ítems que componen el Factor 1 del Inventario COPE mostraron resultados estadísticamente significativos, lo cual obligó al desarrollo de baremos diferenciados. No obstante, lo mencionado difirió de los resultados del Factor 2, cuyas diferencias no fueron estadísticamente significativos. El motivo por el cual se realizaron baremos exclusivamente de la variable sexo y no de otras variables como clasificación de la PEA o edad, radicó básicamente en que las demás variables no contaban con una distribución equitativa, mientras que en la variable sexo, la diferencia entre hombres y mujeres fue de $9.48 \%$. Ahora, es necesario acotar que los baremos no podrán ser generalizables, dado a que la muestra del presente estudio no es representativa con respecto a la población total que compone la PEA de Lima Metropolitana. Por otro lado, del procedimiento realizado resulta evidente el cumplimiento del estándar 5.8, el cual sostiene que en el caso se hagan uso de baremos, se debe hacer mención de una descripción clara de las poblaciones con las que evaluadores podrán querer comparar a sus evaluados (p.104).

Con respecto a las limitaciones de la investigación, si bien es cierto la muestra fue de fácil acceso y por ende se logró superar el mínimo de participantes requerido, la 
primera limitación encontrada en el presente estudio radicó en el tipo de muestreo que fue no aleatorio y por ende no fue representativo con respecto al tipo de población. Además, que el muestreo no probabilístico no fue considerado en cuotas, por lo que los subgrupos que se registraron de las variables presentes en la ficha sociodemográfica no fueron equitativos. La segunda limitación se debió a la longitud de la prueba y en aquellas personas que la desarrollaban durante horas laborales, ya que implicaba el pause temporal de sus actividades. Sin embargo, a pesar de sus limitaciones, esta investigación contribuye en gran medida a un mejor empleo de la prueba en el ámbito laboral para evaluar factores de riesgos psicosociales, los cuales hoy en día se encuentran teniendo mayor protagonismo para fomentar la salud y seguridad en el trabajo. 


\section{CAPÍTULO VII: CONCLUSIONES}

- En relación a la adaptación lingüística del Inventario COPE, se propusieron cambios en 18 ítems con la finalidad de aumentar su claridad.

- Se encontraron evidencias de validez basadas en el contenido del instrumento mediante el método de criterio de jueces.

- Respecto a las evidencias de validez relacionadas a la estructura interna, se halló una estructura factorial compuesta de 2 factores la cual difiere en gran medida de la encontrada en la prueba original (Carver et al,. 1989) y en la adaptación realizada en Perú (Cassaretto y Chau, 2016).

- Sobre la estimación de la confiabilidad del Inventario COPE, de los puntajes de la aplicación se obtuvo un Coeficientes de Omega de .96 para la prueba en general, para cada el primer factor .92 y para el segundo .93 .

- Se encontraron diferencias estadísticamente significativas en las puntuaciones entre hombres y mujeres.

- Se elabora una propuesta del Inventario COPE para personas pertenecientes a la PEA conformado por 44 ítems y organizados en dos factores. 


\section{CAPÍTULO VIII: RECOMENDACIONES}

- Se sugiere realizar un nuevo estudio con una muestra que sea más equitativa en relación a las demás variables sociodemográficas como edad y categoría de PEA.

- Sería recomendable poder llevar a cabo un análisis factorial confirmatoria o un análisis paralelo con el objetivo de corroborar la base teórica con el proceso de análisis estadísticos.

- Resultaría interesante que en futuras investigaciones con el instrumento COPE, se aplique conjuntamente una prueba que mida los niveles de estrés, con la finalidad de poder investigar la correlación entre ambos constructos. Así, se podría explorar otros tipos de validez como predictiva y concurrente, analizando la relación del COPE con pruebas que midan el constructo del estrés.

- Debido a la coyuntura actual de migración por la que atraviesa el Perú, interesante poder incluir a extranjeros dentro de una investigación de afrontamiento, sobre todo por el proceso de estrés -afrontamiento que resulta propio de los cambios por los que se ven forzados a experimentar por la situación complicada que viven.

- Sería interesante poder realizar una investigación similar con una muestra mayor a las 1000 personas, de modo que se pueda verificar si aumenta el nivel de confiabilidad y validez del instrumento, además que permitirá realizar una mayor generalización de los resultados.

\section{REFERENCIAS}


Agüero, L., Rodriguez, M., Ibarra, O., De La Fuente, L., y Mangué, J.J. (2014). Estrategias de afrontamiento de una muestra de pacientes con trastorno límite de personalidad en terapia dialéctico-conductual Apuntes de Psicología, 32(2), 103-106. Recuperado de http://www.apuntesdepsicologia.es/index.php/revista/article/view/501 .

Alarcón, R. (2008). Métodos y Diseño de Investigación del Comportamiento. Lima: Editorial Universitaria.

Aldwin, C.M. (2012).Stress, Coping and Development: An integrative perspective ( $2^{\text {nd }}$ ed.). New York: Guildford Press.

Amaris, M., Madariaga, C., Valle, M. y Zambrano, J. (2013). Estrategias de afrontamiento individual y familiar frente a situaciones de estrés psicológico. Psicología desde el Caribe, $30 \quad$ (1), 123- $145 . \quad$ Recuperado de http://www.redalyc.org/articulo.oa?id=21328600007 .

Amirkhan, J. H. (1994). Criterion validity of a coping measure. Journal of Personality Assessment, 62(2), 242-61.doi: 10.1207/s15327752jpa6202_6

Anson, K., \& Ponsford, J. (2006). Coping and emotional adjustment following traumatic brain injury. The Journal of Head Trauma Rehabilitation, 3(21), 240 -248. doi:10.1097/00001199-200605000-00005

Ascencio, A. (2015). Resiliencia y estilos de afrontamiento en mujeres con cáncer de mama de un Hospital Estatal de Chiclayo (tesis para optar el título de Licenciada en Psicología). Recuperada de http://tesis.usat.edu.pe/handle/usat/336

Astetre,P .,Arzapalo,N.,Cabrera, S., Cabrera, S., Carranza, S., Carrera, M .,.., y Tintaya, M (Marzo 2018). Una Mirada a la salud mental debe la opinión de los peruanos. Boletín Estado de la Opinión Pública (150), 1-25. Recuperado de http://repositorio.pucp.edu.pe/index/bitstream/handle/123456789/112469/IOP_1117_01 R1.pdf?sequence $=4 \&$ isAllowed $=y$

Baily, R., \& Clarke, M. (2013). Stress and Coping in Nursing. Singapore: Spring.

Barbosa, L.C., Muñoz, M.L., Rueda, P., y Suárez, K. (2009). Síndrome de burnout y estrategias de afrontamiento en docentes universitarios. Revista Iberoamericana de Psicología: $\begin{array}{lllll}\text { Ciencia } & y & \text { Tecnología, 2(1), } 21- & 30 . & \text { Recuperado }\end{array}$ de https://dialnet.unirioja.es/descarga/articulo/4905126.pdf

Becerra, S. (2013). Rol de estrés percibido y su afrontamiento en las conductas de salud de estudiantes universitarios de Lima (tesis para optar por el título de Magister en Psicología Clínica de la Salud). Pontificia Universidad Católica del Perú, Lima.

Blanch, A., \& Aluja, A. (2016). Text mining a self-report back-translation. Psychological Assessment, 28(6), 750-764. doi:10.1037/pas0000213

Briones, E. (2010). La aculturación de adolescentes inmigrantes en España. España: Ediciones Universidad de Salamanca. 
Buendía, J. (1993). Estrés y Psicopatología. Madrid: Pirámide.

Campillo, A. J. E. (2012). El mono estresado: Todo lo que usted necesita saber sobre el estrés, su prevención y su tratamiento, como nunca se lo habían contado. Barcelona: Critica.

Campo-Arias, A., y Oviedo, H.C. (2008). Propiedades Psicométricas de una Escala: La Consistencia Interna. Revista de Salud Pública, 10(6), 831-839. doi: 10.1590/S012400642008000500015.

Cannon, W. B. (1932). The Wisdom of the Body. New York, NY: W. W. Norton \& Company, Inc.

Cañete, R., Guilhem, D., y Brio, K. (2012). Consentimiento informado: algunas consideraciones actuales. Acta Bioethica, 18(1), 121-127. doi: 10.4067/S1726-569X2012000100011

Cardenal, M., y Cruzado, J.A. (2014). Estrategias de afrontamiento y malestar emocional en mujeres con resultados dudosos de su mamografía de cribado. Psicooncología, 11(2-3), 285-299. doi: 10.5209/rev_PSIC.2014.v11.n2-3.47391.

Cardoso, C., Gomez - Conesa, A., e Hidalgo, M.D. (2010). Metodología para la adaptación de instrumentos de evaluación. Revista Fisioterapia, 32(6), 264-270. doi:10.1016/j.ft.2010.05.001.

Carver, C. S. (2007). Cope complete version. Recuperado de http://local.psy.miami.edu/faculty/ccarver/sclCOPEF.html

Carver, C. S., Scheier, M. F., \& Weintraub, J. K. (1989). Assessing coping strategies: A theoretically based approach. Journal of Personality and Social Psychology, 56(2), 267283. doi: 10.1037/0022-3514.56.2.267.

Carver, C. S., \& Connor-Smith, J. (2010). Personality and coping. Annual Review of Psychology, 61, 679-704. doi: 10.1146/annurev.psych.093008.100352.

Cassaretto, M., y Chau, C. (2016). Afrontamiento al estrés: Adaptación del Cuestionario COPE en Universitarios de Lima. Revista Iberoamericana de Diagnóstico y Evaluación, 42(2), 95- 109. doi: 10.21865/RIDEP42_95.

Cassuso, L. (1996). Adaptación de la prueba COPE sobre estilos de afrontamiento en un grupo de estudiantes universitarios de Lima (Tesis para optar el grado de Licenciada en Psicología). Pontificia Universidad Católica del Perú, Lima.

Castaño, E.F., y León, B. (2010). Estrategias de afrontamiento del estrés y estilos de conducta interpersonal. International Journal of Psychological Therapy, 10(2), 245-257. Recuperado de http://www.redalyc.org/articulo.oa?id=56017095004

Ceballos, P., Valenzuela, S., y Paravic, T. (2014). Factores de riesgos psicosociales en el trabajo: género y enfermería. Avances en Enfermería, 32(2), 271-279. https://doi.org/10.15446/av.enferm.v32n2.46231

Cervantes, V.H. (2005). Interpretaciones del coeficiente alpha de crobanch. Avances de Medición, 3, 9-28. Recuperado de 
http://www.humanas.unal.edu.co/psicometria/files/1113/8574/8604/Articulo_1_Alfa_de _Cronbach_9-28_2.pdf

Cohen, F., \& Lazarus, R.S. (1979). Coping with the stresses of illnes. In G.C.Stone, F.Cohen, \& N.E. Adler (Eds.), Health Psychology. San Francisco: Jossey-Bass.

Comrey, A. L., \& Lee, H. B. (1992). A first course in factor analysis (2nd ed.). Hillsdale, NJ, US: Lawrence Erlbaum Associates, Inc.

Craşovan, D., \& Sava, F. (2013). Translation, adaptation, and validation on romanian population of COPE Questionnaire for Coping Mechanisms Analysis. Cognition, Brain \& Behavior. An Interdisciplinary Journal, 17(1), 61-76. Recuperado de https://irpi.ro/wpcontent/uploads/2018/04/Translation-adaptation-and-validation-on-Romanianpopulation-of-COPE-Questionnaire-for-coping-mechanisms-analysis.pdf

Crespo, M., y Cruzado, J. (1997). La evaluación del afrontamiento: adaptación española del cuestionario COPE con una muestra de estudiantes universitarios. Revista Análisis y Modificación de la Conducta, 23 (92), 797-830. doi: 10.21865/RIDEP42_95

Cruz, C., Olivares., S., y Gonzales, M. (2014). Metodología a la Investigación. México: Grupo Editorial Patria.

De Rivera, L. (2010). Los síndromes de estrés. Madrid: Síntesis.

Dunn, T.H., Baguley, T.S., y Brunden, V. (2013). From alpha to omega: A practical solution to the pervasive problem of internal consistency estimation. The British Journal of Psychology, 2-12. doi: 10.1111/bjop.12046.

Eckenrode, J. (2013). The social context of coping. Boston: Spring. doi: 10.1007/978-1-48993740-7.

Endler, N., \& Parker, J. (1990) Multidimensional assessment of coping. A critical evaluation. Journal of personality and social psychology, 58(5), 844-854. doi: 10.1037/00223514.58.5.844.

Escurra, L. M. (1988). Cuantificación de la validez de contenido por criterio de jueces. Revista de Psicología de la PUCP, 6(1-2), 103-109.

Everly, G \& Lalingen J. (2013). A Clinical guide to the treatment of the human stress response $\left(3^{\text {rd }}\right.$ ed.). New York: Springer.

Fernández-Abascal, E. G. (1997). Estilos y estrategias de afrontamiento. En E. G. FernándezAbascal, F. Palmero, M. Chóliz y F. Martínez (Eds.). Cuaderno de Prácticas de Motivación y Emoción. Madrid: Pirámide

Fernández, A., Pérez, E., Alderete, A. M., Richaud, M. C. y Fernández- Liporace, M. (2011). ¿Construir o Adaptar Test Psicológicos? Diferentes respuestas a una cuestión controvertida. Revista Evaluar, 10, 60-74.

Ferrando, P. J. y Anguiano-Carrasco, C. (2010). El análisis factorial como técnica de investigación en psicología. Papeles del Psicólogo, 31(1), 18-33. 
Field, A. (2009). Discovering Statistics using SPSS (3 ${ }^{\text {rd }}$ ed.). London: Sage.

Folkman, S., \& Lazarus, R. (1980). An Analysis of Coping in a Middle-Aged Community Sample. Journal of Health and Social Behavior, 21 (3), 219 -239. doi:10.2307/2136617

Garcia-Moran, M., y Gil-La Cruz, M. (2016). El estrés en el ámbito de los profesionales de la salud. Revista Persona, 19, 11 - 33. Recuperado de http://repositorio.ulima.edu.pe/handle/ulima/3236

Gil, J.A. (2011). Técnicas e instrumentos para la recogida de información. Madrid: Universidad Nacional de Educación a Distancia.

Gregory, R. J. (2012). Pruebas psicológicas: Historia, principios y aplicaciones. México: Pearson.

Guevara, G., Hernández, H., y Flores, T. (2001). Estilos de afrontamiento al estrés en pacientes drogodependientes. Revista de Investigación en Psicología, 4(1), 53-65.doi: 10.15381/rinvp.v4i1.5007

Guilford, J. P. (1954). Psychometric methods (2nd ed.). New York, NY, US: McGraw-Hill.

Hair, J. F., Black, W. C., Balbin, B. J., \& Anderson, R. E. (2014). Análisis Multivariante (7a ed.). Madrid: Pearson.

Hambleton, R. K. (1996). Adaptación de tests para su uso en diferentes idiomas y culturas: Fuentes de error, posibles soluciones y directrices prácticas. En J. Muñiz (Ed.), Psicometría (pp. 207-238). Madrid: Universitas.

Hambleton, R. K. (2005). Issues, designs, and technical guidelines for adapting tests into multiple languages and cultures. In R. K. Hambleton, P. F. Merenda, \& C. D. Spielberger (Eds.), Adapting educational and psychological tests for cross-cultural assessment (pp. 3-38). Mahwah, NJ: Lawrence Erlbaum Associates.

Hernandez, S. R., Fernández, C. C., y Baptista, L. P. (2014). Metodología de la investigación (6 ${ }^{a}$ ed.). México, D.F: McGraw-Hill Education.

Hogan, T. P., Cisneros, H. J., Aragón, B. L. E., e In Viveros, F. S. (2015). Pruebas psicológicas: Una introducción práctica (2a ed.). México, D.F: El Manual Moderno.

Hudek-Knežević, J., Kardum, I., \& Vukmirović, Z. (1999). The Structure of coping styles: A comparative study of croatian sample. European Journal of Personality, 13, 149-161.doi: 10.1002/(SICI)1099-0984(199903/04)13:2<149::AID-PER326>3.0.CO;2-Z.

Instituto de Análisis y Comunicación Integración (2015). Los porqués del estrés. Recuperado de http://www.integracion.pe/los-porques-del-estres/

Instituto Nacional de Estadística e Informática (2016). El empleo informal en el Perú disminuyó en 3,9 puntos porcentuales. Recuperado de https://www.inei.gob.pe/prensa/noticias/elempleo-informal-en-el-peru-disminuyo-en-39-puntos-porcentuales-9142/

Instituto Nacional de Estadística e Informática (2017). Principales Indicadores. Recuperado de https://www.inei.gob.pe/ 
Kallasmaa, T., \& Pulver, A. (2000). The structure and properties of the Estonian COPE inventory. Personality and Individual Differences, 29, 881-894.

Kass, R. A., \& Tinsley, H. E. A. (1979). Factor analysis. Journal of Leisure Research, 11, 120138. doi:10.1080/00222216.1979.11969385

Kline, P. (1999). The Handbook of psychological testing. London: Routledge.

Lazarus, R., \& Folkman, S. (1984). Stress, appraisal and coping. New York: Springer.

Lazarus, R., y Folkman, S. (1986). Estrés y procesos cognitivos. Barcelona: Martínez Roca.

Lazarus, R. S. (2000). Estrés y emoción: Manejo e implicaciones en nuestra salud. Bilbao: Desclée de Brouwer.

Lazarus, R. S. \& Launier, R. (1978). Stress-related transactions between person and environment. In Perspectives in Interactional Psychology ed. L. A. Pervin, M. Lewis, 287-327. New York: Plenum

Lee, R. (2010). El síndrome del superestrés: cómo revertir los efectos del estrés acumulado y recuperar la capacidad natural de relajarse. Barcelona: Urano.

Llaneza, F. J. (2017). Ergonomía y psicosociología aplicada. España: Lex Nova.

Llerena, E.E. (2015). Consumo de drogas, percepción de riesgo y afrontamiento en soldados del Ejército (tesis para optar el título de Licenciada en Psicología). Pontificia Universidad Católica del Perú, Lima.

Lloret, S., Ferreres, A., Hernández, A. y Tomás, I. (2014). El análisis factorial exploratorio de los ítems: Una guía práctica, revisada y actualizada. Anales de Psicología, 30 (3), 11511169.

Lorenzo-Seva, U. (1999). Promin: A method for oblique factor rotation. Multivariate Behavioral Research, 34, 347-365. doi: 10.1207/S15327906MBR3403_3

Lorenzo-Seva, U., y Ferrando, P.J. (2015). Factor (Versión 10.8.04) [Software de computación]. Recuperado de: http://psico.fcep.urv.es/utilitats/factor/Download.html

Lozano, A. (2015). Cuestiones éticas en la intervención con familias y menores. Cuadernos de Trabajo Social, 28(1), 127-136. doi: 10.5209/rev_CUTS.2015.v28.n1.45727

Martín, M., Jimenez, M., y Fernandez - Abascal, E. (2000). Estudio sobre escala de estilos de afrontamiento. Departamento de Psicología Básica. Revista Electrónica de Motivación y Emoción. 3 (4). Recuperado de http://reme.uji.es/articulos/agarce4960806100/texto.html

McKay, D. (2008). Handbook of Search Methods in Abnormal and Clinical Psychology. California: Sage.

Merino, C., y Livia, J. (2009). Intervalos de confianza asimétricos para el índice la validez de contenido: Un programa Visual Basic para la V de Aiken. Anales de Psicología, 25 (1), 169-171. 
Miller, A., \& Shelly, S. (2010). Living with Stress. New York: Facts on File Inc.

Mingote, J.C., Jimenez, M.A., Osorio, R., y Palomo, T. (2004). Suicidio: asistencia clínica, guía práctica de psiquiatría médica. Madrid: Ediciones Díaz de Santo, S.A.

Ministerio de Trabajo y Promoción del Empleo (2012). Glosario de término de temas de empleo. Recuperado de http://www.mintra.gob.pe/mostrarContenido.php?id=165

Monras, M., Mondon, S. y Jou, J. (2010). Estrategias de afrontamiento en enfermos alcohólicos. Diferencias según el consumo de benzodiacepinas, los trastornos de la personalidad y el deterioro cognitivo. Adicciones, 22 (3), 191 -198. doi: 10.20882/adicciones.179

Moos, R.H., \& Schaefer, J.A. (1993). Coping resources and process: Current concepts and measures. En: Goldberger, L y Breznitz, S, (Eds.), Handbook of stress: theoretical and clinical aspects (pp. 234-257). New York: Free Press.

Moos, R. (1997). Coping Responses Inventory: A measure of approach and avoidance coping skills. En: Zalaquett C.P. \& Wood R.J. (Eds.), Evaluating stress: A book of resources (pp. 51-65). Lanham, MD: Scarecrow.

Muñiz, J., Elousa, P., y Hambleton, R. (2013). Directrices para la traducción y adaptación de los tests: segunda edición. Psicotherma, 25 (2), 151-157. doi: 10.7334/psicothema2013.24

Nunnally, J. C. (1987). Teoría psicométrica. México D.F.: Trillas.

Organización Internacional de Salud (2013). La prevención del estrés en el trabajo: Lista de puntos de comprobación. Ginebra: OIT.

Organización Mundial de Salud (2014).Protección de la salud de los trabajadores. Recuperado de http://www.who.int/mediacentre/factsheets/fs389/es/

Organización Panamericana de la Salud (2013). Assessment and Management Conditions Specifically Related to Stress: mhGAP Intervention Guide Module. Washington D.C: OPS.

Organización Panamericana de la Salud (2016).Estrés laboral es una carga para los individuos, los trabajadores y las sociedades. Recuperado de http://www.paho.org/hq/index.php?option=com_content\&view=article\&id=11973\%3A workplace-stress-takes-a-toll-on-individuals-employers-andsocieties\&Itemid=135\&lang=es

Organización Panamericana de la Salud (2017). Programa Salud de los Trabajadores. Recuperado de http://www.paho.org/hq/index.php?option=com_content \&view=article\&id=1643\&ltemi $\underline{\mathrm{d}=1340 \& \text { lang }=\mathrm{es}}$

Pedrosa, I., Juarros-Basterretxea, J., Robles-Fernández, A., Basteiro, J., \& García-Cueto, E. (2015). Pruebas de bondad de ajuste en distribuciones simétricas, ¿qué estadístico utilizar? Universitas Psychologica, 14(1), 245-254. Doi: 10.11144/Javeriana.upsy135.pbad. 
Pett, M.A., Lackey, N.R., \& Sullivan, J. J. (2003). Making Sense of Factor Analysis: The Use of Factor Analysis for Instrument Developing in Health Care Research. California: Sage.

Pillaca, H. (2013). Estrategias de afrontamiento el paciente que asiste al ESN-PCT en el Centro de Salud Max Arias Schreiber (tesis para optar el título profesional de Licenciado en Enfermería). Universidad Nacional Mayor de San Marcos, Lima.

Pineda, D. (2012). Estrés parental y estilo de afrontamiento en padres de niños con trastornos del espectro autista (tesis para optar el título de Licenciada en Psicología). Pontificia Universidad Católica del Perú, Lima.

Quiros, S. (2013). Burnout y Afrontamiento en un grupo de agentes de tráfico del aeropuerto (tesis para optar el título de Licenciada en Psicología). Pontificia Universidad Católica del Perú, Lima.

Rice, V. (2012). Handbook of stress, coping and health ( $2^{\text {nd }}$ ed.).California: Sage.

Rodriguez, A. (2012). Afrontamiento y soporte social en un grupo de adictos de un hospital psiquiátrico de Lima (tesis de para optar el título profesional de Licenciada en Psicología). Pontificia Universidad Católica del Perú, Lima.

Rojas, M. y Ramos, N. (2013). Salud, optimismo y afrontamiento en trabajadores profesionales y no profesionales que trabajan en contextos altamente estresantes. Acta Colombiana de $\begin{array}{lllllll}\text { Psicología, } & 15 & \text { (1), } & 140 & - & 157 . & \text { Recuperado de }\end{array}$ http://editorial.ucatolica.edu.co/ojsucatolica/revistas_ucatolica/index.php/actacolombiana-psicologia/article/view/256

Romero, S. (2009). Niveles de estrés percibido y estilos de afrontamiento en pacientes con bulimia nerviosa (tesis para optar el grado de Licenciada en Psicología). Pontificia Universidad Católica del Perú, Lima.

Sánchez-Cánovas, J. (1991). Evaluación de las estrategias de afrontamiento. En G. Buela-Casals \& V. E. Caballo (Eds.), Manual de Psicología Clínica Aplicada (pp. 247-270). Madrid: Siglo XXI.

Sandín, B. (2008). El Estrés. En A. Belloch, B. Sandín y F, Ramos (Eds.), Manual de Psicopatología, edición revisada (Vol. II) (pp. 4-48). Madrid: McGraw Hill.

Seiffge- Krenke, I. (2015). Stress, Coping and Relationships in Adolescence. New Jersey: Lawrence Erlbau Associates Inc.

Selye, H. (1952). The Story of the Adaptation Syndrome. Montreal: Acta.

Sica, C., Novara, C., Dorz, S., \& Sanavio, E. (1997). Coping strategies: Evidence for crosscultural differences? A preliminary study with the Italian version of coping orientations to problems experienced (COPE). Personality and Individual Differences, 23(6), 10251029. doi:10.1016/s0191-8869(97)00112-8

Sireci, S. \& Faulkner-Bond, M. (2014). Validity evidence based on test content. Psicothema, 26(1), 100-107. doi: 10.7334/psicothema2013.256 
Solano, M. (2013). Relaciones entre dolor por artritis reumatoide con el bienestar psicológico, afrontamiento y síntomas depresivos (Tesis de maestría). Pontificia Universidad Católica del Perú, Lima.

Soto, R. (2010). Sintomatología depresiva y afrontamiento en pacientes con cáncer de mama (tesis de para optar el título profesional de Licenciada en Psicología). Pontificia Universidad Católica del Perú, Lima.

Taylor, S. E., Hano, R. M. C. E., Sánchez, G., y Reynoso, E. L. (2007). Psicología de la salud. México: McGraw-Hill Interamericana.

Tello, I. (2009). Nivel de síndrome de Burnout y estrategias de afrontamiento en enfermeros de los Servicios Críticos del Hospital Nacional Daniel Alcides Carrión. (Tesis para optar el título de Licenciado en Enfermería). Universidad Nacional Mayor de San Marcos, Lima.

Tobin, D. L., Holroyd, K. A., Reynolds, R. V., \& Kigal, J. K. (1989). The hierarchical factor structure of the Coping Strategies Inventory. Cognitive Therapy and Research, 13, 343361.

Torrejón, C. (2011). Ansiedad y afrontamiento en universitarios migrantes (Tesis para optar el título de Licenciatura de Psicología). Pontificia Universidad Católica del Perú, Lima.

Valadez, A., Flores, M.M., Garcés, E.J., Solís, O.B. y Reynaga, P. (2016). Estilos de afrontamiento en entrenadores: un análisis entre mujeres y hombres yucatecos. Retos, 30, 198-202. Recuperado de: https://conacyt.elsevierpure.com/es/publications/estilos-deafrontamiento-en-entrenadores-un-análisis-entre-mujere

Valdés, M., y De Flores, T. (1990). Psicobiología del estrés (Conceptos y estrategias de investigación). Barcelona: Ediciones Martínez Roca.

Ventura-León, J., \& Caycho-Rodríguez, T. (2017). El coeficiente Omega: un método alternativo para la estimación de la confiabilidad. Revista Latinoamericana de Ciencias Sociales, Niñez y Juventud, 15 (1), 625-627. doi: 10.20882/adicciones.962

Zeidner, M., \& Hammer, A.L (1992). Coping with missile attack: Resources, strategies and outcomes. Journal of Personality, 60 (4), 709-749. doi:10.1111/j.14676494.1992.tb00271.x.

Zorrilla Hidalgo, A.M. (2017). Estrés en la profesión docente: estudio de su relación con variables laborales y de contexto. (Tesis Doctoral Inédita). Universidad de Sevilla, Sevilla. Recuperado de: https://idus.us.es/xmlui/handle/11441/65269. 
ANEXOS 


\section{ANEXO 1: Ficha Sociodemográfica}

\section{FICHA SOCIODEMOGRAFICA}

\begin{tabular}{|c|c|}
\hline Sexo: & Femenino \\
\hline & Masculino \\
\hline Estudios: & Técnicos \\
\hline & Universitarios \\
\hline & Ninguno \\
\hline Ocupación: & Estudiante \\
\hline & Trabajador \\
\hline & Ambos \\
\hline & Otros \\
\hline
\end{tabular}

En caso se encuentre estudiando, indicar qué tipo de estudios se encuentra cursando:

Maestría o Doctorado

Cursos de Post grado

Diplomado

Especialización

( )

Carrera de pregrado

Categoría PEA: Empleador o patrono

Empleado

Obrero

Trabajador independiente

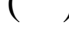

Trabajador del hogar

(

Trabajador familiar no remunerado

$($ )
$($ )
$($ )
$($ )
$($ )
$($ )

Edad:

18 a 35 años ( )

36 a 64 años ( )

65 a más años ( ) 


\section{ANEXO 2: Inventario COPE versión en Inglés}

\section{Cope Inventory}

We are interested in how people respond when they confront difficult or stressful events in their lives. There are lots of ways to try to deal with stress. This questionnaire asks you to indicate what you generally do and feel, when you experience stressful events. Obviously, different events bring out somewhat different responses, but think about what you usually do when you are under a lot of stress.

Then respond to each of the following items by blackening one number on your answer sheet for each, using the response choices listed just below. Please try to respond to each item separately in your mind from each other item.

Choose your answers thoughtfully, and make your answers as true FOR YOU as you can. Please answer every item. There are no "right" or "wrong" answers, so choose the most accurate answer for YOU--not what you think "most people" would say or do. Indicate what YOU usually do when YOU experience a stressful event.

$1=$ I usually don't do this at all.

$2=$ I usually do this a little bit.

3= I usually do this a medium amount.

$4=$ I usually do this a lot. 


\begin{tabular}{|c|c|c|c|c|}
\hline & 1 & 2 & 3 & 4 \\
\hline 1. I try to grow as a person as a result of the experience. & & & & \\
\hline $\begin{array}{l}\text { 2. I turn to work or other substitute activities to take my mind } \\
\text { off things. }\end{array}$ & & & & \\
\hline 3. I get upset and let my emotions out. & & & & \\
\hline 4. I try to get advice from someone about what to do. & & & & \\
\hline 5. I concentrate my efforts on doing something about it. & & & & \\
\hline 6. I say to myself "this isn't real." & & & & \\
\hline 7. I put my trust in God. & & & & \\
\hline 8. I laugh about the situation. & & & & \\
\hline 9. I admit to myself that I can't deal with it, and quit trying. & & & & \\
\hline 10. I restrain myself from doing anything too quickly. & & & & \\
\hline 11. I discuss my feelings with someone. & & & & \\
\hline 12. I use alcohol or drugs to make myself feel better. & & & & \\
\hline 13. I get used to the idea that it happened. & & & & \\
\hline 14. I talk to someone to find out more about the situation. & & & & \\
\hline $\begin{array}{l}\text { 15. I keep myself from getting distracted by other thoughts or } \\
\text { activities. }\end{array}$ & & & & \\
\hline 16. I daydream about things other than this. & & & & \\
\hline 17. I get upset, and am really aware of it. & & & & \\
\hline 18. I seek God's help. & & & 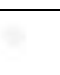 & \\
\hline 19. I make a plan of action. & & & & \\
\hline 20. I make jokes about it. & & & & \\
\hline $\begin{array}{l}\text { 21. I accept that this has happened and that it can't be } \\
\text { changed. }\end{array}$ & & & & \\
\hline $\begin{array}{l}\text { 22. I hold off doing anything about it until the situation } \\
\text { permits. }\end{array}$ & & & & \\
\hline 23. I try to get emotional support from friends or relatives. & & & & \\
\hline 24. I just give up trying to reach my goal. & & & & \\
\hline 25. I take additional action to try to get rid of the problem. & & & & \\
\hline $\begin{array}{l}\text { 26. I try to lose myself for a while by drinking alcohol or } \\
\text { taking drugs. }\end{array}$ & & & & \\
\hline 27. I refuse to believe that it has happened. & & & & \\
\hline
\end{tabular}




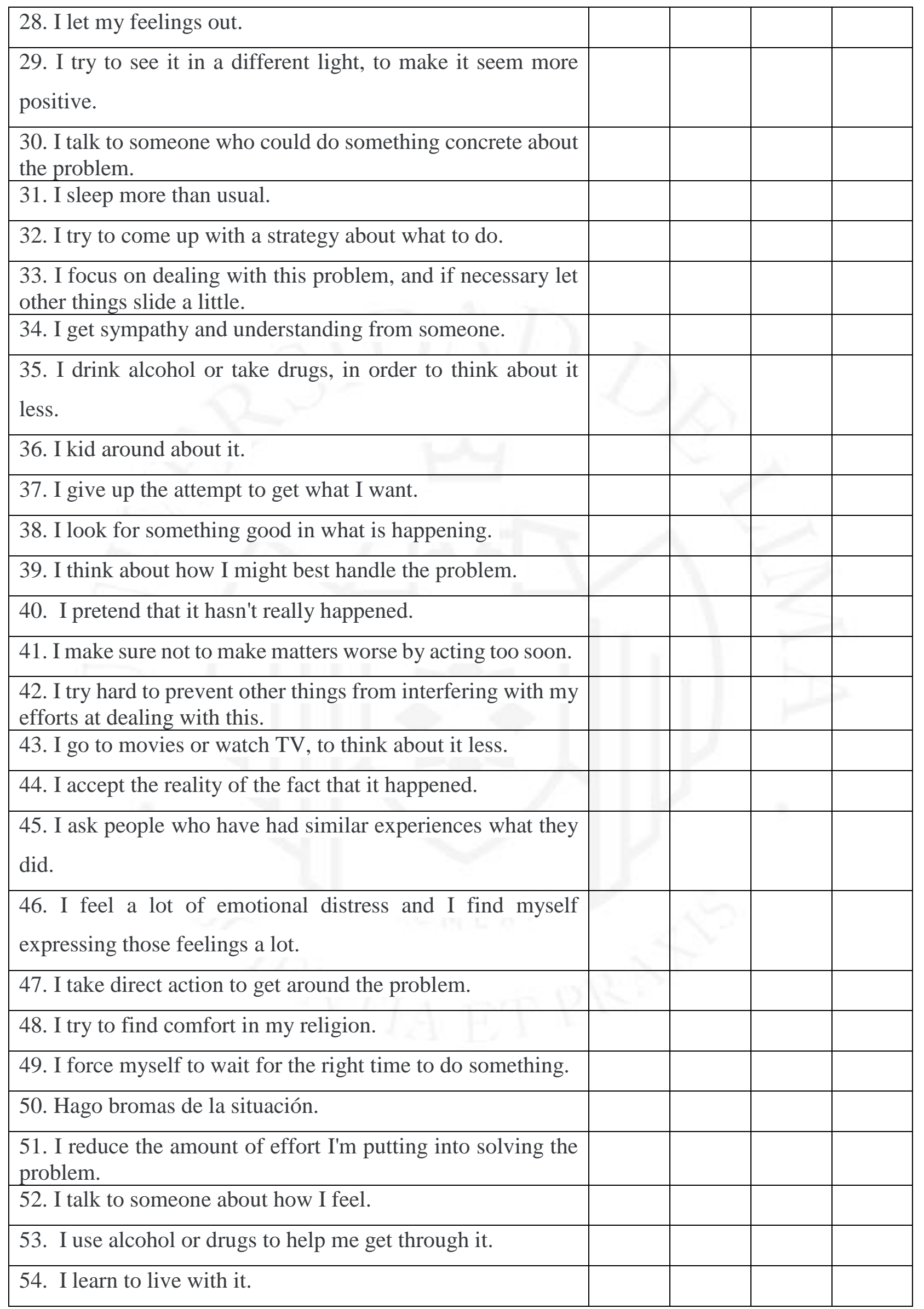




\begin{tabular}{|l|l|l|l|l|}
\hline 55. I put aside other activities in order to concentrate on this. & & & & \\
\hline 56. I think hard about what steps to take. & & & & \\
\hline 57. I act as though it hasn't even happened. & & & & \\
\hline 58. I do what has to be done, one step at a time. & & & & \\
\hline 59. I learn something from the experience. & & & & \\
\hline 60. I pray more than usual. & & & \\
\hline
\end{tabular}




\title{
ANEXO 3: Inventario COPE versión oficial en Español
}

\author{
$\underline{\text { Inventario de Afrontamiento COPE }}$
}

Estamos interesados en la forma en que las personas responden cuando tienen que hacer frente a acontecimientos difíciles o estresantes en sus vidas. Hay muchas formas de intentar manejar el estrés. Este cuestionario le pide que indique lo que generalmente hace y siente cuando experimenta acontecimientos estresantes. Obviamente, sucesos diferentes provocan respuestas algo diferentes, pero piense acerca de lo que hace habitualmente cuando está bajo un estrés intenso.

Entonces responda a cada uno de los siguientes ítems marcando el número que corresponda, utilizando las opciones de respuesta que se presentan abajo. Por favor, intente responder a cada ítem de forma separada a los demás.

Elija sus respuestas cuidadosamente, y responda de la forma más sincera que le sea posible. Por favor responda todos los ítems. No hay respuestas correctas o incorrectas, de modo que elija la respuesta que más se le ajuste a USTED, no la que usted piense que la mayoría de la gente diría o haría. Indique lo que USTED habitualmente hace cuando experimenta un acontecimiento estresante.

\author{
$1=$ No suelo hacer esto en absoluto \\ $2=$ Suelo hacer esto un poco \\ $3=$ Suelo hacer esto moderadamente \\ 4= Suelo hacer esto mucho
}




\begin{tabular}{|c|c|c|c|c|}
\hline \multirow{2}{*}{$\begin{array}{l}\text { 1. Intento desarrollarme como persona como resultado de la } \\
\text { experiencia. }\end{array}$} & 1 & 2 & 3 & 4 \\
\hline & & & & \\
\hline $\begin{array}{l}\text { 2. Me concentro en el trabajo u otras actividades sustitutivas } \\
\text { para alejar el tema de mi mente. }\end{array}$ & & & & \\
\hline 3. Me altero y dejo aflorar mis emociones. & & & & \\
\hline 4. Intento conseguir consejo de alguien sobre qué hacer. & & & & \\
\hline $\begin{array}{l}\text { 5. Concentro mis esfuerzos en hacer algo acerca de la } \\
\text { situación. }\end{array}$ & & & & \\
\hline 6. Me digo a mí mismo: "Esto no es real" & & & & \\
\hline 7. Confío en Dios. & & & & \\
\hline 8. Me río acerca de la situación. & & & & \\
\hline 9. Admito que no puedo con ello y dejo de intentarlo. & & & & \\
\hline $\begin{array}{l}\text { 10. Me disuado a mí mismo de hacer algo con demasiada } \\
\text { rapidez. }\end{array}$ & & & & \\
\hline 11. Hablo de mis sentimientos con alguien. & & & & \\
\hline 12. Consumo alcohol o drogas para sentirme mejor & & & & \\
\hline 13. Me acostumbro a la idea de lo que sucedió. & & & & \\
\hline 14. Hablo con alguien para saber más acerca de la situación. & & & & \\
\hline 15. Evito distraerme con otros pensamientos o actividades. & & & & \\
\hline 16. Sueño despierto con otras cosas diferentes. & & & & \\
\hline 17. Me altero y soy realmente consciente de la situación. & & & & \\
\hline 18. Pido la ayuda de Dios. & & & & \\
\hline 19. Hago un plan de acción. & & & & \\
\hline 20. Hago bromas sobre la situación & & & & \\
\hline 21. Acepto que ha sucedido y que no puede cambiarse. & & & & \\
\hline $\begin{array}{l}\text { 22. Demoro hacer algo sobre el tema hasta que la situación lo } \\
\text { permita. }\end{array}$ & & & & \\
\hline $\begin{array}{l}\text { 23. Intento conseguir apoyo emocional de amigos o } \\
\text { familiares. }\end{array}$ & & & & \\
\hline $\begin{array}{l}\text { 24. Simplemente abandono en el intento de lograr mi } \\
\text { objetivo. }\end{array}$ & & & & \\
\hline
\end{tabular}




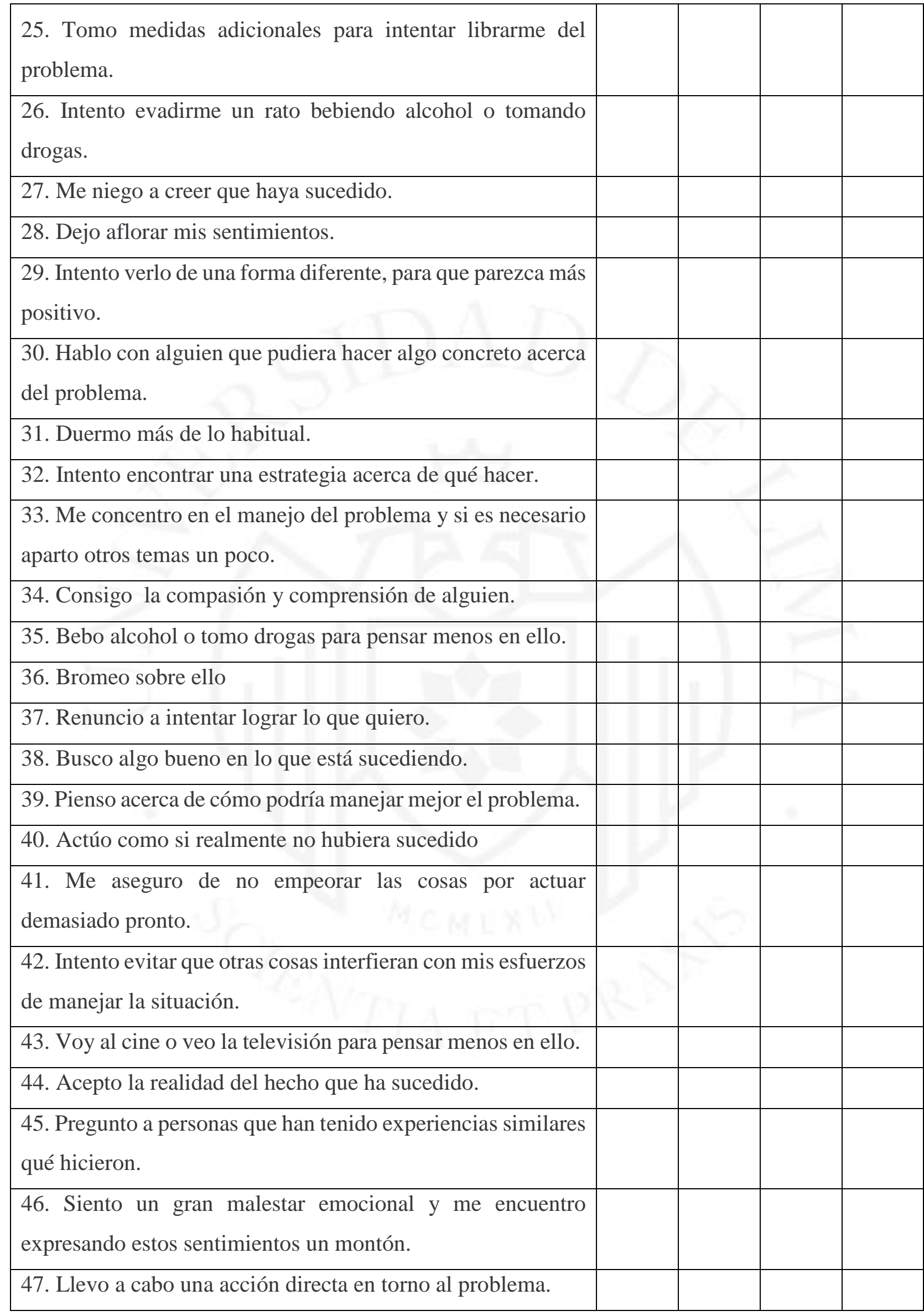




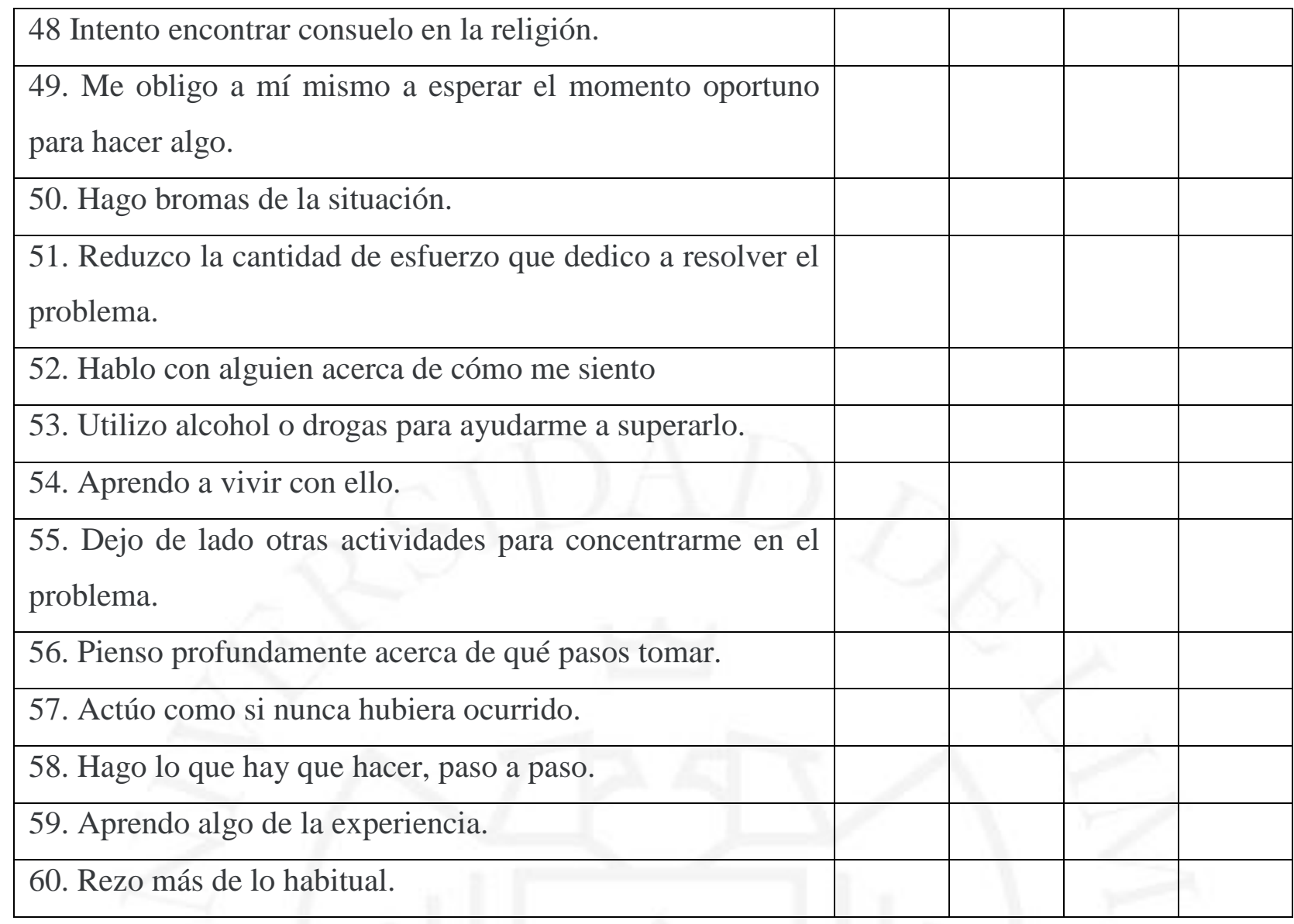




\section{ANEXO 4: Consentimiento Informado}

Estimado(a),

El presente estudio se encuentra dirigido por Jocelyn Polanco Cano, identificada con DNI N47602636, bachiller de la carrera de Psicología de la Universidad de Lima. El objetivo de la investigación es poder conocer las formas cómo las personas reaccionan ante situaciones estresantes.

$\mathrm{Al}$ acceder a participar en el estudio, se le solicitará que responda a las preguntas de un cuestionario que consiste en 60 ítems, el cual le tomará un aproximado de 15 minutos para completarlo. Todo resultado emitido será totalmente anónimo, por lo que nadie podrá saber las respuestas brindadas. Asimismo, es importante recalcar que la participación en la investigación es voluntaria, por lo que podrá optar por desistir de llenar la encuesta.

Agradeceré pueda responder de manera sincera a la encuesta que se le entregará, ya que de lo contrario podrá influir en los resultados que se obtendrán a nivel general. Los resultados finales permitirán obtener información para en un futuro poder implementar intervenciones para afrontar de manera adecuada el estrés.

En caso de tener alguna pregunta, puede consultarme mediante el siguiente correo: jocelynpc@ hotmail.com y responderé inmediatamente.

Por el presente documento, declara su conformidad de participar en el estudio previamente mencionado de manera voluntaria. Además, confirma que accede a que los datos obtenidos sean usados con fines académicos, respetando la confidencialidad del caso.

Nombre y Apellidos

Firma

Fecha 


\section{ANEXO 5: Presupuesto de Investigación}

En base a la proyección de lo que se estaría invirtiendo para poder realizar el proyecto se realizó el siguiente presupuesto:

\begin{tabular}{lcc}
\hline \multicolumn{1}{c}{ Gatos } & Costo & Financiamiento \\
\hline Fotocopias & S/. 300.00 & \\
Movilidad & S/. 200.00 & Propio \\
Lapiceros & S/. 20.00 & \\
Total & S/. 720.00 & \\
\hline
\end{tabular}




\section{ANEXO 6: Autorización de uso del autor original}

En el link http://www.psy.miami.edu/faculty/ccarver/CCscales.html :

\section{Self- Report Measures Available:}

All of these scales are being made available here for use in research and teaching applications. All available without charge and without any need for permission. Please do not write to me requesting a letter of permission, because this is all you will get. Download or print them from the linked pages.

LOT-R (a measure of optimism- pessimism)

COPE (the full version of our measure of coping)

Brief COPE (an abbreviated version of the COPE)

BIS/BAS scales (measures of the sensitivity of incentive and aversive $\underline{\text { motivational system) }}$

MAQ (a measure of adult attachment qualities)

MBA (a measure of investment in body image as a source of feelings of selfworth)

ATS (a measure of generalization, overly high standards, and self-criticism)

Benefit finding (a measure of finding benefit in the experience of having for long-term survivors)

QLACS: Quality of Life in Adult Cancer Survivors (a new QOL measure for long-term survivors)

MOCS (a measure of targeted and nonspecific effects of an intervention)

$\underline{\text { SSSS (Sources of Social Support Scale) }}$

WASSUP (Willingly Approach Set of Statistically Unlikely Pursuits)

$\underline{\text { POG (a measure of three aspects of positive generalization) }}$

RITSS (measure of the sensitivity to incentives and threats in intimate relationships) 


\section{ANEXO 7: Autorización de uso de la autora de la versión oficial en Español}

El 9 jul 2016, a las 17:05, Jocelyn Polanco Cano <jocelynpc@ @otmail.com> escribió:

Estimada Dra. Esther,

Permítame presentarme, mi nombre es Jocelyn Polanco, soy Bachiller de la Universidad de Lima (Perú) y actualmente me encuentro iniciando mi tesis la cual tiene como tema de estudio los estilos y estrategias de afrontamiento. Me gustaría poder aplicar la prueba COPE, la cual usted tradujo al idioma Español con la autorización del Profesor Carver.

Por temas legales, mi universidad me solicita tener su autorización para hacer uso de la prueba traducida. Es por dicho motivo que recurro a usted para que me pueda dar su visto bueno.

Quedo atenta a sus comentarios.

Gracias de antemano.

Saludos,

Jocelyn Polanco.

El 9 jul. 2016, a las 10:29 a.m., Esther calvete zumalde <esther.calvete@ deusto.es> escribió:

Estimada jocelyn

La autorización deberías solicitarla al dr carver

Un saludo.

El 10 jul 2016, a las 1:27, Jocelyn Polanco Cano <jocelynpc@ @otmail.com> escribió:

Justo en su página web indica una relación de pruebas cuyo uso es libre para fines académicos, por lo que tengo la autorización para hacer uso del inventario Cope. Como le indiqué previamente, yo tengo la intención de aplicarla en Perú, por lo cual deseo usar su traducción, ya que al aplicarla en inglés, mi población de estudio no la entendería ya que en su mayoría solo hablan español.

¿Me daría usted su autorización para usar su traducción? 
Gracias de antemano.

Saludos,

From: Esther.calvete@deusto.es

Subject: Re: Inventario de Estrategias Cope - Perú

Date: Sun, 10 Jul 2016 08:49:25 +0200

To: jocelynpc@hotmail.com

Hola

Yo no tengo inconveniente en que utilices mi traducción del cope si cuentas con la autorización del Dr Carver.

Mucho éxito con tu estudio

Cordial saludo 


\title{
ANEXO 8: Formato de Criterio de Jueces del Inventario COPE
}

\author{
Estimado Profesor,
}

Le escribo para solicitar su apoyo como juez(a) en el proceso de encontrar evidencias de validez de contenido del Inventario COPE versión 60 ítems mediante el criterio de jueces. Dicha investigación tiene como objetivo adaptar y analizar las propiedades psicométricas del Inventario de afrontamiento COPE en un grupo de personas pertenecientes a la PEA de Lima Metropolitana.

El Inventario de Estimación de Afrontamiento (COPE) fue elaborado por Carver, Scheier \& Weintraub (1989) y tiene como finalidad identificar los estilos y estrategias que hacen uso las personas cuando se encuentran bajo situaciones de estrés.

Inicialmente el inventario COPE contaba con 52 ítems que hacían alusión a 13 sub escalas, comúnmente llamadas "estrategias", con las cuales las personas pueden hacerle frente al estrés; sin embargo, los autores consideraron adicionar 2 sub escalas más, obteniendo un inventario final de 60 ítems y 15 sub escalas. Esta nueva versión tiene una traducción oficial al castellano, la cual fue realizada por Esther Calvete, profesora de la Universidad de Deusto en España.

En la tabla adjunta, se le presentarán los ítems agrupados de acuerdo a la segmentación mencionada. Estos deberán ser calificados de acuerdo a los siguientes criterios:

- Claridad: Los ítems cuentan con un orden correcto de las palabras de modo que la oración expresa de manera clara lo que el mensaje desea transmitir. Deberá calificar este criterio mencionando "SI", si es que el ítem es entendible de manera clara; y "NO", si es que el ítem genera confusión o ambigüedad a la hora de leerlo.

- Representatividad: Los ítems pertenecen a la dimensión en la que han sido agrupados.

Deberá calificar este criterio mencionando "SI", en caso el ítem sea representativo del área; y "NO", si es que el ítem no es representativo del área. En caso de considerar que un ítem es poco representativo del área, no es claro en su sintaxis, o en el caso de tener alguna observación adicional, indicar la razón o duda en la casilla de "Observaciones".

De antemano, agradezco por su valioso tiempo y el apoyo brindado.

Saludos cordiales.

Atentamente,

Jocelyn Polanco Cano

(993101140) 


\section{DEFINICIONES:}

Afrontamiento:

Es entendido como los esfuerzos cognitivos y conductuales que se encuentran en cambios continuos y que se producen con la finalidad de controlar las demandas ya sean internas o externas, las cuales son consideradas como excedentes ante los recursos con los que cuenta la persona (Lazarus y Folkman, 1984).

Estrategias de afrontamiento:

Las estrategias de afrontamiento son entendidas como los recursos psicológicos que las personas emplean para hacer frente a eventos estresantes ya que ayudan a evitar y reducir los conflictos (Amaris, Madariaga, Valle y Zambrano, 2013) 


\section{CONSIGNA DEL INVENTARIO COPE}

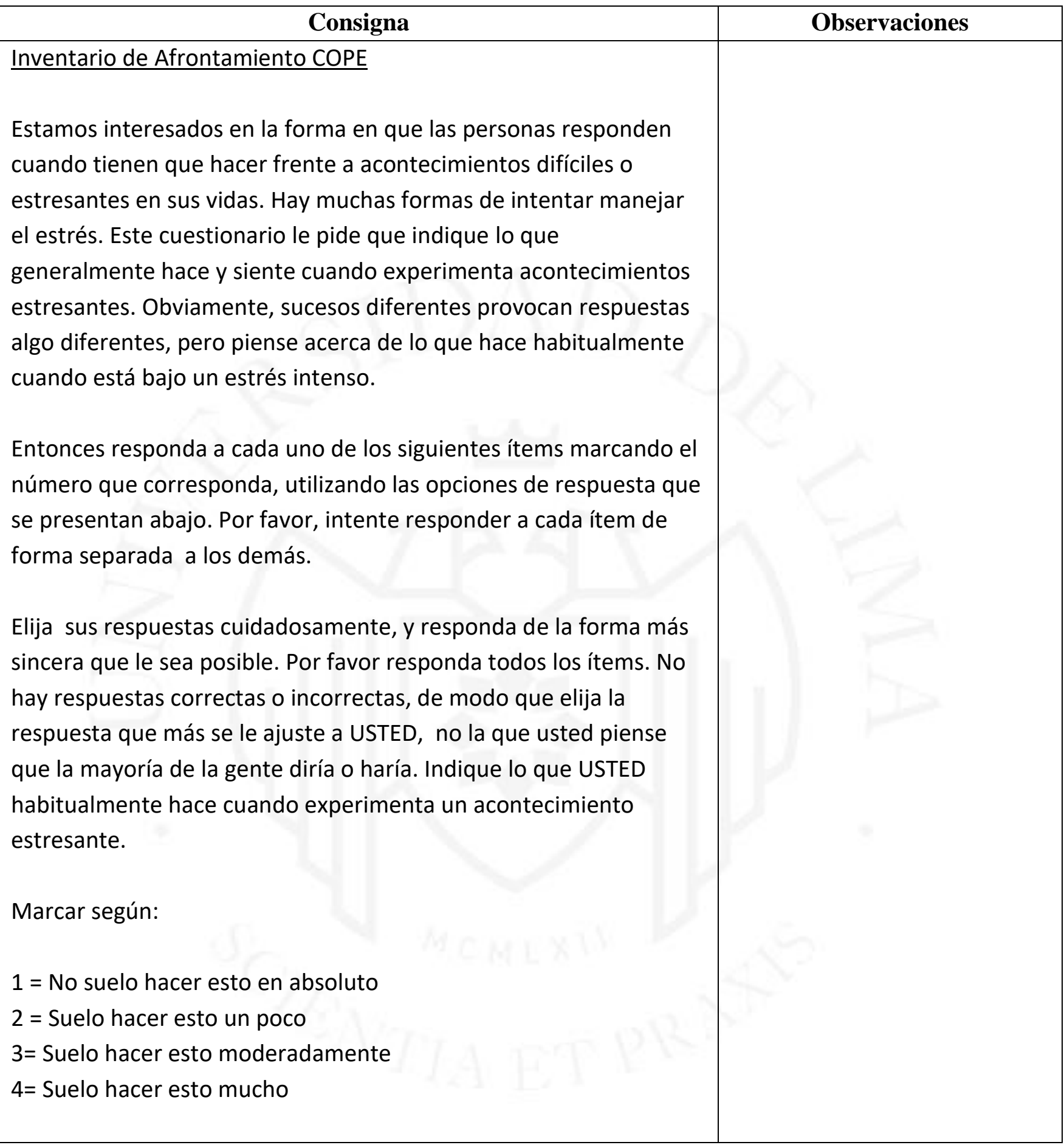




\begin{tabular}{|c|c|c|c|c|c|c|c|}
\hline \multirow{2}{*}{ Ítem } & \multirow{2}{*}{ Propuesta } & \multicolumn{2}{|c|}{ Claridad } & \multirow{2}{*}{ Observaciones } & \multicolumn{2}{|c|}{ Representatividad } & \multirow{2}{*}{ Observaciones } \\
\hline & & SI & NO & & SI & NO & \\
\hline 5 & $\begin{array}{l}\text { Concentro mis esfuerzos en hacer algo acerca de la } \\
\text { situación. }\end{array}$ & & & & & & \\
\hline 25 & Simplemente dejo de intentar lograr mi objetivo. & & & & & & \\
\hline 47 & $\begin{array}{l}\text { Llevo a cabo una acción directa en torno al } \\
\text { problema. }\end{array}$ & & & & & & \\
\hline 58 & Hago lo que hay que hacer, paso a paso. & & & & & & \\
\hline
\end{tabular}

\begin{tabular}{l}
\multicolumn{6}{|c|}{ Estrategia Planificación: Es la elaboración mental de estrategias para controlar el evento que provoca estrés. Consiste en pensar en los pasos que se } \\
debe tomar para amortiguar el problema.
\end{tabular}




\begin{tabular}{|c|c|c|c|c|c|c|c|}
\hline \multicolumn{8}{|c|}{ Estrategia Supresión de otras actividades: Dejar de lado momentáneamente actividades que interfieren con el afrontamiento del problema. } \\
\hline \multirow[b]{2}{*}{ Ítem } & \multirow[b]{2}{*}{ Propuesta } & \multicolumn{2}{|c|}{ Claridad } & \multirow[t]{2}{*}{ Observaciones } & \multicolumn{2}{|c|}{ Representatividad } & \multirow[t]{2}{*}{ Observaciones } \\
\hline & & SI & NO & & SI & NO & \\
\hline 15 & $\begin{array}{l}\text { Evito distraerme tanto con otros pensamientos, } \\
\text { como con otras actividades. }\end{array}$ & & & & & & \\
\hline 33 & $\begin{array}{l}\text { Me concentro en el manejo del problema, } \\
\text { apartando otros temas un poco, en caso sea } \\
\text { necesario. }\end{array}$ & & & & & & \\
\hline 42 & $\begin{array}{l}\text { Intento evitar que otras cosas interfieran } \\
\text { con mis esfuerzos de manejar la situación. }\end{array}$ & & & & & & \\
\hline 55 & $\begin{array}{l}\text { Dejo de lado otras actividades para concentrarme } \\
\text { en el problema. }\end{array}$ & & & & & & \\
\hline
\end{tabular}

Estrategia Postergación del afrontamiento: Esperar la aparición del momento más apropiado para afrontar el problema, de manera que no se actué prematuramente.

\begin{tabular}{|c|c|c|c|c|c|c|c|}
\hline \multirow[b]{2}{*}{ Ítem } & \multirow{2}{*}{ Propuesta } & \multicolumn{2}{|c|}{ Claridad } & \multirow[b]{2}{*}{ Observaciones } & \multicolumn{2}{|c|}{$\begin{array}{c}\text { Representativida } \\
\text { d }\end{array}$} & \multirow[t]{2}{*}{ Observaciones } \\
\hline & & SI & NO & & SI & NO & \\
\hline 10 & $\begin{array}{l}\text { Me convenzo a mí mismo de no hacer algo con } \\
\text { demasiada rapidez. }\end{array}$ & & & & & & \\
\hline 22 & $\begin{array}{l}\text { Demoro en hacer algo hasta que la situación lo } \\
\text { permita. }\end{array}$ & & & & & & \\
\hline 41 & $\begin{array}{l}\text { Me aseguro de no empeorar las cosas por } \\
\text { actuar demasiado pronto. }\end{array}$ & & & & & & \\
\hline 49 & $\begin{array}{l}\text { Me obligo a mí mismo a esperar el momento } \\
\text { oportuno para hacer algo. }\end{array}$ & & & & & & \\
\hline
\end{tabular}




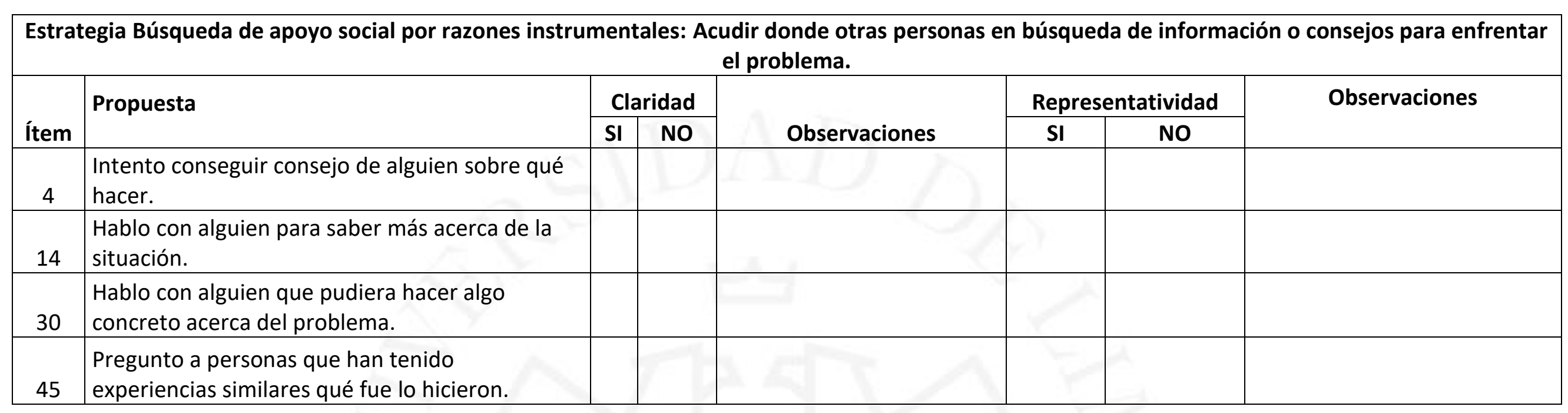

\begin{tabular}{l}
\hline \multicolumn{2}{|c|}{ Estrategia Búsqueda de apoyo social por razones emocionales: Acudir a otras personas para expresar los problemas emocionales y obtener de estos, } \\
apoyo moral. \\
\cline { 1 - 4 } Í́tem
\end{tabular}




\begin{tabular}{|c|c|c|c|c|c|c|c|}
\hline \multicolumn{8}{|c|}{$\begin{array}{c}\text { Estrategia Reinterpretación positiva y crecimiento: Encontrar el lado positivo o favorable del estresor y crecer como persona a raíz de la experiencia } \\
\text { vivida. }\end{array}$} \\
\hline \multirow{2}{*}{ Ítem } & \multirow{2}{*}{ Propuesta } & \multicolumn{2}{|c|}{ Claridad } & \multirow{2}{*}{ Observaciones } & \multicolumn{2}{|c|}{ Representatividad } & \multirow{2}{*}{ Observaciones } \\
\hline & & SI & NO & & SI & NO & \\
\hline 1 & $\begin{array}{l}\text { Intento desarrollarme como persona a partir } \\
\text { del resultado de la experiencia. }\end{array}$ & & & & & & \\
\hline 29 & $\begin{array}{l}\text { Intento verlo de una forma diferente, para que } \\
\text { parezca más positivo. }\end{array}$ & & & & & & \\
\hline 38 & Busco algo bueno en lo que está sucediendo. & & & & & & \\
\hline 59 & Aprendo algo de la experiencia. & & & & & & \\
\hline
\end{tabular}

\begin{tabular}{|c|c|c|c|c|c|c|c|}
\hline \multirow{3}{*}{ Ítem } & \multicolumn{7}{|c|}{ Estrategia Aceptación: Reconocer que el estresor no podrá ser modificado. Se acepta la realidad y se enfoca en manejarla. } \\
\hline & \multirow{2}{*}{ 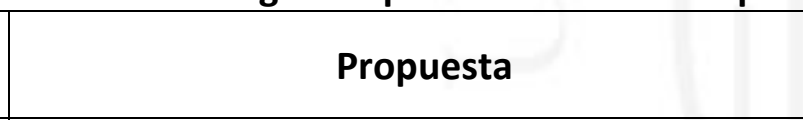 } & \multicolumn{2}{|c|}{ Claridad } & \multirow{2}{*}{ Observaciones } & \multicolumn{2}{|c|}{ Representatividad } & \multirow{2}{*}{ Observaciones } \\
\hline & & SI & NO & & SI & NO & \\
\hline 13 & Me acostumbro a la idea de lo que sucedió. & & & & & & \\
\hline 21 & $\begin{array}{l}\text { Acepto tanto que ha sucedido, como el hecho } \\
\text { de que no puede cambiarse. }\end{array}$ & & & & & & \\
\hline 44 & $\begin{array}{l}\text { Acepto la realidad del hecho que ha } \\
\text { sucedido. }\end{array}$ & & & & & & \\
\hline 54 & Aprendo a vivir con ello. & & & & & & \\
\hline
\end{tabular}




\begin{tabular}{|c|c|c|c|c|c|c|c|}
\hline \multicolumn{8}{|c|}{$\begin{array}{l}\text { Estrategia Negación: Actuar ignorando el problema o rechazar su existencia. La negación es aceptada durante las primeras etapas del estrés, ya que } \\
\text { permite al cuerpo prepararse emocionalmente ante éste, adaptando al organismo al problema que debe superar y empezando a afrontar. }\end{array}$} \\
\hline \multirow{2}{*}{ Ítem } & \multirow{2}{*}{ Propuesta } & \multicolumn{2}{|c|}{ Claridad } & \multirow{2}{*}{ Observaciones } & \multicolumn{2}{|c|}{ Representatividad } & \multirow{2}{*}{ Observaciones } \\
\hline & & SI & NO & & SI & NO & \\
\hline 6 & Me digo a mí mismo: "Esto no es real" & & & & & & \\
\hline 27 & Me niego a creer que haya sucedido. & & & & & & \\
\hline 40 & $\begin{array}{l}\text { Actúo como si realmente no hubiera } \\
\text { sucedido. }\end{array}$ & & & & & & \\
\hline 57 & Actúo como si nunca hubiera ocurrido. & & & & & & \\
\hline
\end{tabular}

\begin{tabular}{|c|c|c|c|c|c|c|c|}
\hline \multicolumn{8}{|c|}{$\begin{array}{l}\text { Estrategia Acudir a la religión: Es una estrategia orientada a controlar el malestar emocional acudiendo a actividades religiosas como guía para la } \\
\text { reinterpretación de un problema. }\end{array}$} \\
\hline \multirow{2}{*}{ Ítem } & \multirow{2}{*}{ Propuesta } & \multicolumn{2}{|c|}{ Claridad } & \multirow{2}{*}{ Observaciones } & \multicolumn{2}{|c|}{ Representatividad } & \multirow{2}{*}{ Observaciones } \\
\hline & & SI & NO & & SI & NO & \\
\hline 7 & Confío en Dios. & & & & & & \\
\hline 18 & Pido la ayuda de Dios. & & & & & & \\
\hline 48 & Intento encontrar consuelo en la religión. & & & & & & \\
\hline 60 & Rezo más de lo habitual. & & & & 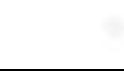 & & \\
\hline
\end{tabular}

\begin{tabular}{|c|c|c|c|c|c|c|c|}
\hline \multicolumn{8}{|c|}{$\begin{array}{l}\text { Estrategia Enfocar y liberar emociones: Enfocar en la perturbación emocional y su subsecuente liberación, es decir, la tendencia a centralizar toda la } \\
\text { cólera que se está experimentando para luego ventilarla. }\end{array}$} \\
\hline \multirow{2}{*}{ Ítem } & \multirow{2}{*}{ Propuesta } & \multicolumn{2}{|c|}{ Claridad } & \multirow{2}{*}{ Observaciones } & \multicolumn{2}{|c|}{ Representatividad } & \multirow{2}{*}{ Observaciones } \\
\hline & & SI & NO & & SI & No & \\
\hline 3 & Me altero manifestando mis emociones. & & & & & & \\
\hline 17 & $\begin{array}{l}\text { Me altero, siendo realmente consciente de la } \\
\text { situación. }\end{array}$ & & & & & & \\
\hline
\end{tabular}


Dejo manifestar mis sentimientos.

Siento un gran malestar emocional que me provoca expresar mis sentimientos en gran

\begin{tabular}{|l|l|l|l|l|l|} 
& & & & & \\
\hline & & & & & \\
\hline
\end{tabular}

Estrategia Desentendimiento conductual: Evitar esforzarse al enfrentar el problema, aunque esto signifique el sacrificio de situaciones importantes. Es reducir los esfuerzos contra el estresor abandonando los objetivos con los cuales la situación estresante interfiere.

\begin{tabular}{|c|c|c|c|c|c|c|c|}
\hline \multirow{2}{*}{ Ítem } & \multirow{2}{*}{ Propuesta } & \multicolumn{2}{|c|}{ Claridad } & \multirow{2}{*}{ Observaciones } & \multicolumn{2}{|c|}{ Representatividad } & \multirow{2}{*}{ Observaciones } \\
\hline & & SI & NO & & SI & NO & \\
\hline 9 & $\begin{array}{l}\text { Admito que no puedo con ello, por lo que dejo } \\
\text { de intentarlo. }\end{array}$ & & & & & & \\
\hline 24 & $\begin{array}{l}\text { Simplemente dejo de intentar lograr mi } \\
\text { objetivo. }\end{array}$ & & & & & & \\
\hline 37 & Renuncio a intentar lograr lo que quiero. & & & & & & \\
\hline 51 & $\begin{array}{l}\text { Reduzco la cantidad de esfuerzo que dedico a } \\
\text { resolver el problema. }\end{array}$ & & & & & & \\
\hline
\end{tabular}

\begin{tabular}{|c|c|c|c|c|c|c|c|}
\hline \multicolumn{8}{|c|}{ Estrategia Desentendimiento mental: Ejecutar actividades con el propósito de distraer el pensamiento y olvidarse del problema y sus efectos. } \\
\hline \multirow{2}{*}{ Ítem } & \multirow{2}{*}{ Propuesta } & \multicolumn{2}{|c|}{ Claridad } & \multirow{2}{*}{ Observaciones } & \multicolumn{2}{|c|}{ Representatividad } & \multirow{2}{*}{ Observaciones } \\
\hline & & SI & NO & & SI & NO & \\
\hline 2 & $\begin{array}{l}\text { Me concentro ya sea en el trabajo, como en } \\
\text { otras actividades sustitutivas para alejar el } \\
\text { tema de mi mente }\end{array}$ & & & & & & \\
\hline 16 & Sueño despierto con otras diferentes. & & & & & & \\
\hline 31 & Duermo más de lo habitual. & & & & & & \\
\hline 43 & $\begin{array}{l}\text { Para no pensar en ello, voy al cine así como } \\
\text { veo televisión. }\end{array}$ & & & & & & \\
\hline
\end{tabular}




\begin{tabular}{|c|c|c|c|c|c|c|c|}
\hline \multicolumn{8}{|c|}{ Estrategia Humor: Hacer bromas sobre el estresor o reírse de las situaciones estresantes, haciendo burlas de la misma. } \\
\hline \multirow{2}{*}{ Ítem } & \multirow{2}{*}{ Propuesta } & \multicolumn{2}{|c|}{ Claridad } & \multirow{2}{*}{ Observaciones } & \multicolumn{2}{|c|}{ Representatividad } & \multirow{2}{*}{ Observaciones } \\
\hline & & SI & NO & & SI & NO & \\
\hline 8 & Me río acerca de la situación. & & & & & & \\
\hline 20 & Hago bromas sobre la situación & & & & & & \\
\hline 36 & Bromeo sobre ello. & & & & & & \\
\hline 50 & Hago bromas de la situación. & & & & & & \\
\hline
\end{tabular}

\begin{tabular}{|c|c|c|c|c|c|c|c|}
\hline \multicolumn{8}{|c|}{ Estrategia Consumo de alcohol y drogas: Hacer uso de alcohol o drogas con la finalidad de evitar pensar en el estresor. } \\
\hline \multirow{2}{*}{ Ítem } & \multirow{2}{*}{ Propuesta } & \multicolumn{2}{|c|}{ Claridad } & \multirow{2}{*}{ Observaciones } & \multicolumn{2}{|c|}{ Representatividad } & \multirow{2}{*}{ Observaciones } \\
\hline & & SI & NO & & SI & NO & \\
\hline 12 & $\begin{array}{l}\text { Para sentirme mejor consumo alcohol y/o } \\
\text { drogas. }\end{array}$ & & & & & & \\
\hline 26 & $\begin{array}{l}\text { Intento distraerme un rato consumiendo } \\
\text { alcohol y/o drogas. }\end{array}$ & & & & & & \\
\hline 35 & $\begin{array}{l}\text { Para pensar menos en ello consumo alcohol } \\
\text { y/o drogas. }\end{array}$ & & & & & & \\
\hline 53 & $\begin{array}{l}\text { Consumo alcohol y/o drogas para ayudarme a } \\
\text { superarlo. }\end{array}$ & & & & & & \\
\hline
\end{tabular}

Psicólogo/a:

Fecha:.

Firma

C. Ps. P. $\mathrm{N}^{\circ}$ : 


\section{ANEXO 9: Versión Final del Inventario COPE en Español}

\begin{tabular}{|c|c|c|c|c|}
\hline \multirow{2}{*}{$\begin{array}{l}\text { 1. Intento desarrollarme como persona a partir del resultado } \\
\text { de la experiencia. }\end{array}$} & 1 & 2 & 3 & 4 \\
\hline & & & & \\
\hline 3. Me altero manifestando mis emociones. & & & & \\
\hline $\begin{array}{l}\text { 4. Intento conseguir consejo de alguien sobre qué hacer en } \\
\text { situaciones estresantes. }\end{array}$ & & & & \\
\hline $\begin{array}{l}\text { 5. Concentro mis esfuerzos en hacer algo acerca de la } \\
\text { situación estresante. }\end{array}$ & & & & \\
\hline 6. Me digo a mí mismo: "Esto no es real”. & & & & \\
\hline 9. Admito que no puedo con ello y dejo de intentarlo. & & & & \\
\hline $\begin{array}{l}\text { 10. Me convenzo a mí mismo de no hacer algo con } \\
\text { demasiada rapidez. }\end{array}$ & & & & \\
\hline 12. Para sentirme mejor consumo alcohol y/o drogas & & & & \\
\hline $\begin{array}{l}\text { 13. Me acostumbro a la idea de que sucedió un evento } \\
\text { estresante. }\end{array}$ & & & & \\
\hline 14. Hablo con alguien para saber más acerca de la situación. & & & & \\
\hline 16. Sueño despierto con otras cosas diferentes. & & & & \\
\hline 17. Me altero, siendo realmente consciente de ello. & & & & \\
\hline 19. Hago un plan de acción. & & & & \\
\hline $\begin{array}{l}\text { 22. Me tomo un tiempo en tomar acción sobre el tema hasta } \\
\text { que la situación lo permita }\end{array}$ & & & 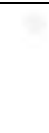 & \\
\hline $\begin{array}{l}\text { 23. Intento conseguir apoyo emocional de amigos y/o } \\
\text { familiares. }\end{array}$ & & & & \\
\hline 24. Simplemente dejo de intentar lograr mi objetivo. & & & & \\
\hline $\begin{array}{l}\text { 25. Tomo medidas adicionales para intentar librarme del } \\
\text { problema. }\end{array}$ & & & & \\
\hline $\begin{array}{l}\text { 26. Intento distraerme un rato consumiendo alcohol y/o } \\
\text { drogas. }\end{array}$ & & & & \\
\hline 27. Me niego a creer que haya sucedido. & & & & \\
\hline $\begin{array}{l}\text { 29. Intento ver el suceso estresante de una forma diferente, } \\
\text { para que parezca más positivo. }\end{array}$ & & & & \\
\hline $\begin{array}{l}\text { 30. Hablo con alguien que pudiera hacer algo concreto } \\
\text { acerca del problema. }\end{array}$ & & & & \\
\hline
\end{tabular}




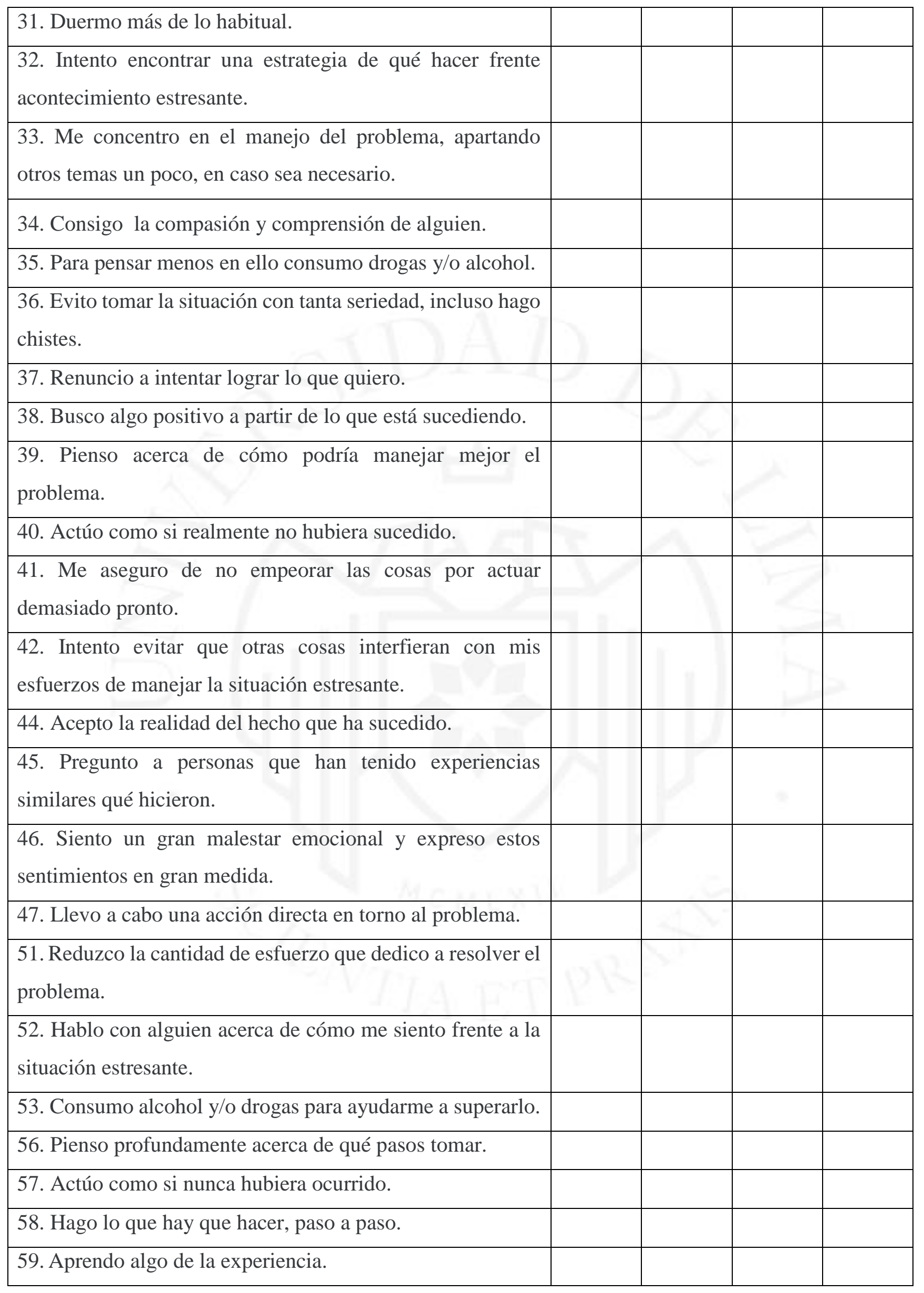




\section{ANEXO 10: Distribución de la muestra según variables sociodemográfica}

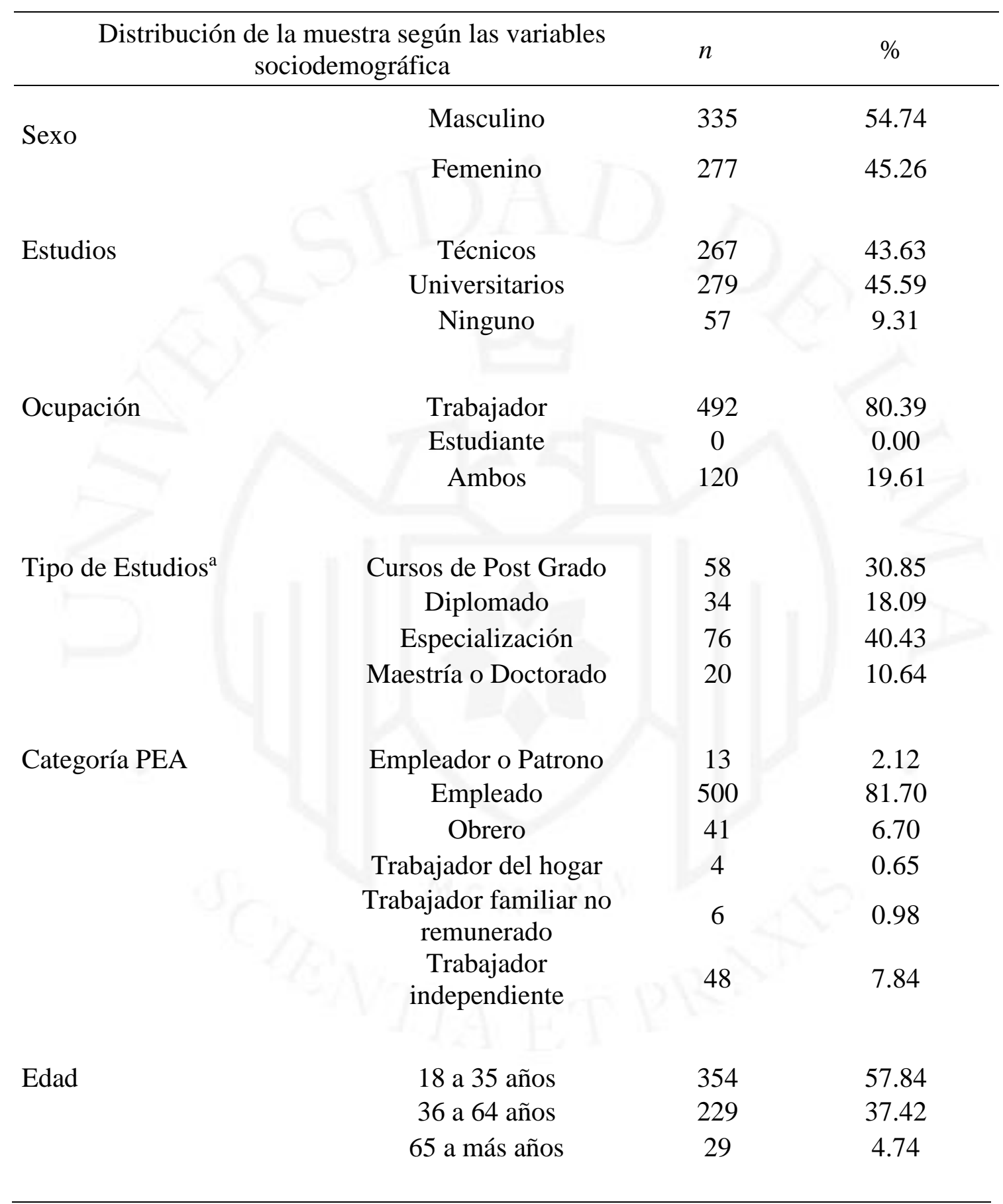

${ }^{\text {a }}$ En base a los 188 participantes que se encontraban realizando estudios de post grado. 


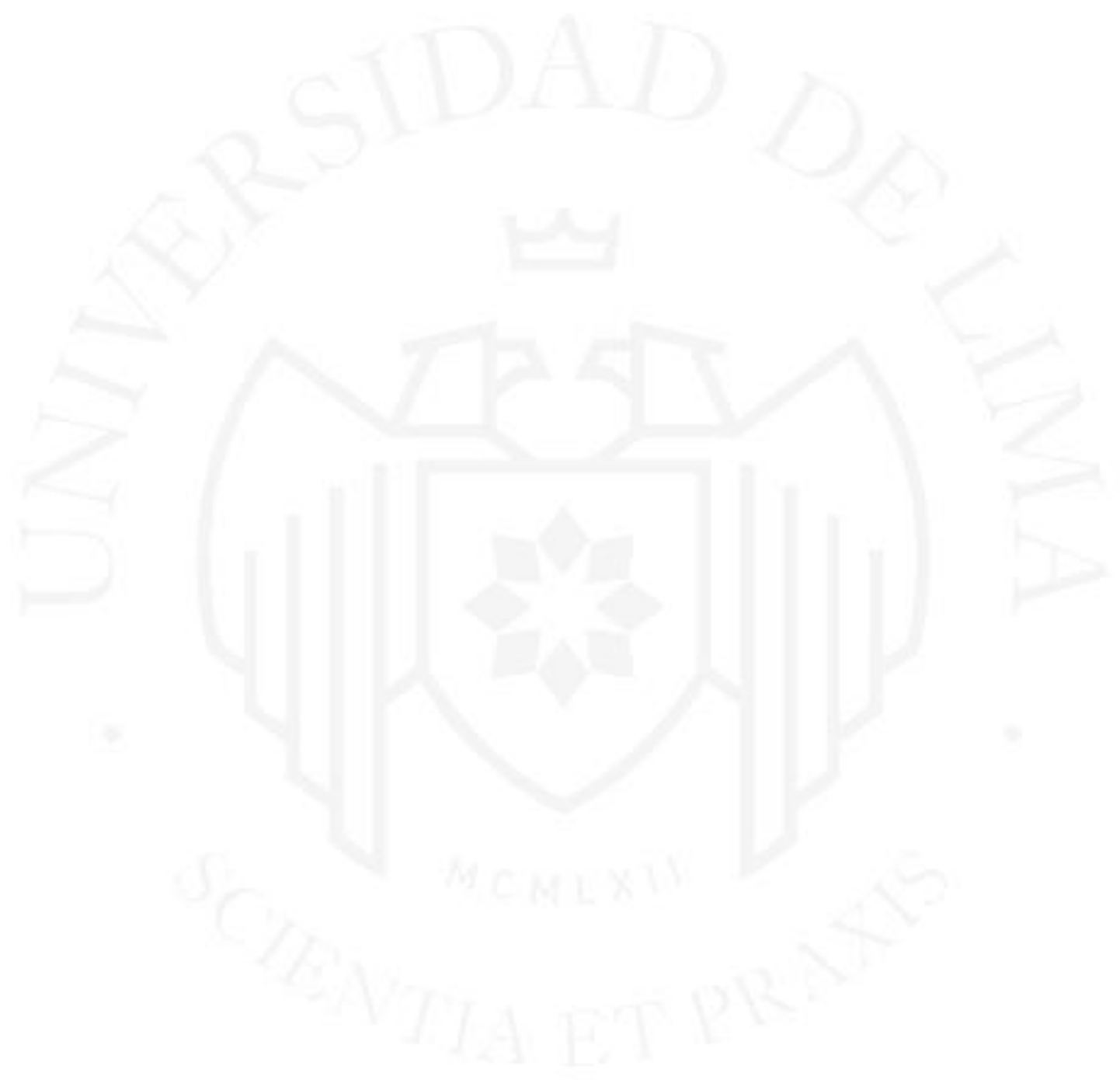

